
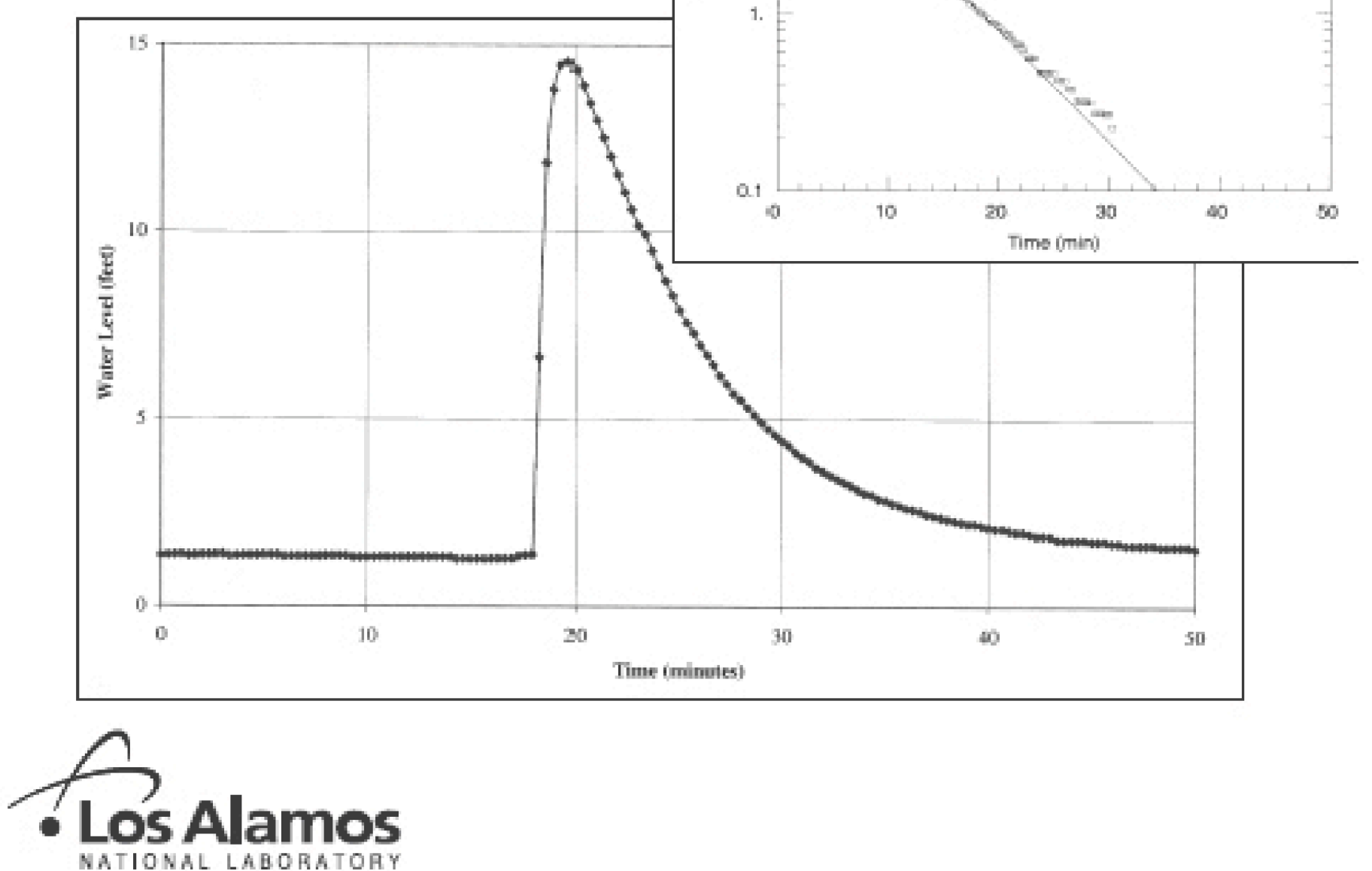
Froduced by Growntusa Prokdton Progras,

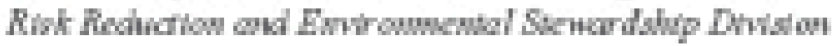

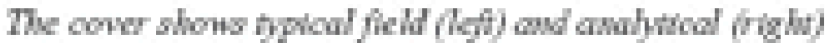

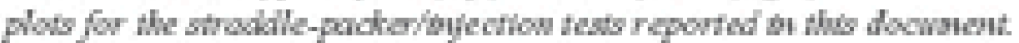

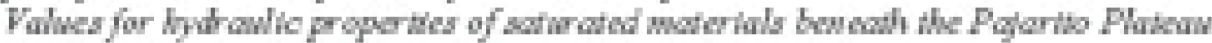

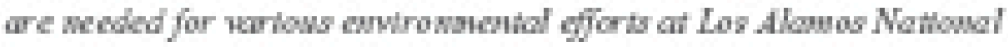

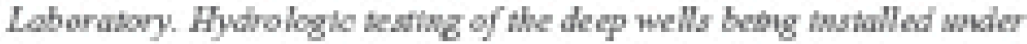
the Hydrgeologio Horklow is productug swoh dota.

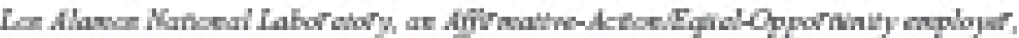

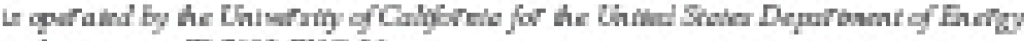

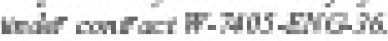

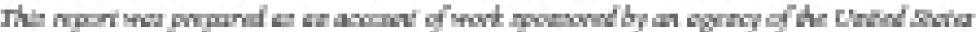

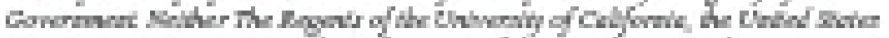

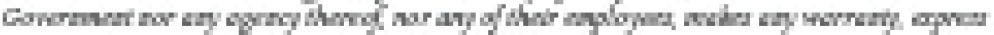

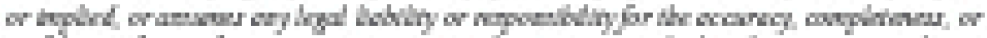

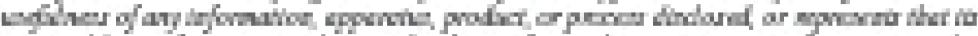

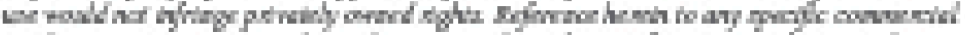

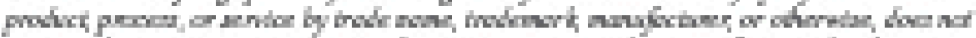

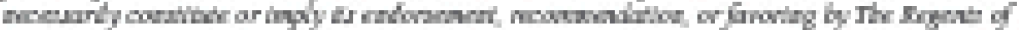

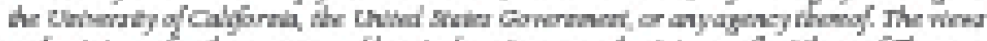

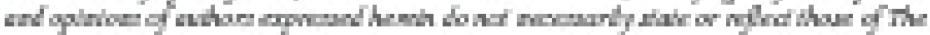

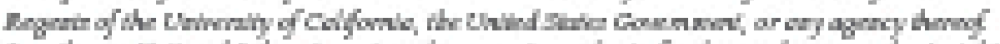

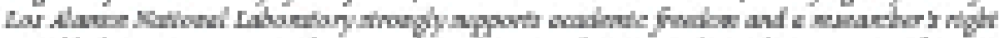

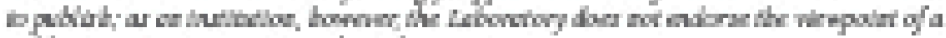

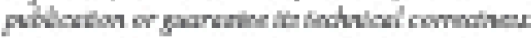


Hydrologic Tests at Characterization Wells $R-9 i, R-13, R-19, R-22$, and $R-31$

William J. Stone

Stephen G. McLin 

ABBREVIATIONS, ACRONYMS, AND NOTATION

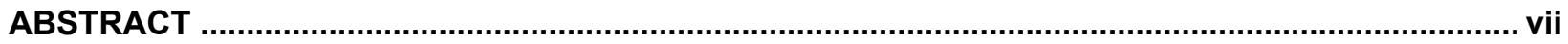

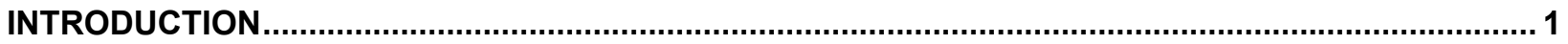

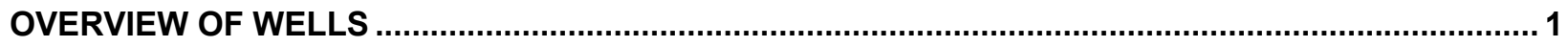

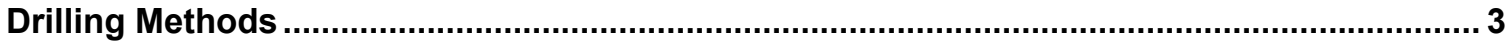

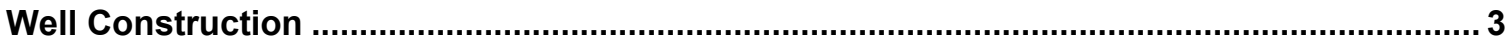

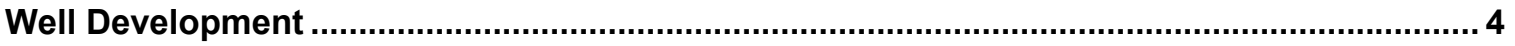

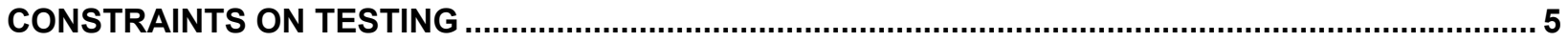

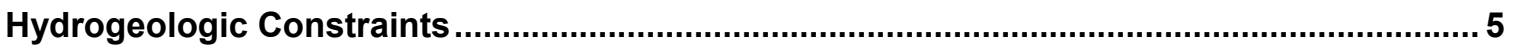

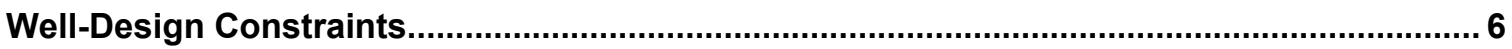

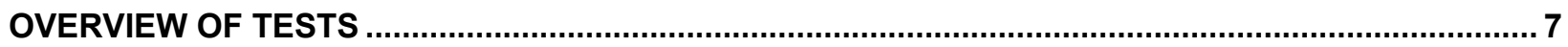

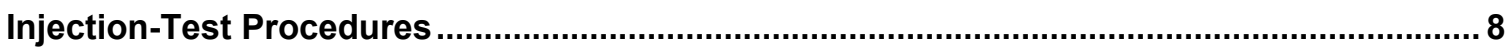

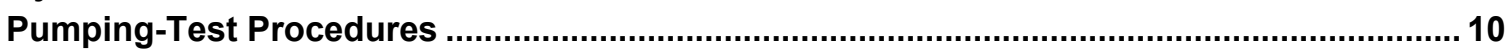

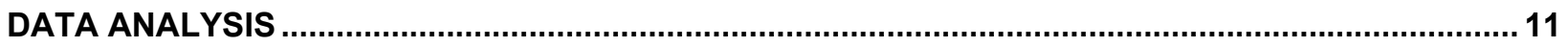

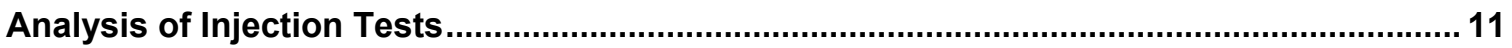

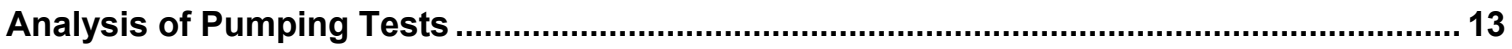

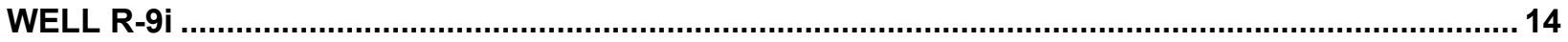

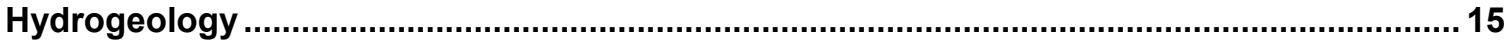

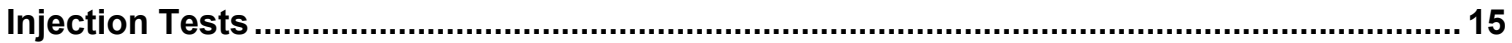

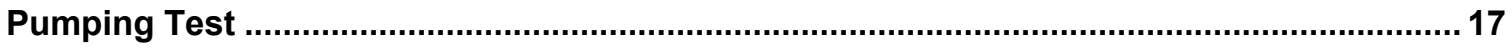

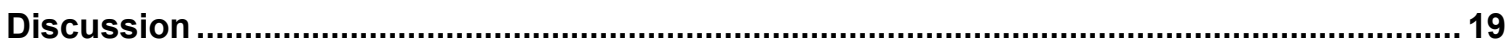

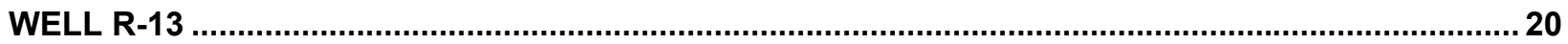

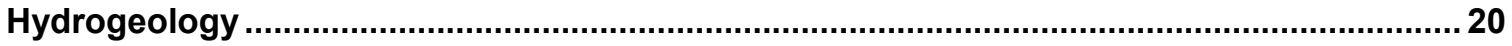

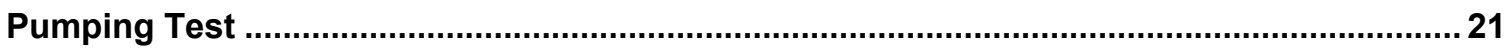

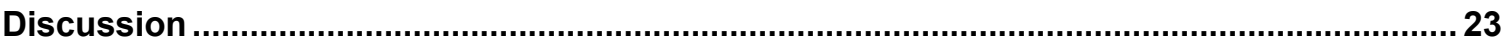

WELL R-19

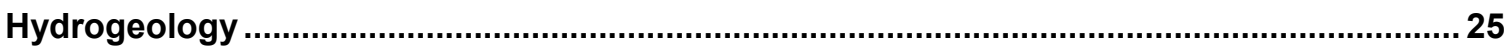

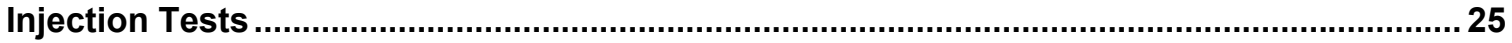

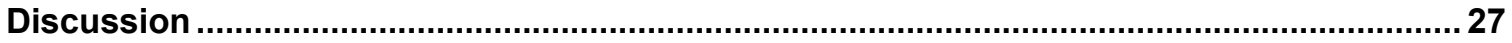

WELL R-22

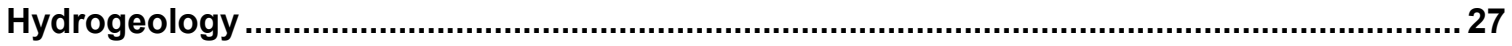

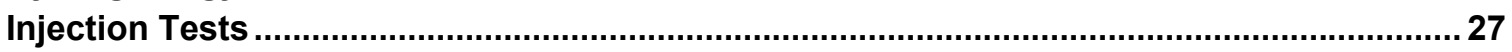

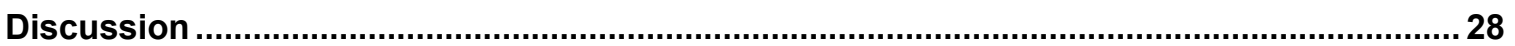

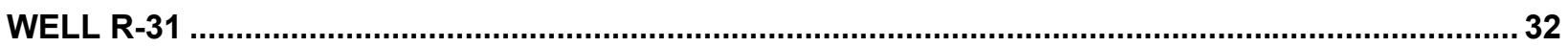

Hydrogeology

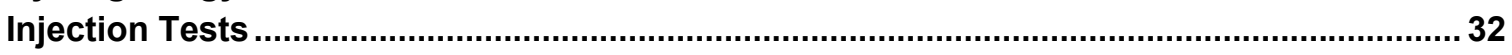

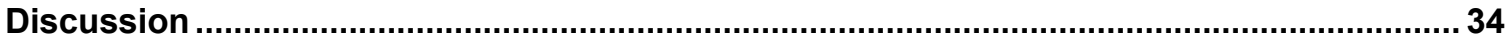

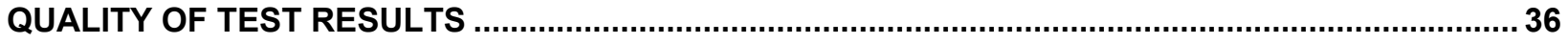

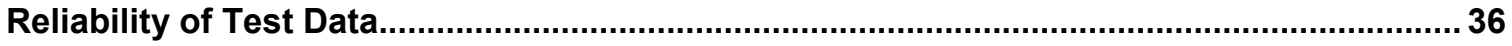

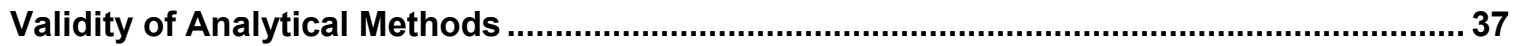

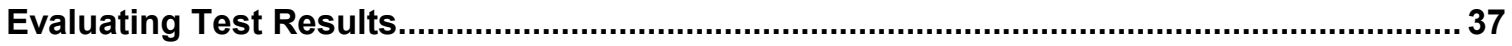




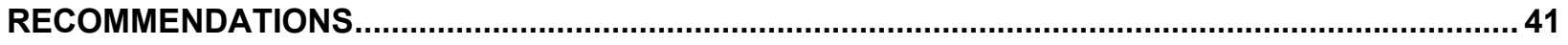

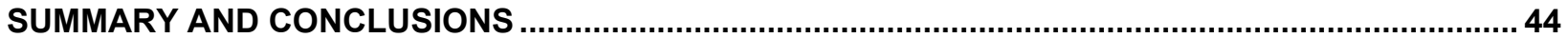

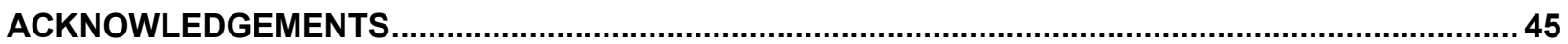

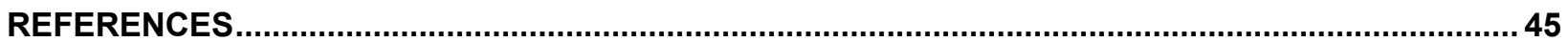

Appendices

Appendix A Well R-9i Test Data

Appendix B Well R-13 Test Data

Appendix C Well R-19 Test Data

Appendix D Well R-22 Test Data

Appendix E Well R-31 Test Data

\section{List of Figures}

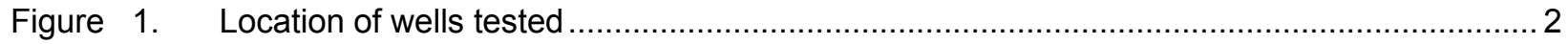

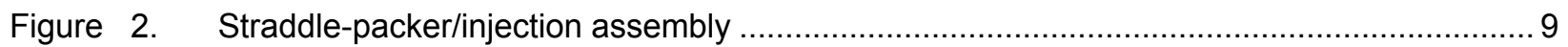

Figure 3. Typical field-data plot for the injection tests conducted ............................................. 12

Figure 4. Relationship of Bouwer-Rice parameters to water level in well for different test types ....... 13

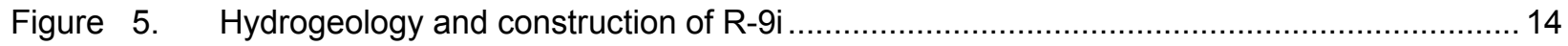

Figure 6. Bouwer-Rice analysis of injection-test recovery data for R-9i, screen 1a........................ 16

Figure 7. Bouwer-Rice analysis of injection-test recovery data for R-9i, screen 2 ........................ 16

Figure 8. Theis analysis of pumping-test drawdown data for R-9i, both screens .......................... 18

Figure 9. Neuman analysis of early pumping-test drawdown data for R-9i, both screens................. 18

Figure 10. Neuman analysis of late pumping-test drawdown data for R-9i, both screens.................. 19

Figure 11. Hydrogeology and construction of R-13 ............................................................... 21

Figure 12. Hantush-Jacob analysis of pumping-test recovery data for R-13b ............................... 23

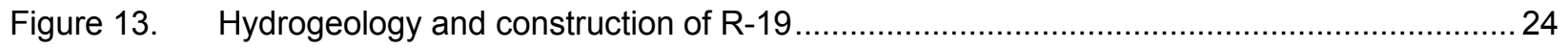

Figure 14. Bouwer-Rice analysis of injection-test recovery data for R-19, screen 6 ....................... 26

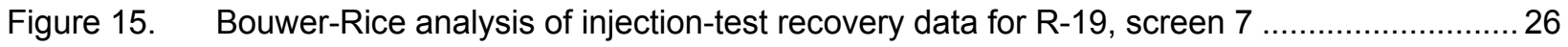

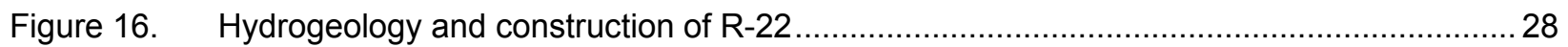

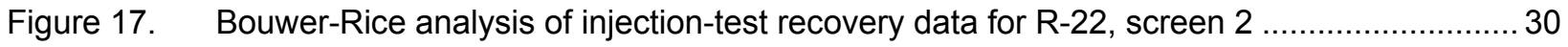

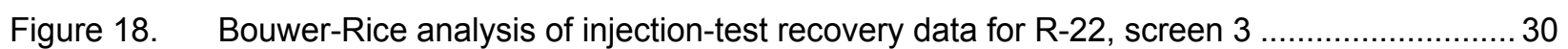

Figure 19. Bouwer-Rice analysis of injection-test recovery data for R-22, screen 4a ...................... 31

Figure 20. Bouwer-Rice analysis of injection-test recovery data for R-22, screen 5 ....................... 31

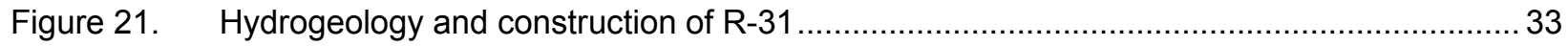

Figure 22. Bouwer-Rice analysis of injection-test recovery data for R-31, screen 3 ........................ 35

Figure 23. Bouwer-Rice analysis of injection-test recovery data for R-31, screen 4 ...................... 35

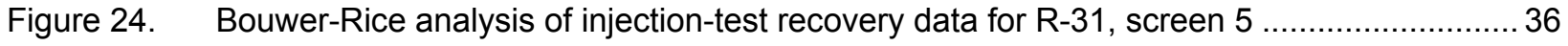

Figure 25. Comparison of results for various test methods............................................................ 40 


\section{List of Tables}

Table 1 Drilling and Completion of Wells Tested .............................................................................. 3

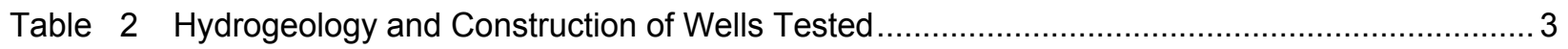

Table 3 Methods Used to Develop Wells Tested ...................................................................... 5

Table 4 Filter-Pack Length vs. Screen Length in Wells Tested .......................................................... 7

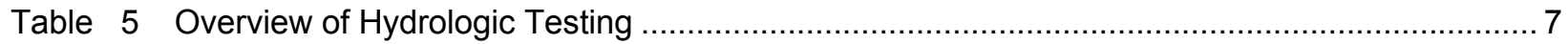

Table 6 Water Introduced and Extracted at Wells Tested by Injection ........................................... 9

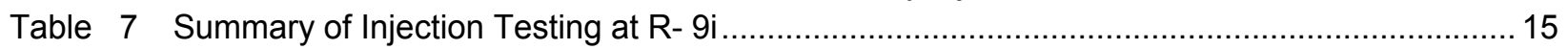

Table 8 Summary of Single-Well Pumping Test at R-9i................................................................. 17

Table 9 Summary of Single-Well Pumping Tests at R-13............................................................ 22

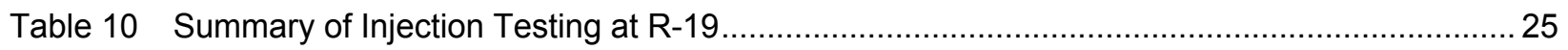

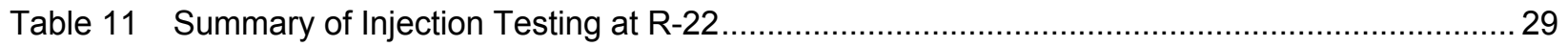

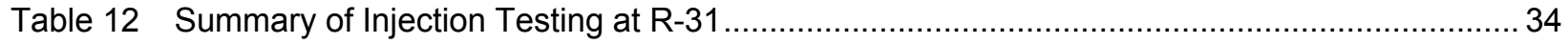

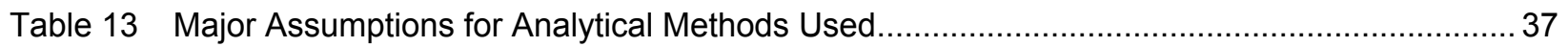

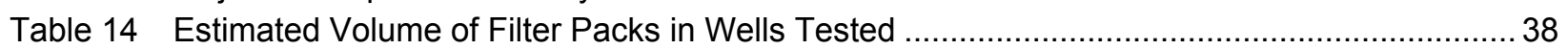

Table 15 Volume of Water Injected vs. Pore Volume of Filter Packs in Wells Tested .......................... 39

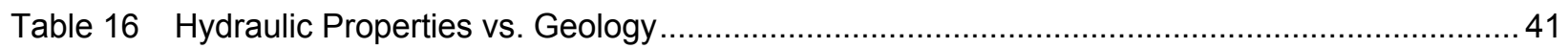




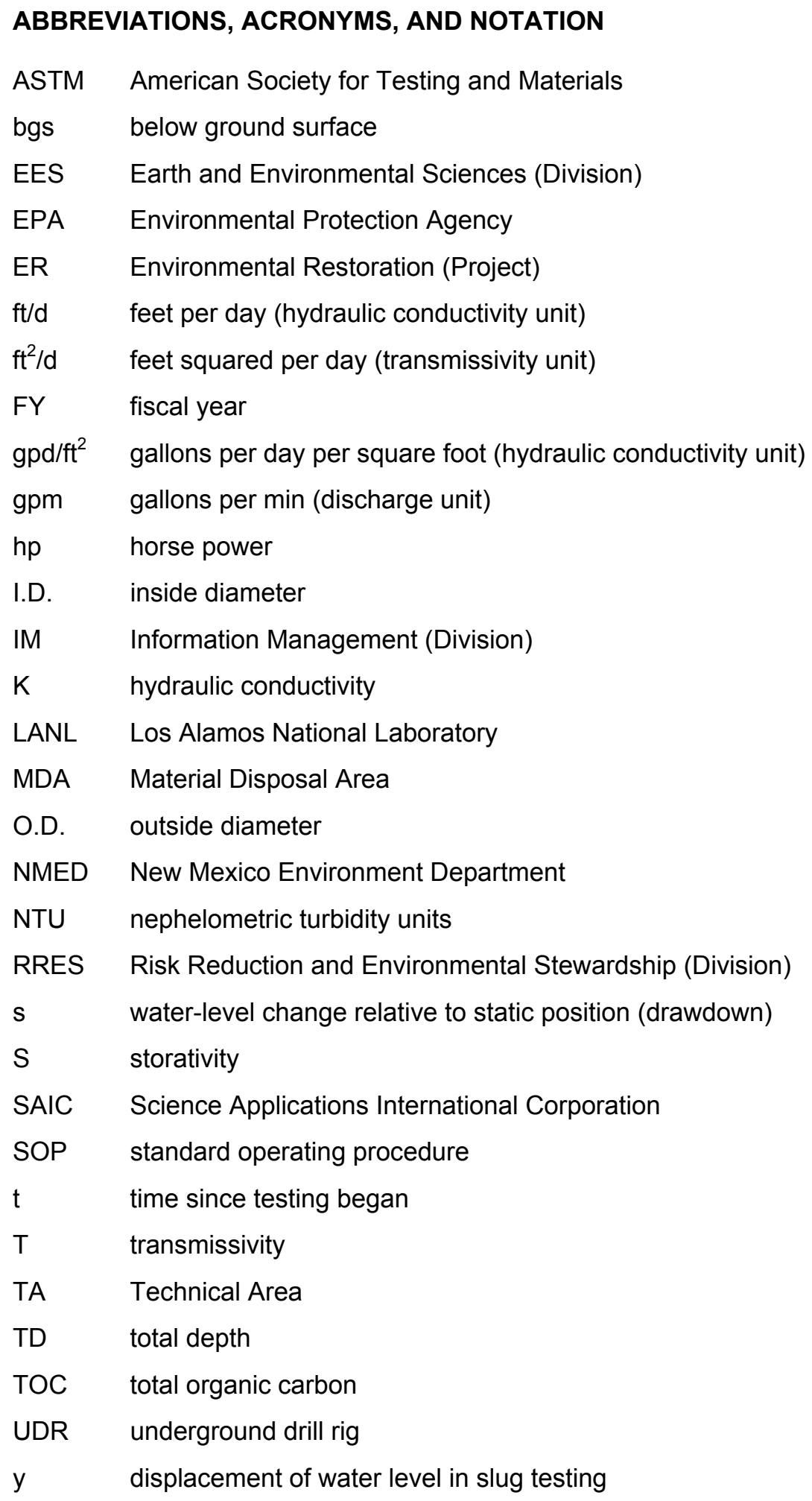




\title{
HYDROLOGIC TESTS AT CHARACTERIZATION WELLS R-9i, R-13, R-19, R-22, AND R-31
}

\author{
by
}

William J. Stone and Stephen G. McLin

\begin{abstract}
Hydrologic information is essential for environmental efforts at Los Alamos National Laboratory. Testing at new characterization wells being drilled to the regional aquifer ("R wells") to improve the conceptual hydrogeologic model of the Pajarito Plateau is providing such information. Drilling has been by air-rotary casing-advance or open-hole methods. Most wells are completed with multiple screens. After their construction, wells were rigorously developed by wire-brushing, bailing, followed by surging, swabbing, or jetting, and finally by pumping. These methods are effective based on field-parameter measurements and comparison of results of hydrologic testing at well R-31 before and after complete well development.

We conducted field tests on various zones of saturation penetrated by the R wells to collect data needed for determining hydraulic properties. This document provides details of the design and execution of testing as well as an analysis of data for five of the new wells: R-9i, R-13, R-19, R-22, and R-31. One well was evaluated by a pumping test (R-13), another was evaluated by both straddle-packer/injection and pumping tests (R-9i), and the rest were evaluated by injection tests alone (R-19, R-22, R-31).

Testing was constrained by the regional setting (complex geology and multiple zones of saturation) and well construction (multiscreen completion and the small diameter of the production casing). Packers are required for testing multiscreen wells. The small diameter of the production casing not only precludes the use of a slugger but also limits the capacity of pumps that can be used in testing, especially for the depths involved in the $\mathrm{R}$ wells. For example, pumping at a maximum rate of 19 gallons per minute did not significantly stress the regional aquifer at $\mathrm{R}-13$.
\end{abstract}

Although not slug tests, the injection tests are comparable in several ways, and analysis of data by slugtest methods is appropriate. Despite constraints, the results obtained appear valid based on (1) the care taken during test implementation and data analysis, (2) comparison of results for initial and repeated tests obtained by the same analytical method, (3) comparison of results obtained for a given test by different analytical methods, (4) comparison of results with values determined by geophysical logging in the wells and pumping tests of the same geologic units elsewhere on the plateau, and (5) comparison with hydraulic properties commonly reported for similar geologic materials outside the area.

Significant contributions of this report are not only the documentation of test design, implementation, and analysis but also a comprehensive table showing the distribution of hydraulic properties for the saturated geologic units tested beneath the Pajarito Plateau.

We also offer several recommendations based on testing to date. Placing screens across the water table and geologic contacts as well as employing oversized filter packs hinders testing and should be avoided. In addition, we recommend that future testing include some alternative designs and methods. Multiple methods and routine repeat testing for a given screened interval would permit comparison of results. 



\section{INTRODUCTION}

Hydrologic information is essential for surveillance efforts, environmental restoration activities as well as numerical modeling of groundwater flow and transport at Los Alamos National Laboratory (LANL or the Laboratory). Various kinds of hydrologic observations at new wells being drilled across the Pajarito Plateau under the Hydrogeologic Workplan (LANL 1998, 59599) provide this information. Saturated zones are identified and characterized as to water level, stratigraphic unit, hydraulic condition (unconfined or confined), and scale (perched or regional). Head measurements at different depths within the regional zone of saturation indicate the direction of the vertical gradient. Field hydrologic tests provide data for determining hydraulic properties of the saturated media. As the new wells penetrate the regional water table and are completed in the regional aquifer, they are identified by an "R" prefix and are commonly referred to as "R wells."

This document reports on the collection to date of hydraulic-property data from the new deep $R$ wells. The well-completion reports present only brief summaries and preliminary results of hydrologic testing. By contrast, this document captures and preserves details of the design, execution, and analysis of such tests as well as a discussion of the quality of the data and results obtained. More specifically, this report describes tests performed at five wells (Figure 1). This includes one intermediate-depth offset well (R-9i) and four deep characterization wells (R-13, R-19, R-22, and R-31).

Testing at seven other $\mathrm{R}$ wells recently installed on the plateau is not discussed in this report for the following reasons. Low water production or placement of screens across the water table precluded meaningful testing of saturated hydraulic properties at wells R-5 and R-7. Data from testing at well R-8A were lost before they could be analyzed because of equipment malfunction. Tests conducted by contractors at wells R-9 and R-12 are invalid because of variable flow rates during the tests. A report on the pumping test at well R-15 is being prepared separately. Testing at well R-25 was inconclusive because introduced water was rejected and there were no falling-head data to analyze.

Information presented below for the hydrogeology and construction of all but one of the wells comes from completion reports. Final reports are available for wells R-9i (Broxton et al. 2001, 66600), R-19 (Broxton et al. 2001, 71253), R-22 (Ball et al. 2001, 71471), and R-31 (Vaniman et al. 2001, 72615). As the report for R-13 is not yet written, information presented for R-13 comes from the Fact Sheet prepared for the well. The stratigraphy shown for most of the wells differs slightly from that in the completion reports as a result of additional analysis since the reports were published. It should be noted at the outset that the term Cerros del Rio basalt is an informal name commonly applied to local Tertiary lavas of various compositions (not all basaltic).

Some conventions were adopted to enhance the clarity, usefulness, and consistency of this report. Reference citations for the analytical methods used are only given under Data Analysis to avoid repetition in the text. Tables summarizing tests in the text are placed in boxes for quick identification and reference. Labels given within the analytical plots serve the same purpose; these are based on the well and screen number, for example R-9i-1. Various letters at the end of such labels identify specific conditions: $a=$ the first test when there was a repeat test, $b=$ the repeat test, $P=$ pumping-test data, $D=$ drawdown data, $\mathrm{E}=$ early-time drawdown data, $\mathrm{L}=$ late-time drawdown data, and $\mathrm{R}=$ recovery data. Although the design and results of repeat tests are given in the summary tables, analytical plots are not presented in the interest of saving space. Graphs and raw field data for water level versus time as well as additional analytical data for the selected tests are given in the appendices.

\section{OVERVIEW OF WELLS}

Deep wells to the regional zone of saturation are being installed at the Laboratory as part of a program to improve the conceptual hydrogeologic model for the Pajarito Plateau (LANL 1998, 59599). Although 
some of these wells may become part of the groundwater surveillance network, they are characterization wells. That is, each provides geologic, hydrologic, and hydrochemical observations in an area where there are data gaps. The information obtained will be used to design a sound groundwater-monitoring network.

The drilling, construction, and development of the wells are briefly outlined below. Complete details can be found in the well-completion reports listed above. Methods used in drilling, constructing and developing the wells are compatible with Environmental Protection Agency (EPA) guidelines (Aller et al. 1991, 70112).

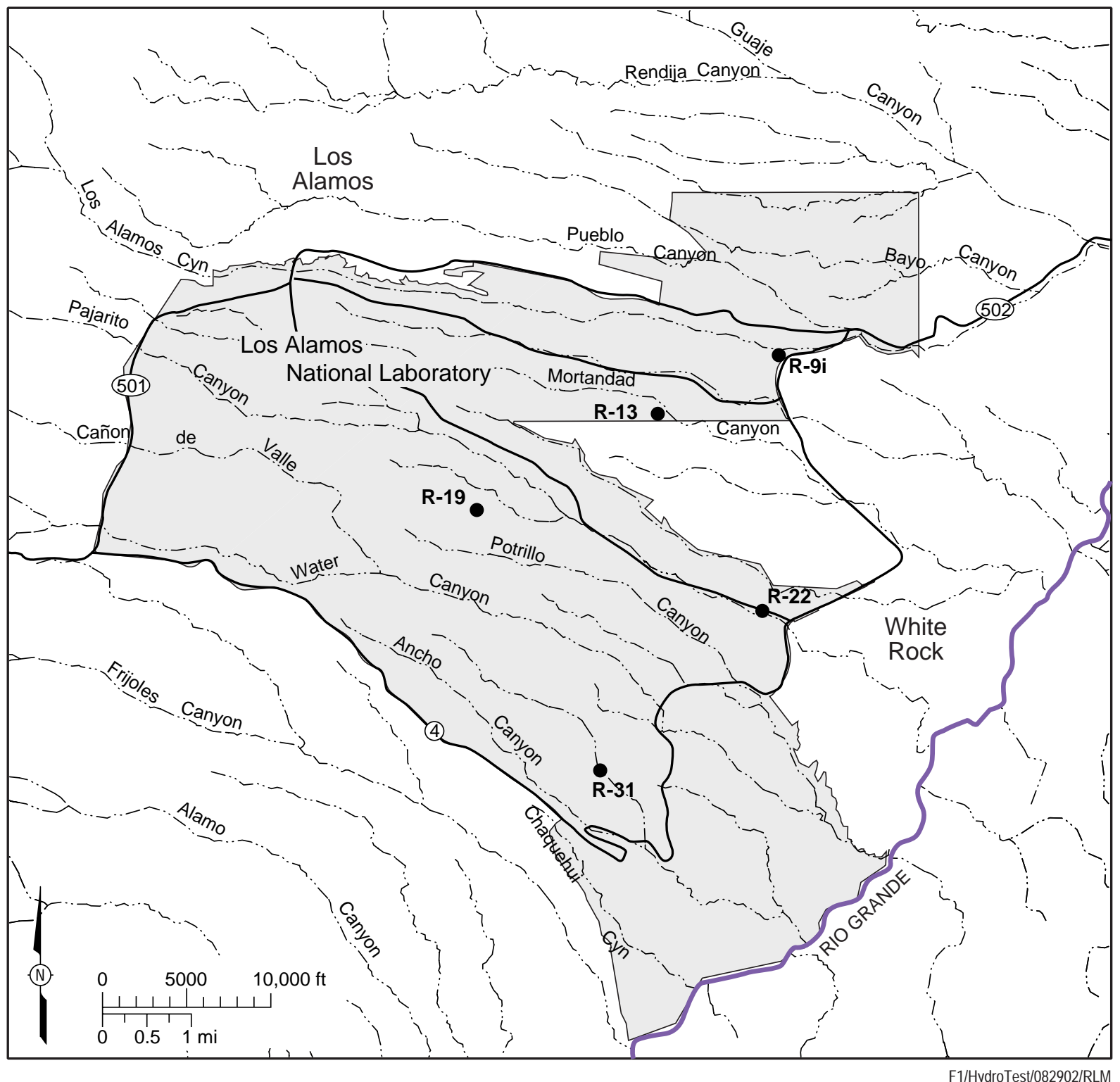

Figure 1. Location of wells tested 


\section{Drilling Methods}

Drilling methods have changed throughout the deep-well program (Table 1). Initially, wells were drilled by air-rotary casing-advance and coring methods. More recently, drilling has been by open-hole methods, and geophysical logging has replaced coring as the means of supplementing both geologic and hydrologic observations. The holes have been drilled essentially dry so that saturated zones can be more easily recognized. However, water and minor amounts of various drilling fluids have been added at times to enhance lubricity during casing-advance operations or formation stability during open-hole operations.

Table 1

Drilling and Completion of Wells Tested

\begin{tabular}{|c|c|c|c|c|c|}
\hline Well & $\begin{array}{l}\text { Drilling } \\
\text { Method }\end{array}$ & $\begin{array}{l}\text { Circulation } \\
\text { Fluid }^{a}\end{array}$ & $\begin{array}{l}\text { No. of } \\
\text { Screens }\end{array}$ & $\begin{array}{l}\text { Screen } \\
\text { Type }^{b}\end{array}$ & $\begin{array}{l}\text { Open Area } \\
(\%)^{c}\end{array}$ \\
\hline$R-9 i$ & Air-rotary, open-hole & Air & 2 & $\begin{array}{l}\text { Rod-based, } \\
\text { wire-wrapped }\end{array}$ & 7.9 \\
\hline $\mathrm{R}-13$ & $\begin{array}{l}\text { Air-rotary, open-hole/ } \\
\text { casing advance }\end{array}$ & $\begin{array}{l}\text { Air and water (EZ-MUD plus } \\
\text { QUIK FOAM) }\end{array}$ & 1 & $\begin{array}{l}\text { Pipe-based, } \\
\text { wire-wrapped }\end{array}$ & 8.75 \\
\hline R-19 & $\begin{array}{l}\text { Air-rotary, casing- } \\
\text { advance }\end{array}$ & $\begin{array}{l}\text { Air and water (EZ-MUD plus } \\
\text { QUIK FOAM, Torkease) }\end{array}$ & 7 & $\begin{array}{l}\text { Pipe-based, } \\
\text { wire-wrapped }\end{array}$ & 8.75 \\
\hline R-22 & $\begin{array}{l}\text { Air-rotary, open-hole/ } \\
\text { casing advance }\end{array}$ & $\begin{array}{l}\text { Air and water (EZ-MUD plus } \\
\text { QUIK FOAM) }\end{array}$ & 5 & $\begin{array}{l}\text { Pipe-based, } \\
\text { wire-wrapped }\end{array}$ & 8.75 \\
\hline R-31 & $\begin{array}{l}\text { Air-rotary, open-hole/ } \\
\text { casing advance }\end{array}$ & $\begin{array}{l}\text { Air and water (Torkease, } \\
\text { EZ-Mud plus) }\end{array}$ & 5 & $\begin{array}{l}\text { Rod-based, } \\
\text { wire-wrapped }\end{array}$ & 7.9 \\
\hline
\end{tabular}

${ }^{a}$ Air and water were the primary fluids; others listed were added only as deemed necessary.

${ }^{b}$ Wire-wrap in all screens is 10 -slot stainless steel.

${ }^{\mathrm{C}}$ For pipe-based screen, value given is that for drilled pipe.

\section{Well Construction}

Construction has varied slightly from well to well. As-built diagrams, provided for each well in the sections that follow, give specific details. Nonetheless, some generalizations are offered here as background.

Most of the wells are completed with multiple screens placed within perched and regional zones of saturation (Table 2). All screens are constructed of stainless steel and have a $0.010 \mathrm{in}$. slot size. Rodbased, wire-wrapped screens were used in wells R-9i and R-31. That is the more common type of wirewrapped screen. These screens were fabricated with 32 rods and have an open area of $7.9 \%$. Pipebased, wire-wrapped screens were used in the other three wells. In that type of screen, a wire-wrapped jacket is placed around a pipe in which round holes have been drilled. In the screens used, the holes are $0.5 \mathrm{in}$. in diameter, and their density is up to 84 holes/ft. Open area for the drilled pipe is $8.75 \%$. The New Mexico Environment Department (NMED) has required that the uppermost screens be positioned so that the upper $5 \mathrm{ft}$ lie above the water table. Most screens are $10 \mathrm{ft}$ long, except those straddling the regional water table, which are longer in anticipation of the water level declining with time.

Annular fill consists of primary and secondary filter packs as well as seals. Screened intervals are isolated from each other by seals in the annulus between filter packs. Annular-seal material generally consists of bentonite, but in some places additional cement seals were emplaced. Filter-pack material consists of sand in all wells described in this report. The primary filter pack is coarser (usually 20/40 sand) to ensure that water flows easily to the screen. The secondary filter pack is finer (usually $30 / 70$ sand). It is placed between the primary filter pack and the seal to prevent bentonite from reaching the screen. These 
different sizes of sand are not distinguished on the construction diagrams for the wells tested. Rather, the total length of filterpack (sand) is illustrated.

Table 2

Hydrogeology and Construction of Wells Tested

\begin{tabular}{|c|c|c|c|c|c|c|c|}
\hline Well & $\begin{array}{l}\text { TD } \\
\text { (ft) }\end{array}$ & $\begin{array}{c}\text { Ground } \\
\text { Elevation } \\
\text { (ft) }\end{array}$ & $\begin{array}{l}\text { Saturated } \\
\text { Zone/Unit }\end{array}$ & $\begin{array}{c}\text { Saturated } \\
\text { Interval } \\
(\mathrm{ft})^{\mathrm{b}}\end{array}$ & $\begin{array}{l}\text { Screen } \\
\text { Number }\end{array}$ & $\begin{array}{l}\text { Screened } \\
\text { Interval } \\
(\mathrm{ft})^{c}\end{array}$ & $\begin{array}{l}\text { Head } \\
(\mathrm{ft})^{\mathrm{d}}\end{array}$ \\
\hline \multirow[t]{2}{*}{ R-9i } & \multirow{2}{*}{322} & \multirow[t]{2}{*}{6383} & UP/Tb & $142-236$ & 1 & 189-199 & 6241 \\
\hline & & & $\mathrm{LP} / \mathrm{Tb}$ & 264-282 & 2 & $270-280$ & 6119 \\
\hline R-13 & 1133 & 6660 & $\mathrm{R} / \mathrm{Tpf}$ & 883-TD & 1 & 958-1019 & 5827 \\
\hline \multirow[t]{7}{*}{ R-19 } & \multirow{7}{*}{$\begin{array}{c}1885 \\
\text { Sloughed } \\
\text { From } 1902\end{array}$} & \multirow[t]{7}{*}{7066} & UP/Qbof & $834-840$ & 1 & $827-844$ & 6337 \\
\hline & & & LP/Tpf & 894-912 & 2 & $893-910$ & 6241 \\
\hline & & & \multirow[t]{5}{*}{$\mathrm{R} / \mathrm{Tpf}$} & \multirow[t]{5}{*}{ 1178-TD } & 3 & $1171-1215$ & 5888 \\
\hline & & & & & 4 & 1410-1417 & $N A^{e}$ \\
\hline & & & & & 5 & $1583-1590$ & NA \\
\hline & & & & & 6 & $1727-1734$ & $5932 \mathbf{t}$ \\
\hline & & & & & 7 & 1832-1839 & $5903 t$ \\
\hline \multirow[t]{5}{*}{ R-22 } & \multirow[t]{5}{*}{1489} & \multirow[t]{5}{*}{6650} & \multirow[t]{5}{*}{$\mathrm{R} / \mathrm{Tb}$} & \multirow[t]{5}{*}{ 895-TD } & 1 & $872-914$ & $5730 \mathrm{t}$ \\
\hline & & & & & 2 & $947-989$ & $5725 \mathrm{t}$ \\
\hline & & & & & 3 & $1272-1279$ & $5682 \mathrm{t}$ \\
\hline & & & & & 4 & 1389-1385 & $5670 \mathrm{t}$ \\
\hline & & & & & 5 & $1447-1452$ & $<5670 t$ \\
\hline \multirow[t]{5}{*}{ R-31 } & \multirow[t]{5}{*}{1103} & \multirow[t]{5}{*}{6362} & $\mathrm{P} / \mathrm{Tb}$ & $439-455$ & 1 & $439-455$ & Dry \\
\hline & & & \multirow[t]{4}{*}{$\mathrm{R} / \mathrm{Tb}$} & \multirow[t]{4}{*}{ 522-TD } & 2 & $515-546$ & $5853 \mathrm{w}$ \\
\hline & & & & & 3 & $666-676$ & 5852 w \\
\hline & & & & & 4 & $827-837$ & 5854 w \\
\hline & & & & & 5 & $1007-1017$ & 5851 w \\
\hline
\end{tabular}

a Zone: $\mathrm{U}=$ upper, $\mathrm{M}=$ middle, $\mathrm{L}=$ lower; $\mathrm{P}=$ perched, $\mathrm{R}=$ regional; Unit: $\mathrm{Qbof}=$ Otowi Member ashflow, Bandelier Tuff, $\mathrm{Tb}=$ Cerros del Rio basalt, Tpf = Puye Formation, fanglomerate, $\mathrm{Tsfb}=$ Santa Fe Group basalt.

b Based on observations during drilling or geophysical logs.

c Top and bottom of open interval, not screen joints.

d Composite for screened interval; $\mathbf{t}$ indicates value based on static water level for packed-off interval at time of testing, w indicates value from Westbay transducer; otherwise, value is based on water level determined during drilling.

e $\mathrm{NA}=$ not available.

\section{Well Development}

After the wells were constructed, they were developed to (1) remove fines and drilling fluid from both the formation and filter pack behind the screen; (2) create a stable zone of filtration between the screen and formation; and (3) re-establish effective hydraulic conductivity near the well. In most cases, development followed a multiphase protocol (Table 3). Preliminary development involved various combinations of wirebrushing, bailing, airlifting, surging, or jetting. Screens were first wire-brushed to remove particles that might have settled in the larger openings of the pipe-based screen. Next, the sump and screens were bailed to remove the more turbid water from the well and thus protect the pump. Where deemed beneficial, surging, swabbing, or jetting followed bailing. Final development was by pumping. 
Table 3

Methods Used to Develop Wells Tested

\begin{tabular}{|c|c|c|c|c|c|c|c|}
\hline \multirow[b]{2}{*}{ Wella } & \multicolumn{5}{|c|}{ Preliminary Development } & \multicolumn{2}{|c|}{ Final Development } \\
\hline & $\begin{array}{c}\text { Wire- } \\
\text { Brushing }\end{array}$ & Surging $b$ & Swabbing $c$ & Airlifting & Jetting $^{d}$ & Bailing & Pumping \\
\hline R-9i (m) & $x$ & & & & & $x$ & $x$ \\
\hline R-13 (s) & $x$ & $x$ & $x$ & & & $x$ & $x$ \\
\hline $\mathrm{R}-19(\mathrm{~m})$ & $x$ & & & $x$ & $x$ & $x$ & $x$ \\
\hline $\mathrm{R}-22(\mathrm{~m})$ & $x$ & & & & & $x$ & $x$ \\
\hline $\mathrm{R}-31(\mathrm{~m})$ & $x$ & $x$ & & $x$ & & $x$ & $x$ \\
\hline
\end{tabular}

a $(m)=$ multi-screen completion; $(s)$ = single-screen completion

b Done with surge block attached to wireline (not to rod)

c Involves flowing water out through screen from between two surge blocks

d Done with perforated pipe (not conventional jetting tool)

Development of pipe-based screen is difficult because there are two layers of openings. The effectiveness of well development was evaluated by means of several field parameters $(\mathrm{pH}$, specific conductance, temperature, and turbidity). These were monitored at the outset of bailing and at regular intervals during pumping. When turbidity was $<5$ nephelometric turbidity units (NTU) or could not be improved, the pump was turned off, and the well was allowed to rest for a short interval. Then pumping was resumed briefly and field parameters were monitored at regular intervals to see if the previously obtained turbidity value could be reproduced. This process (pump off/on) was repeated three times. When the turbidity value could be reproduced, a sample was usually collected and analyzed for total organic carbon (TOC), a good indicator of the presence of drilling fluid. If the analytical result approximated the background value for the Pajarito Plateau, development was halted. If it did not, physical development continued until TOC content was at background level or could not be improved. Video logs were an invaluable aid in development. These were made before development to determine target intervals for more intense wire-brushing, at various stages during development if field parameters did not improve, and after development to confirm that the well was ready for Westbay ${ }^{\top \mathrm{M}}$ installation. $^{2}$

\section{CONSTRAINTS ON TESTING}

As field methods of determining hydraulic properties of saturated materials are expensive, funding often dictated the type and duration of testing conducted. Until a separate rig was dedicated to developing and testing the wells, the drilling and Westbay ${ }^{\mathrm{TM}}$-installation schedules often dictated how much time could be spent on testing. Thus, if problems arose, re-running tests was not always possible. If the problem wasn't discovered until after the Westbay ${ }^{\mathrm{TM}}$ system was installed, re-testing was not practical.

However, hydrologic testing of the R wells has been most constrained by the hydrogeologic setting and well construction. These constraints should not be interpreted to mean that the tests were inappropriate or that the data obtained are unreliable. Rather, they are conditions that limited the testing methods that could be applied.

\section{Hydrogeologic Constraints}

Stratigraphy and depth to water are the main hydrogeologic constraints on testing. The stratigraphic sequence underlying the Pajarito Plateau is complex. Interbedded igneous and sedimentary deposits characterize the geologic column. Furthermore, the column varies considerably from place to place 
(Stone et al. 2001, 69830). The variation between hard and soft materials gives rise to irregularities in borehole diameter. Washouts have been fairly common in the Puye Formation. Screens have not been placed in such intervals.

In addition to stratigraphic constraints, the regional water table lies at great depth: as much as $1178 \mathrm{ft}$ below ground surface (bgs) for the wells covered by this report (Table 2). Thus, the wells must also be deep to penetrate the regional zone of saturation. Most $R$ wells are greater than $1000 \mathrm{ft}$ in depth. This depth impacts testing in different ways, depending on test method. In the case of injection tests, introduced water falls a long way before reaching the static water level for a given screen. In the case of pumping tests, pumps used must be able to lift water from such depths at a rate that stresses the saturated medium.

\section{Well-Design Constraints}

Small-diameter production casing, multiple screened intervals, screens spanning contacts between geologic units, pipe-based screens, and long filter packs are the main testing constraints associated with well design. The R wells are commonly constructed with a 4.5-in. inside diameter (I.D.) production casing. Thus, there is little room to accommodate a slugger and transducer for traditional slug tests. This small diameter also limits the size of pump that can be used, which in turn limits the pump capacity. Such limitations impact both well development and evaluation by pumping tests.

Most $\mathrm{R}$ wells are completed with multiple screens (Table 2). Each screen must be isolated both for development and testing. Straddle packers are readily available for shutting in individual screened intervals. However, conducting traditional slug or pumping tests in conjunction with straddle packers is difficult at best. No testing apparatus is readily available that permits interchanging transducers and pumping from considerable depth at a rate sufficient to stress a productive saturated zone, especially in the small-diameter production casing used in the $\mathrm{R}$ wells.

If a screen straddles a geologic contact, testing yields an average result for the two materials involved, or a result biased by the response of the more permeable material, rather than a representative hydraulic property for a single saturated material. Only one of the tests reported here involved a screen that straddles a geologic contact. R-13 was completed with a single screen set in the Puye Formation. However, the screen spanned the contact between the pumiceous and overlying fanglomerate units of the Puye. Presumably, the results of testing at $\mathrm{R}-13$ represent the more permeable of the materials behind the screen, but only tests of screens dedicated to each of the units would reveal conclusively which is more permeable.

In most of the R wells, including four of the five reported on here, the uppermost screen was placed across the water table at the request of the NMED. In these cases, the upper $5 \mathrm{ft}$ or so of screen is in the vadose zone, thus hindering development and ruling out testing of saturated aquifer properties. Any turbid water raised in the well during development simply drains into the unsaturated material lying behind the upper portion of the screen. Furthermore, slug or injection testing is not appropriate as these methods assume the screen is below static water level. For example, the Bouwer-Rice $(1976,64056)$ slug-test method cannot be used if the water level is below the top of the screen because "water would drain from the well into the vadose zone as well as the saturated aquifer" (Fetter 1994, 70942). Thus, testing of screens straddling the water table overestimates permeability because the unsaturated material takes up water faster than the saturated material.

The use of pipe-based screen introduces another constraint to testing. Injected or pumped water must move through the tortuous path presented by two layers of screen: the perforated pipe and the wire-wrap envelope. If one layer has a different open area than the other, it limits the rate at which water is delivered or extracted, thus hindering well development and yielding low test results. 
Usually, the primary filter pack extends $5 \mathrm{ft}$ above and below the screen and the intervals of secondary filter pack are generally also $5 \mathrm{ft}$ long. Where the screen is $10 \mathrm{ft}$ long, the length of filter pack is usually $30 \mathrm{ft}$ or three times that of the screen. In seven of the twelve intervals tested, however, the length of filter pack has exceeded three times the length of associated screens. In some of the wells, the length of some filter packs is many times the length of the associated screen (Table 4).

Table 4

Filter-Pack Length vs. Screen Length in Wells Tested

\begin{tabular}{|r|c|c|c|}
\hline $\begin{array}{c}\text { Well } \\
\text { (Screen) }\end{array}$ & $\begin{array}{c}\text { Screen Length } \\
(\mathbf{f t})^{\mathrm{a}}\end{array}$ & $\begin{array}{c}\text { Filter-Pack Length } \\
(\mathbf{f t})^{\mathrm{b}}\end{array}$ & $\begin{array}{c}\text { Filter-Pack } \\
\text { Length/Screen Length }\end{array}$ \\
\hline R-9i (1) & 10.4 & 19.6 & 1.9 \\
\hline$(2)$ & 10.7 & 18.5 & 1.7 \\
\hline $\mathrm{R}-13^{\mathrm{c}}$ & 60.39 & 86 & 1.4 \\
\hline $\mathrm{R}-19(6)$ & 7.1 & 103.9 & 2.8 \\
\hline$(7)$ & 7.1 & 20.2 & 1.7 \\
\hline $\mathrm{R}-22(2)$ & 41.9 & 69.5 & 7.4 \\
\hline$(3)$ & 6.7 & 49.5 & 3.3 \\
\hline$(4)$ & 6.7 & 22 & 8.6 \\
\hline$(5)$ & 5.0 & 43 & 4.4 \\
\hline $\mathrm{R}-31(3)$ & 10 & 44 & 6.1 \\
\hline$(4)$ & 10 & 61.5 & 19.9 \\
\hline$(5)$ & 10 & 198.9 & \\
\hline
\end{tabular}

a Length of openings, not joints.

b Total; more than one sand size generally used.

c Only one screen in this well.

\section{OVERVIEW OF TESTS}

In view of the constraints described above, the aquifer properties of the saturated materials penetrated by the $\mathrm{R}$ wells were investigated by straddle-packer/injection and/or pumping tests (Table 5). Three of the five wells were investigated by injection tests alone (R-19, R-22, and R-31). One well was tested by both injection and pumping methods (R-9i). One well was tested by the pumping method alone (R-13). Injection tests for R-9i, screen 1 and $\mathrm{R}-22$, screen 4 , as well as the pumping test at R-13 were repeated.

Field and testing methods used are compatible with those recommended by the American Society for Testing and Materials (ASTM 1994, 70099, and 1996, 70100). Furthermore, the use of pressure transducers and collection of water-level measurements in both types of tests followed procedures given in Environmental Restoration (ER) Project Standard Operating Procedures ER-SOP-07.01 and 07.02, respectively. Test data were analyzed by means of commercially available software.

For a given type of test, essentially the same procedures were employed. To avoid repetition in the sections that follow, those methods are summarized once at the outset. 
Table 5

Overview of Hydrologic Testing

\begin{tabular}{|c|c|c|c|c|c|c|}
\hline $\begin{array}{c}\text { Well } \\
\text { (screen) }\end{array}$ & $\begin{array}{c}\text { Saturated } \\
\text { Zone }^{b}\end{array}$ & $\begin{array}{c}\text { Geologic } \\
\text { Unitc }\end{array}$ & $\begin{array}{c}\text { Type of } \\
\text { Test }^{d}\end{array}$ & $\begin{array}{l}\text { Analytical } \\
\text { Methode }\end{array}$ & $\begin{array}{c}K \\
(f t / d)\end{array}$ & $\begin{array}{c}T \\
\left(\mathrm{ft}^{2} / \mathrm{d}\right)\end{array}$ \\
\hline R-9i (1a) & U. perched & $\mathrm{Tb}$ & Injection/R & Bouwer-Rice & 4.87 & \\
\hline$(1 \mathrm{~b})$ & U. perched & $\mathrm{Tb}$ & Injection/R & Bouwer-Rice & 3.88 & \\
\hline$(2)$ & L. perched & $\mathrm{Tb}$ & Injection/R & Bouwer-Rice & 0.11 & \\
\hline$(1)^{f}$ & U. perched & $\mathrm{Tb}$ & Pumping/D & Theis & 4.75 & 49.4 \\
\hline \multirow[t]{2}{*}{$R-13 b$} & Regional & Tpfp & Pumping/P & Hantush-Jacob & 21.4 & 1293.3 \\
\hline & Regional & Tpfp & Pumping/R & Hantush-Jacob & 13.7 & 829.7 \\
\hline $\mathrm{R}-19(6)$ & Regional & Tpp & Injection/R & Bouwer-Rice & 1.10 & \\
\hline$(7)$ & Regional & Tpp & Injection/R & Bouwer-Rice & 0.73 & \\
\hline $\mathrm{R}-22(2)$ & Regional & $\mathrm{Tb}$ & Injection/R & Bouwer-Rice & 0.04 & \\
\hline (3) & Regional & Tpf & Injection/R & Bouwer-Rice & 0.21 & \\
\hline$(4 a)$ & Regional & Tbo & Injection/R & Bouwer-Rice & 0.54 & \\
\hline$(4 b)$ & Regiona & Tbo & Injection/R & Bouwer-Rice & 0.72 & \\
\hline (5) & Regional & Tfo & Injection/R & Bouwer-Rice & 0.27 & \\
\hline $\mathrm{R}-31(3)$ & Regional & $\mathrm{Tb}$ & Injection/R & Bouwer-Rice & 0.41 & \\
\hline$(4)$ & Regional & Tpt & Injection/R & Bouwer-Rice & 1.23 & \\
\hline$(5)^{g}$ & Regional & Tpt & Injection/R & Bouwer-Rice & 0.75 & \\
\hline
\end{tabular}

a See hydrogeology and construction diagrams for depths of screened intervals; R-13 has only 1 screen. Letters after screen number indicate test: $a=$ initial test, $b=$ repeat test with same design, analytical method.

b U. = upper, L. = lower; see hydrogeology and construction diagrams.

c $\mathrm{Tb}=$ Cerros del Rio basalt; Tpf = Puye Formation (fanglomerate); Tpfp = Puye Formation (fanglomerate and pumiceous); $\mathrm{Tpp}=$ Puye Formation (pumiceous); Tpt = Puye Formation, Totavi Lentil; Tbo = older basalt: Tfo = older fanglomerate.

d $R=$ recovery data analyzed; $D=$ drawdown data analyzed (see appendices for field-data plots).

e Bouwer-Rice (1976, 64056); Hantush-Jacob (1955, 70115); Theis (1935, 70102); Table 13 gives major assumptions of analytical methods used. Results are for primary analytical methods or one giving most reasonable results; see summary tables for results of comparative methods.

$f$ Well was open to both upper and lower screens during test, but based on low productivity of material behind lower screen, the test essentially evaluated only that behind upper screen.

$g$ Test conducted before well fully developed but not retested after second round of development.

\section{Injection-Test Procedures}

Hydraulic properties of saturated materials at four of the five wells (R-9i, R-19, R-22, and R-31) were investigated by means of injection tests. First, a target screen was isolated by straddle packers deployed inside the well casing. Then, a finite amount of water was introduced at a constant rate by means of a hose inserted into the open end of the drill rod connected to the injection assembly (Figure 2). Water moved by gravity down the rod, through the upper packer, and out of the perforated pipe in the injection assembly, through the screen, and into the saturated medium.

These are not slug tests, as the water is not introduced instantaneously. Rather, they are a hybrid type of test, necessitated by the constraints described above. Procedures used were those outlined in ER Standard Operating Procedure (SOP) ER-SOP-07.03. 


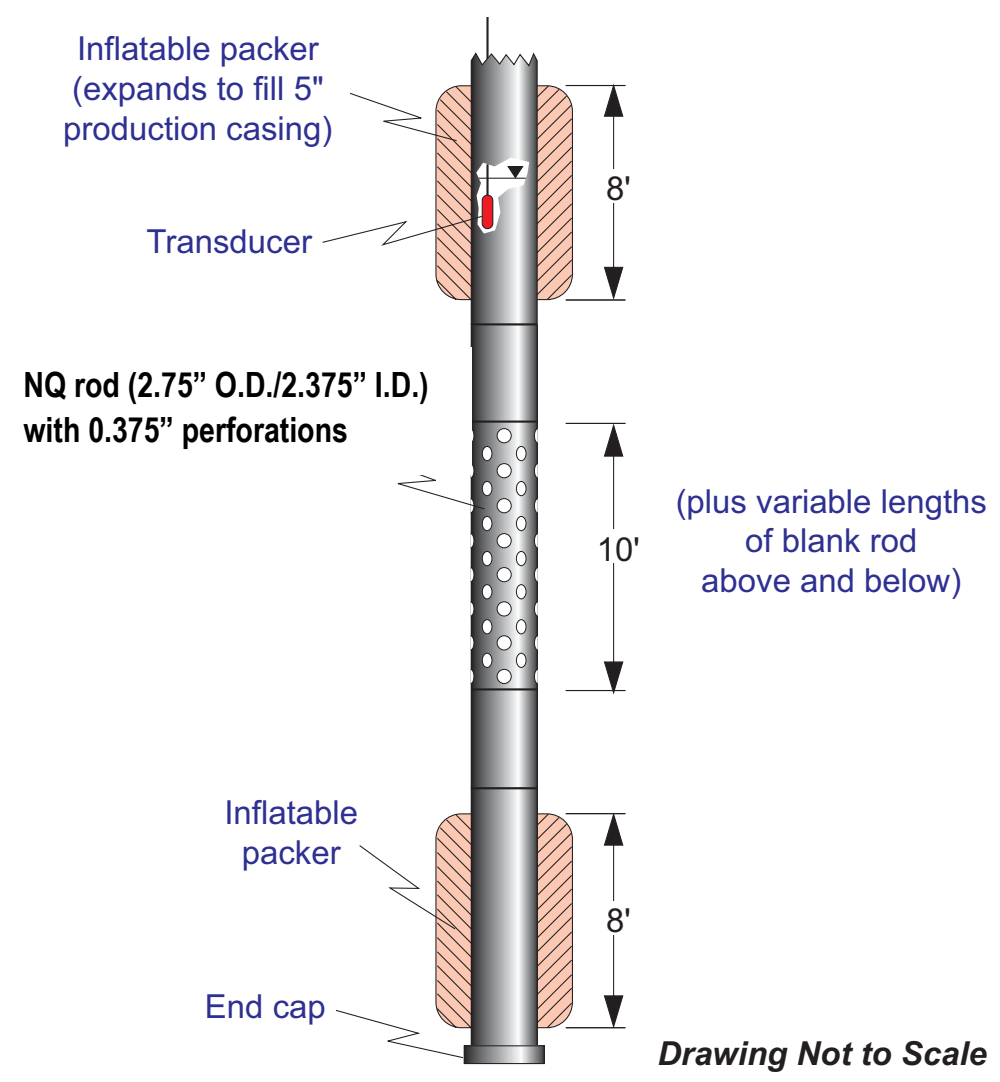

Figure 2. Straddle-packer/injection assembly

Water introduced into the wells during injection testing does not impact water quality for three reasons: (1) the water injected is drinking water from the Los Alamos municipal supply and, therefore, does not introduce contaminants; (2) the volume of water injected is small, especially when compared with the volumes added in other stages of the well installation (Table 6), so there is little dilution of natural groundwater; and (3) following testing, five times the volume of water introduced is pumped from each screened interval where there was injection to remove the foreign water. NMED's Ground-Water Quality Bureau approved the injection of municipal water for these tests without requiring the Lab to file a discharge permit.

Table 6

Water Introduced and Extracted at Wells Tested by Injection

\begin{tabular}{|l|c|c|c|c|}
\hline Well & $\begin{array}{c}\text { Water Added } \\
\text { in Drilling (gal.) }\end{array}$ & $\begin{array}{c}\text { Water Added in } \\
\text { Construction (gal.) }\end{array}$ & $\begin{array}{c}\text { Water Removed in } \\
\text { Development (gal.) }\end{array}$ & $\begin{array}{c}\text { Water Injected } \\
\text { in Testing (gal.) }\end{array}$ \\
\hline R-9i & Minimal $^{\mathbf{a}}$ & $?^{\mathbf{b}}$ & 4465 & $7^{\mathbf{c}}$ \\
\hline R-19 & Minimal & $?^{\mathbf{c}}$ & $\sim 50,000$ & 442 \\
\hline R-22 & Minimal & 42,000 & 34,803 & 440 \\
\hline R-31 & Minimal & 39,000 & 14,930 & 580 \\
\hline
\end{tabular}

Drilled by air-rotary methods.

b = not given in well completion report.

Pumping test following injection test produced 4310 gal. 
Straddle-packer/injection testing involved several steps:

1. Pertinent pre-test information was compiled and recorded.

2. The straddle-packer/injection assembly (Figure 2) was emplaced and inflated. Gauges on the nitrogen tank were checked frequently to ensure that the packers were holding pressure.

3. Water level was measured with an electric probe and the static position was recorded.

4. A transducer was emplaced and its position recorded. Its operation and communication with the datalogger were checked by connection to a laptop computer.

5. Water for injection was placed in a large open stock tank. The water was taken up by means of a hose connected to the Bean pump on the drilling rig. A hose was used to gravity-flow water into the well through drill rods connected to the injection assembly. Only municipal water was used.

6. Prior to testing, the rate of discharge from the injection hose was evaluated and adjusted to an appropriate value, based on yield during development.

7. A fixed volume of water was injected down the rod connected to the straddle-packer assembly, or water was injected over a fixed time interval.

8. The variation in flow rate during injection and total volume injected were evaluated using a flow meter (in-line between the water supply tank and the pump) and a stopwatch or watch with a second hand.

9. Water-level rise during injection was monitored by transducer and recorded by a datalogger.

10. Recovery to pre-test static water level was monitored on a laptop. When water level returned to the static position, the test was halted.

11. Post-test data (duration of test, volume injected, final water level, etc.) were recorded.

Following the tests, up to five times the volume of water injected was pumped out of the well to minimize the impact of introducing foreign water.

\section{Pumping-Test Procedures}

Pumping tests were conducted at two of the five wells (R-9i and R-13). Procedures used were those given in various standard texts (e.g., Driscoll 1986, 70111, or Kruseman and de Ridder 2000, 70110) and as outlined in ER-SOP-07.04.

The pumping tests involved several steps:

1. A submersible pump was installed.

2. An initial static water-level condition in the well was ensured by monitoring for an extended period after the pump was installed but prior to testing.

3. Pertinent pre-test information (pump type, pump depth, static water level) was recorded.

4. A pressure transducer was emplaced and the position recorded. Its operation and communication with the datalogger were checked by connection to a laptop computer.

5. Barometric pressure was recorded during the test period using the transducer.

6. The pump was turned on and the discharge rate was monitored by means of an in-line flow meter and stopwatch or watch with a second hand.

7. Drawdown observations were monitored with a laptop and recorded by a data logger.

8. When the drawdown seemed to be leveling off, the pump was turned off.

9. Recovery of the water level was then monitored.

10. When the pre-test static level was reached or nearly so, the test was halted.

11. Post-test data (duration of test, total volume pumped, final water level, etc.) were recorded.

Produced water was not allowed to re-enter the aquifer being tested. Rather, well discharge was collected in a large-capacity tank. 


\section{DATA ANALYSIS}

Data collected in the injection and pumping tests were analyzed by various standard methods to obtain hydraulic properties. That is, plots were made showing the fit of the test data to appropriate theoretical curves. AQTESOLV ${ }^{\mathrm{TM}}$ for Windows (version 3.01, professional) was used to produce the plots and analyze the data from all tests. For consistency throughout the analyses, standard assumptions were made for some input parameters required by the software:

Saturated thickness $=$ the length of filter pack if confined, the height of water column if unconfined, Anisotropy ratio $=1$,

Filter-pack porosity $=0.25$, and

Well-skin radius $=$ well-bore radius .

The software accounts for the effects of partial aquifer penetration, when specified.

Our general approach was to obtain and present the best curve match possible and then evaluate the resulting values for hydraulic parameters. Any unreasonable results are treated in the sections of this report entitled "Discussion." We analyzed the injection tests only by slug-test methods and the pumping tests only by pumping-test methods. It could be argued that the longer injection tests should be analyzed by some pumping-test methods. We did not do this for two reasons. First, although some injection tests are too long for slug tests, they are too short for pumping tests. Second, since a quasi-static water level was developed in the longer injection tests, the recovery data are comparable to those obtained when a solid slugger is withdrawn in a traditional slug test.

To avoid repetition in the text, parenthetical reference citations for the various analytical methods (that is, the years of publication and ER ID numbers) are only given in the sections below.

\section{Analysis of Injection Tests}

All analyses of injection-test data focused on the recovery portion of the water-level response. Data from each injection test were analyzed by three common slug-test methods for comparison. Although results from all three methods are included in the summary tables for the tests, only plots for the main analytical method (Bouwer-Rice) are presented in the interest of space.

Bouwer-Rice Method. For consistency, we analyzed all of the injection tests by the Bouwer-Rice slug-test technique (Bouwer and Rice 1976, 64056). The Bouwer-Rice method applies to partial or complete well penetration of the aquifer, unconfined or confined conditions, and application of stress by addition or withdrawal of water. Although the injection tests are not slug tests, since water is not introduced instantaneously, the water-level response is very similar to that in traditional slug tests. That is, water level rises abruptly when injection starts and falls gradually after injection stops (Figure 3 ). The falling limbs of the field-data plots are identical to those for traditional slug tests. Therefore, analysis of the recovery (falling-limb) data by well-established slug-test methods, such as Bouwer-Rice, is reasonable. 


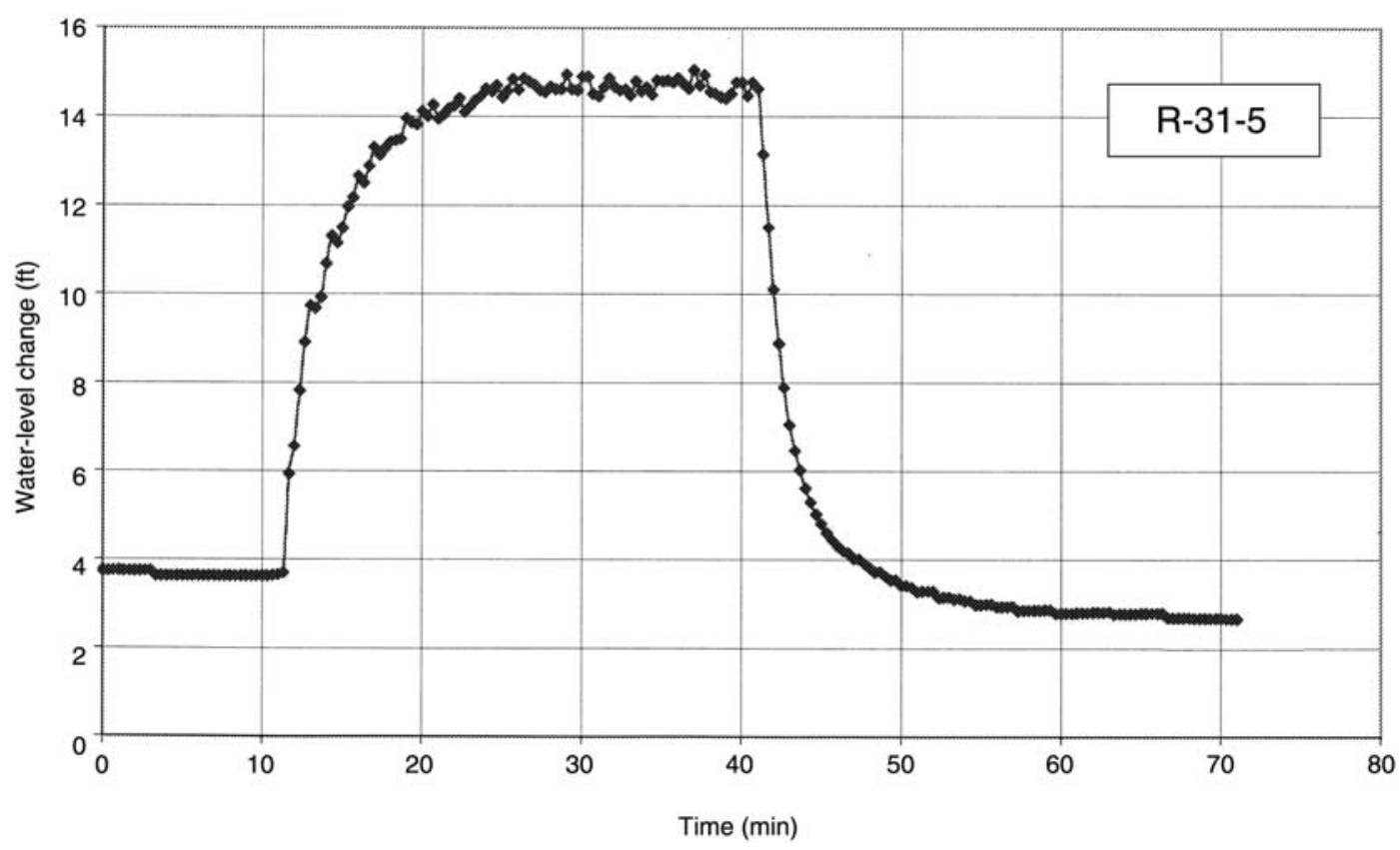

Figure 3. Typical field-data plot for the injection tests conducted

The basic parameters used in Bouwer-Rice analysis are shown in Figure 4. These include water-level change relative to static position $(y)$, length of the well $\left(L_{w}\right)$, radius of the borehole $\left(r_{b}\right)$, length of the screen $\left(L_{s}\right)$ and hydraulic head $(H)$. The Bouwer-Rice slug-test procedure normally employs a solid slugger to displace a volume of water equal to the volume of the slugger. Initially, the slugger is lowered into the well until it is fully submerged. Figure 4a shows a falling-head test in which flow will be out of the well. The slugger displaces water upward in the well bore. This initial displacement above the static water level is measured as the distance $\mathrm{y}_{1}$ (Figure 4a). The amount of displacement depends on the diameter of the well casing as well as the length and diameter of the slugger. Ideally, the value for $y_{1}$ will be several feet or more. In an effort to regain the static pre-test condition, water flows out of the well and into the formation through the well screen and filter pack. The distance $\mathrm{y}_{1}$ slowly decreases back toward zero $\left(\mathrm{y}_{0}\right)$ or the same as before the slugger was inserted (Figure 4b). Figure 4c shows a rising-head test in which water or a slugger is removed and flow is from the formation into the well. It was not possible to perform this type of test because the wells are constructed with multiple screens.

In view of constraints imposed by well design, the Bouwer-Rice slug test procedure as described above was modified to one that is very similar to a drill-stem test commonly used in oil and gas wells (Earlougher 1977, 73478). However, the Bouwer-Rice analysis is still applicable; in fact, the Bouwer-Rice procedure is a type of drill-stem test. Water is injected by gravity into the well at a constant rate. The recorded water level initially rises very fast. However, the rate of rise eventually decreases, and water level reaches a new static equilibrium in response to the constant inflow rate (Figure 3). This new static level is located some distance above the initial static water level and the change corresponds to $y_{1}$ in Figure $4 a$. When water injection is suddenly stopped, the water level in the well immediately starts to fall. The injection tests performed are analogous to an ideal Bouwer-Rice slug test because a new static equilibrium was achieved before injection ceased. Results of these injection tests probably represent a lower limit of values for hydraulic conductivity as they characterize conditions in the disturbed portion of the formation near the well. 


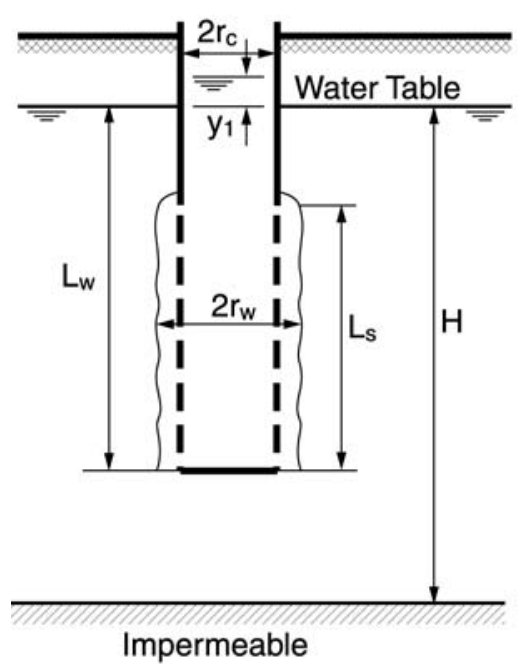

(a)

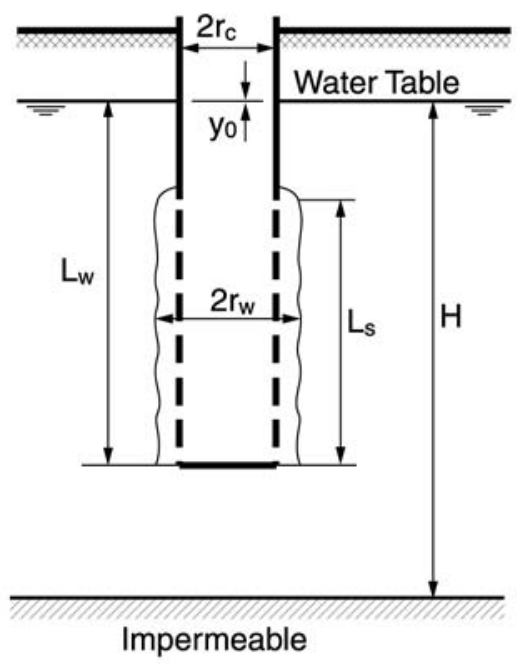

(b)

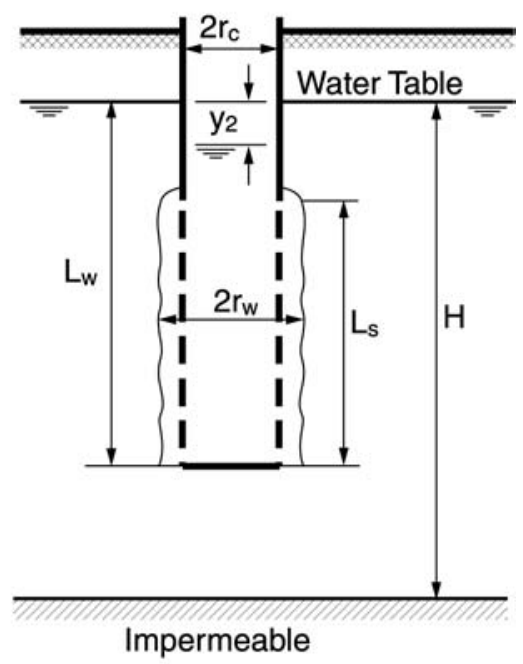

(c)

Figure 4. Relationship of Bouwer-Rice parameters to water level in well for different test types (modified from Bouwer 1978, 73678); (a) slug-injection or falling-head test (flow is out of well), (b) static equilibrium, and (c) slug-withdrawal or rising-head test (flow is into well)

Bouwer-Rice plots can consist of two straight-line segments followed by a curve deviating from the second straight line (Fetter, 1994, Figure 7.27). In such cases, the first straight line is short and represents the filter pack. The second straight line is longer and represents the saturated material tested. Beyond the second straight line segment the plot curves upward, owing to the expansion of the injected water mound. The result is a concave-upward plot.

Cooper-Bredehoeft-Papadopulos (C-B-P) Method. For comparison, injection-test data were also analyzed by the C-B-P method (Cooper et al. 1967, 70108). The C-B-P method assumes complete aquifer penetration, confined hydraulic condition, and application of stress by either addition or withdrawal of water. A drawback to this method is that a storativity (S) value is required. The analysis can be constrained to a specified value for $S$ or allowed to float as the plot is matched to the theoretical curve. If a reasonable $S$ value is used, results obtained by the C-B-P method should be similar to those yielded by the Bouwer-Rice analysis. For the tests reported, results obtained by the C-B-P method are generally comparable to those obtained by the Bouwer-Rice method, but data plots for most tests poorly match the theoretical curve. Results obtained by the C-B-P method are included in the summary tables for the tests for comparison.

Hvorslev Method. All injection tests were also analyzed by the Hvorslev method (Hvorslev 1951, 70101) for further comparison. The Hvorslev method assumes partial aquifer penetration, unconfined or confined conditions, and application of stress by either addition or withdrawal of water. Results obtained by the Hvorslev method are generally comparable to those yielded by the Bouwer-Rice and C-B-P methods. Values are included in the summary tables for the tests for comparison.

\section{Analysis of Pumping Tests}

Both pumping tests were initially analyzed by the Theis method (Theis 1935, 70102). For comparison, data were also analyzed by alternative methods suggested by the curve match for the Theis analysis. For example, we analyzed data from the pumping test at R-9i by both the Theis and Neuman method 
(Neuman 1975, 73479). Data from the other well tested by pumping (R-13) were analyzed by the Theis and Hantush-Jacob methods (Hantush and Jacob 1954, 70115). Results of analysis by all methods are given in the summary tables for the pumping tests, unless a given method yielded questionable results. Plots for all acceptable analyses accompany the summary tables.

Although AQTESOLV ${ }^{\mathrm{TM}}$ automatically provides a storativity value for any analysis of pumping-test data, such a determination is not possible from single-well tests as reported here. Therefore, no results are listed for this parameter in the summary tables for the pumping tests conducted.

\section{WELL R-9i}

$\mathrm{R}-9 \mathrm{i}$ is located beside regional well R-9 on the south bank of Los Alamos Canyon, 0.3 mi west of the White Rock "Y" (Figure 1). During the drilling of regional well R-9 by the casing-advance method, two perched zones of saturation were encountered in the Cerros del Rio basalt (Broxton et al. 2001, 71251). As these zones were sealed off to protect the regional aquifer while R-9 was drilled to TD, R-9i, was installed beside R-9 to monitor the quality of these perched waters (Broxton et al. 2001, 66600). Well R-9i was drilled by air-rotary, casing-advance methods to a total depth (TD) of $322 \mathrm{ft}$. The well was completed with two screened intervals in the Cerros del Rio basalt (Figure 5).

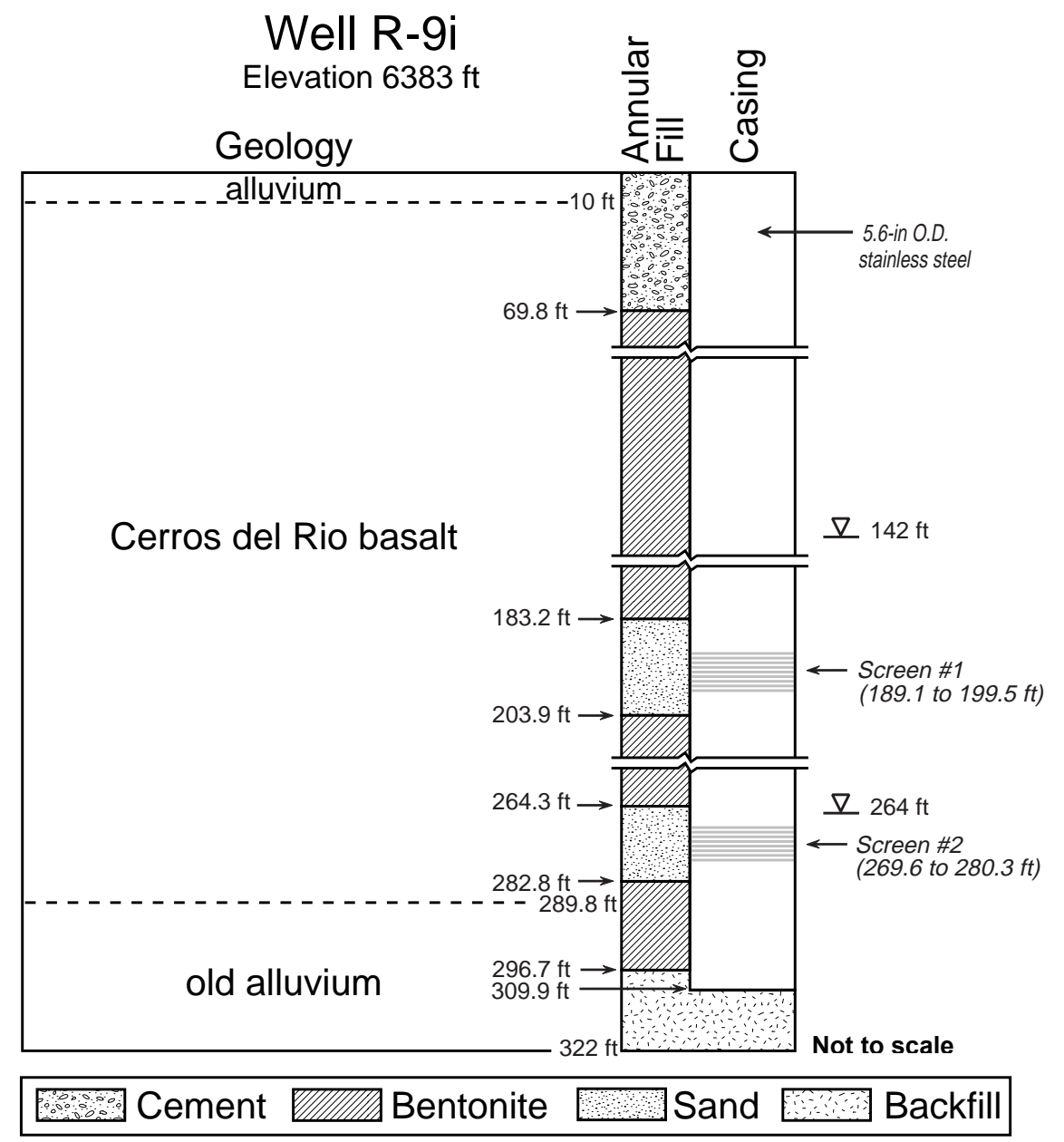

Figure 5. Hydrogeology and construction of R-9i 


\section{Hydrogeology}

Geologic units penetrated by well R-9i are shown in Figure 5. The same perched zones of saturation seen in well R-9 were encountered in R-9i. Water was first recognized in the borehole at a depth of $186 \mathrm{ft}$ in fractured basalt. Ultimately, the water level rose to a depth of $142 \mathrm{ft}$ bgs. Such a water-level rise often indicates confined conditions. While each saturated nonvertical fracture is a miniature confined system, the rise is more likely a result of the basalt being saturated below the shallower depth and (1) water simply entered the hole too slowly to be recognized during drilling or (2) no water-bearing fractures were penetrated above a depth of $186 \mathrm{ft}$. Available head data obtained during drilling suggest a downward vertical gradient, as expected for perched saturation, thus ruling out confinement.

\section{Injection Tests}

Injection tests were attempted for both screened intervals in well R-9i (Table 7). The lower interval (screen 2) was tested first. However, this zone was so tight that within 2 min injected water came out of the top of the rod connected to the packer assembly. Injection was halted and recovery data were collected. Next, the packers were moved to the upper interval (screen 1), and two injection tests were performed there. Test design and results are summarized in Table 7. Analyses of injection-test data from $\mathrm{R}-9 \mathrm{i}$ are shown in Figures 6 and 7. Field and analytical data are given in Appendix A.

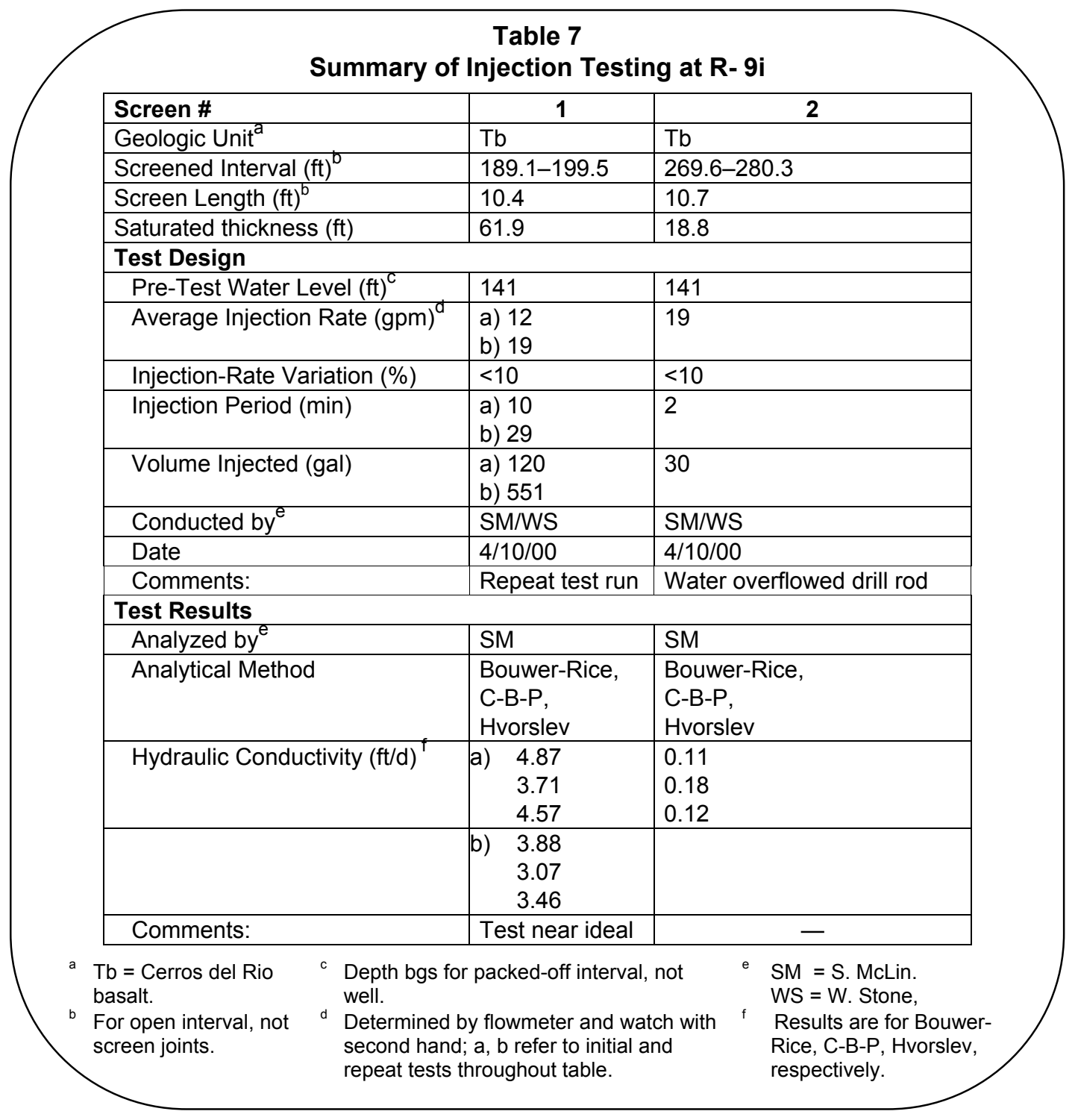




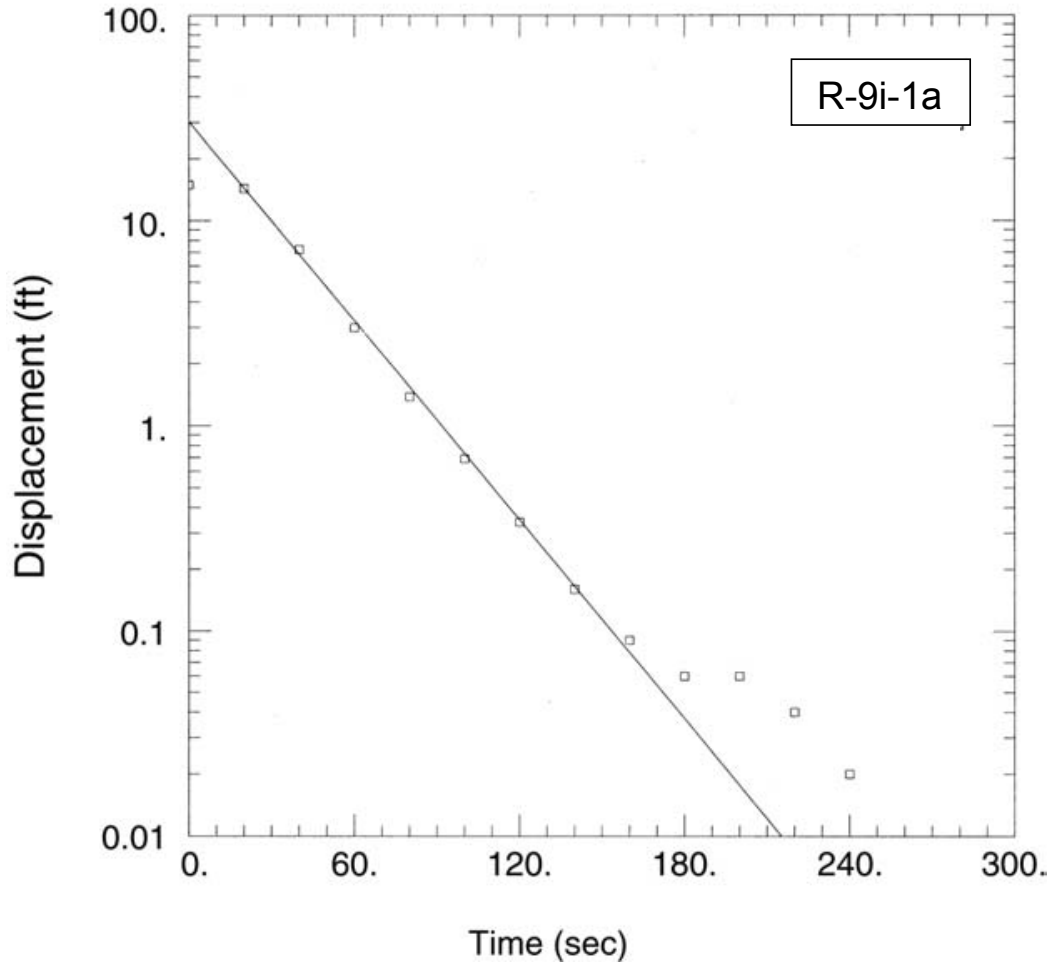

Figure 6. Bouwer-Rice analysis of injection-test recovery data for R-9i, screen 1a

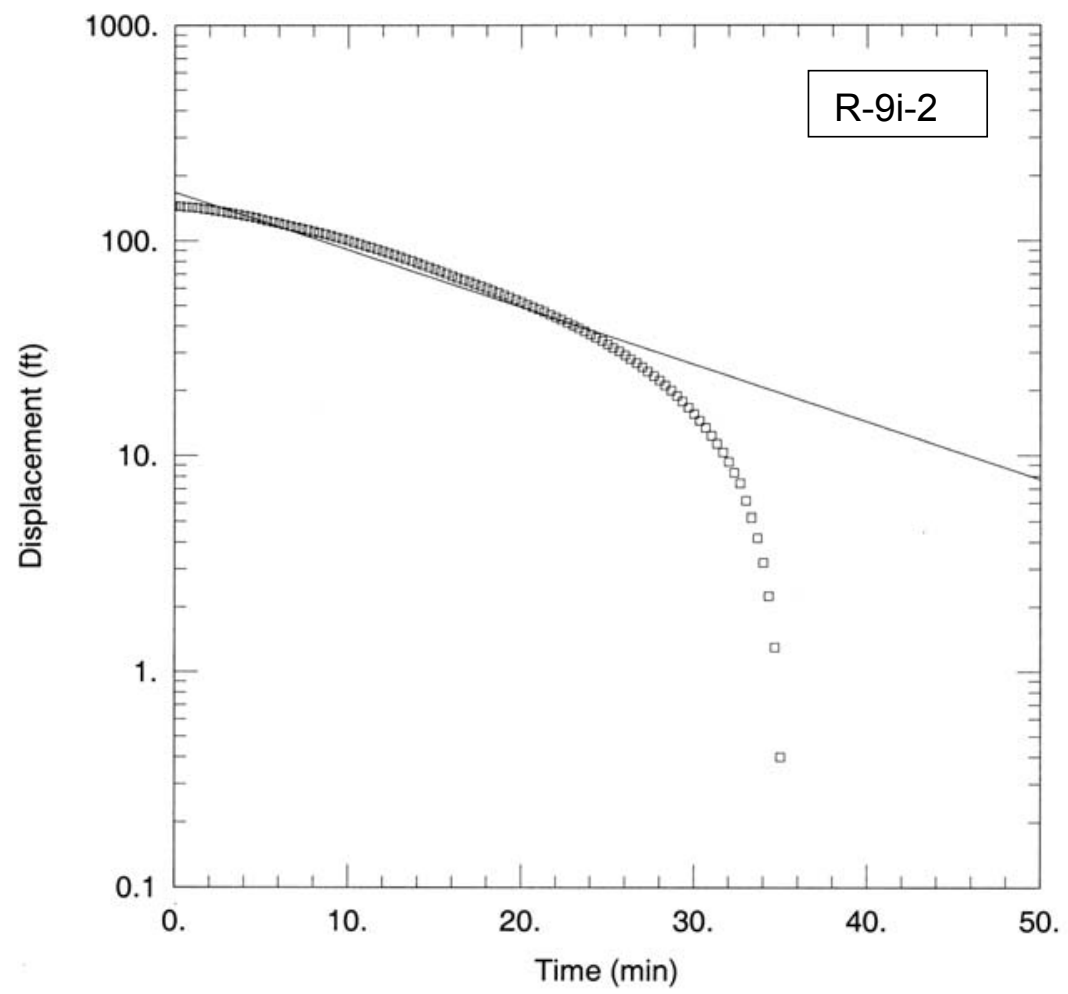

Figure 7. Bouwer-Rice analysis of injection-test recovery data for R-9i, screen 2 


\section{Pumping Test}

A short-term pumping test (lasting about $7 \mathrm{hrs}$ ) was also conducted in well R-9i using a small submersible pump set inside the well casing. During this test, both screens were open. However, as shown by the injection tests, the hydraulic conductivity of material behind screen 1 is so much greater than that behind screen 2 that most of the pumped water came from screen 1 , and the hydraulic conductivity $(K)$ for the test represents the undisturbed formation that surrounds screen 1. Test design and results are summarized in Table 8. Analyses of pumping-test data are shown in Figures 8, 9, and 10. Field and analytical data are presented in Appendix A.

\begin{tabular}{|c|c|}
\hline \multicolumn{2}{|c|}{$\begin{array}{c}\text { Table } 8 \\
\text { Summary of Single-Well Pumping Test at R-9i }\end{array}$} \\
\hline Geologic Unit & Cerros del Rio basalt \\
\hline Screened Interval (ft) ${ }^{a}$ & $189.1-199.5$ \\
\hline Screen Length $(\mathrm{ft})^{\mathrm{a}}$ & 10.4 \\
\hline Saturated Thickness (ft) & 61.9 \\
\hline \multicolumn{2}{|l|}{ Test Design } \\
\hline Pre-Test Water Level (ft) & 141 \\
\hline Pump Type & 10 hp submersible \\
\hline Depth of Pump Intake (ft) & 183 \\
\hline Average Pumping Rate $(\mathrm{gpm})^{\mathrm{c}}$ & 15.41 \\
\hline Pumping Period (hrs) & 7 \\
\hline Volume Pumped (gal.) & 4500 \\
\hline Conducted by ${ }^{d}$ & SM \\
\hline Date & $4 / 11 / 00$ \\
\hline \multicolumn{2}{|c|}{$\begin{array}{l}\text { Comments: Well also open to deeper unproductive zone (screen \#2), but } \\
\text { test presumably evaluated material behind upper screen (\#1). }\end{array}$} \\
\hline \multicolumn{2}{|c|}{ Test Results } \\
\hline Analyzed by ${ }^{d}$ & SM \\
\hline Analytical Method & $\begin{array}{l}\text { Theis } \\
\text { Neuman (early) } \\
\text { Neuman (late) }\end{array}$ \\
\hline Transmissivity $\left(\mathrm{ft}^{2} / \mathrm{d}\right)^{\mathrm{e}}$ & $\begin{array}{r}49.4 \\
315.3 \\
13.2 \\
\end{array}$ \\
\hline Hydraulic Conductivity $(\mathrm{ft} / \mathrm{d})^{f}$ & $\begin{array}{c}4.75 \\
30.3 \\
1.3\end{array}$ \\
\hline Storativity & Not valid from single-well tests \\
\hline \multicolumn{2}{|c|}{ Comments: Theis results comparable to injection test results } \\
\hline \multicolumn{2}{|c|}{$\begin{array}{l}\text { Length of open interval, not screen joints (screen \#1). } \\
\text { Composite value with well open to both screens. } \\
\text { Determined by flowmeter and watch with second hand. } \\
\text { SM = S. McLin. } \\
\text { Results are for Neuman (early data) and Neuman (late data) respectively. } \\
\text { Derived from transmissivity, using screen length because of shortness of test. }\end{array}$} \\
\hline
\end{tabular}




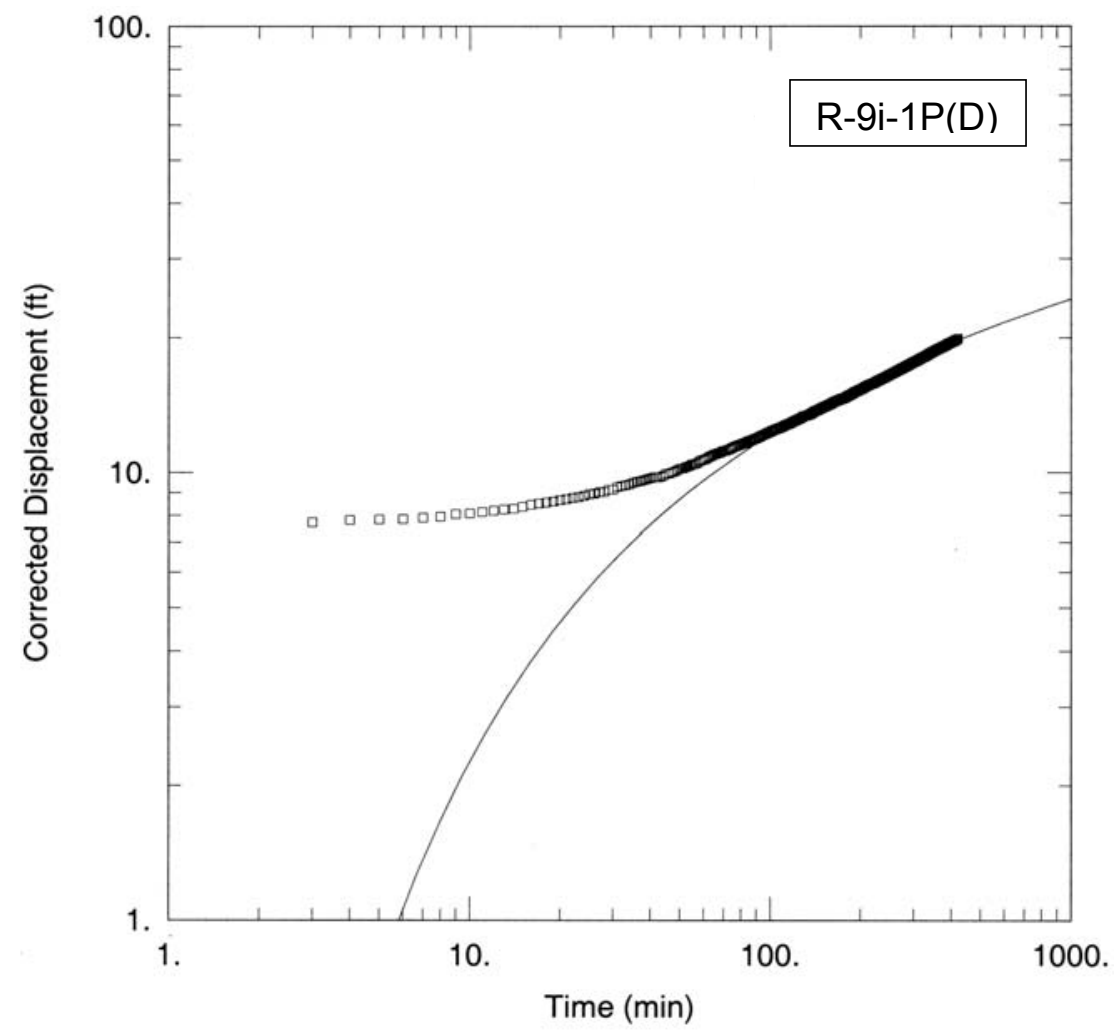

Figure 8. Theis analysis of pumping-test drawdown data for R-9i, both screens

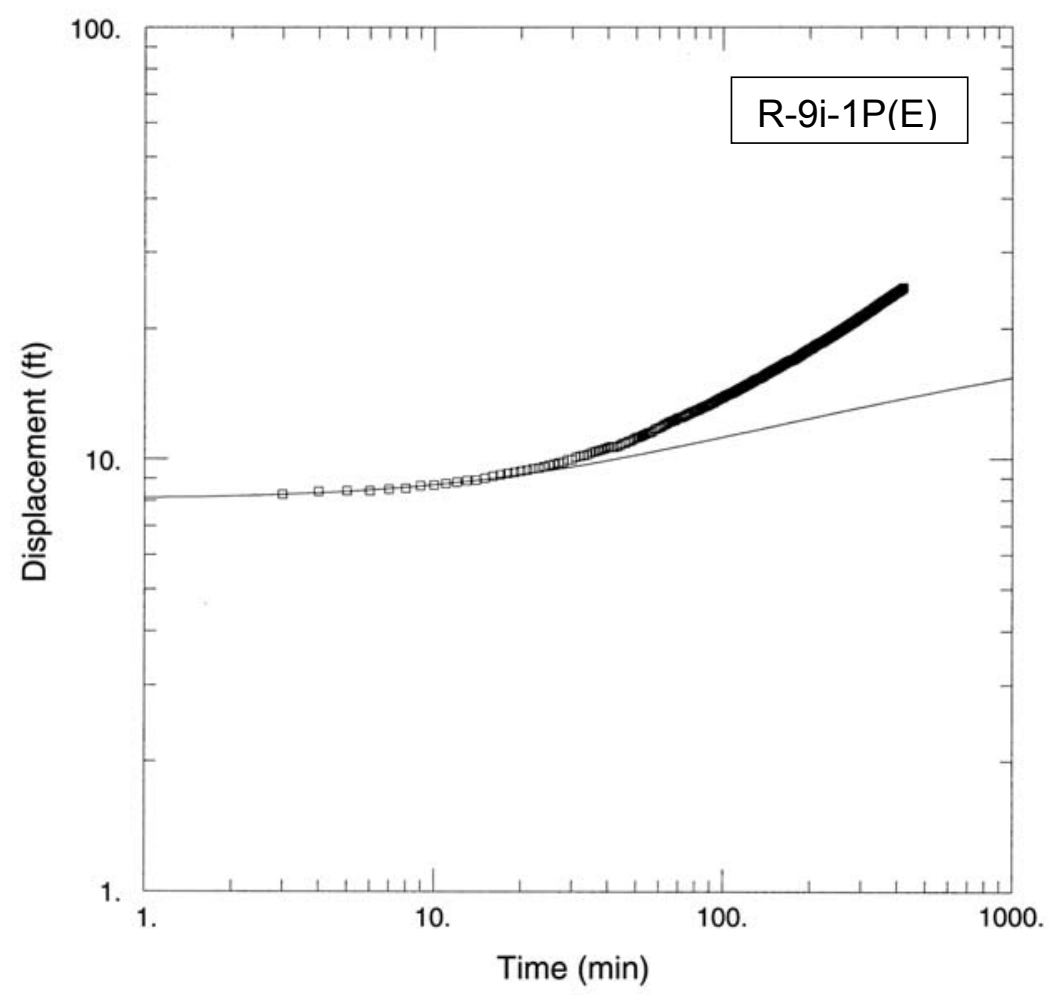

Figure 9. Neuman analysis of early pumping-test drawdown data for R-9i, both screens 


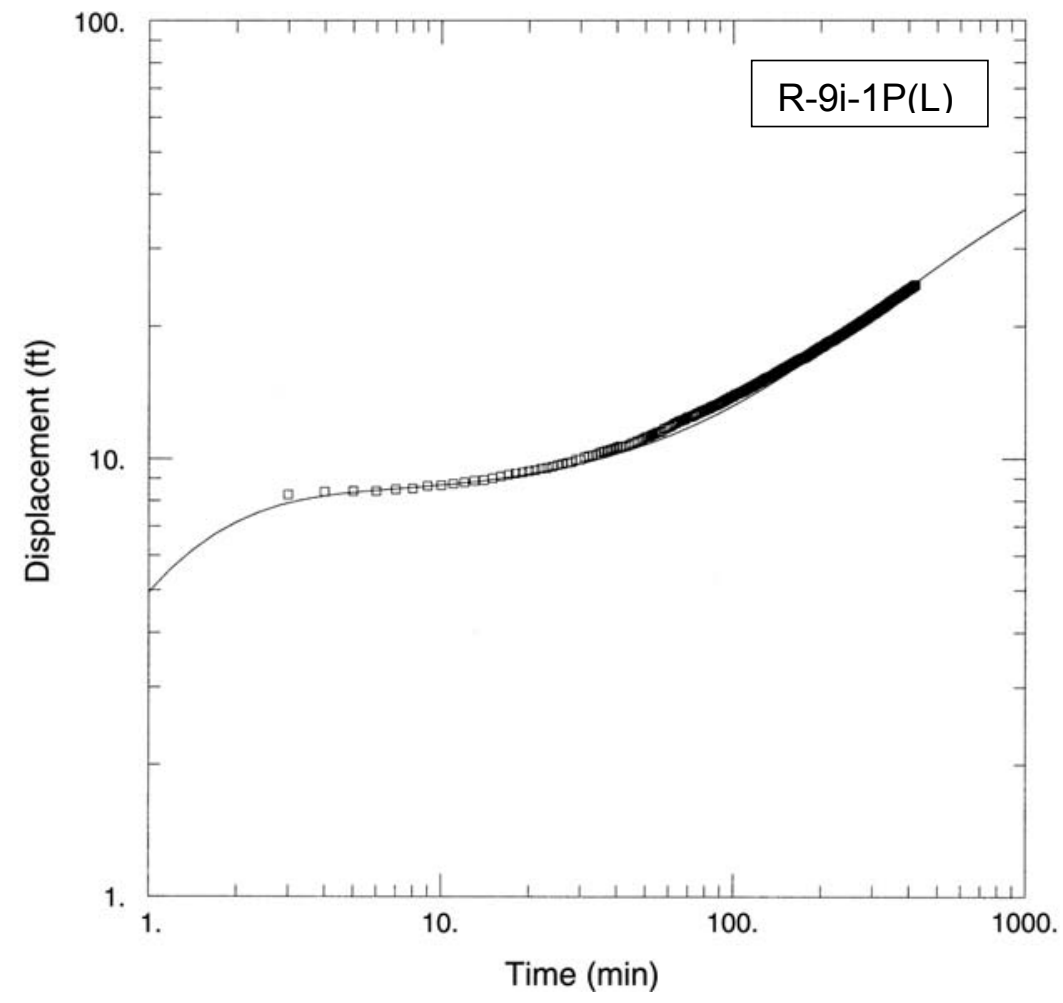

Figure 10. Neuman analysis of late pumping-test drawdown data for R-9i, both screens

\section{Discussion}

Injection Tests. Two tests were conducted for screen 1. During the first test (R-9-i-1a), water level dropped sharply in the midst of injection (the double-peak curve at the left in Appendix A-1) because of a brief cessation in water flow. No such interruption occurred during a repeat test (R-9i-1b), conducted with a greater injection rate and time.

Water injected at screen 2 quickly rose to the surface. Although Figure 5 shows a static water level for the lower perched zone of $264 \mathrm{ft}$ bgs, a water-level depth of only $141 \mathrm{ft}$ was measured with the packers set on that zone prior to testing. This discrepancy is the result of the hole being open to both zones before the packers were set at the lower screen and the water level did not drop to a position appropriate for the lower zone because of its low permeability. Thus, water remained at the composite level and a rise of only 141 feet was sufficient to cause water to overflow the rod connected to the injection assembly.

Pumping Test. Inasmuch as the lower screened interval was tight, it was reasoned that pumping the well when it was open to both screens would in fact test mainly the upper productive interval. Results are not the same as if only screen 1 were tested by pumping. However, as screen 2 was nonproductive, the test probably gives order-of-magnitude results for the basalt in screen 1.

Analysis/Injection Tests. The water-level response to injection at screen 1 (Appendix A-1) is similar to that in traditional slug tests. Therefore, we analyzed injection-test data for well R-9i, screen 1 by the BouwerRice slug technique. The Bouwer-Rice plot for the initial injection test (R-9i-1a) is shown in Figure 6. The linear portion of the plot (i.e., the first 150 seconds) covers most of the data points collected and is the valid part of such plots. The upward turn of the plot after that is a typical Bouwer-Rice response. BouwerRice analysis yielded a K of 4.87 feet per day $(\mathrm{ft} / \mathrm{d})$. The repeat test reproduced the first test with some deviation in the linear portion of the curve and yielded a $\mathrm{K}$ of $3.88 \mathrm{ft} / \mathrm{d}$. 
For comparison, we also analyzed injection test data for screen 1 by the C-B-P and Hvorslev slug test methods. C-B-P analysis yielded a K of $3.71 \mathrm{ft} / \mathrm{d}$ for the initial test, when $\mathrm{S}$ was constrained to a value of $5 \times 10^{-5}$, and a $\mathrm{K}$ of $3.07 \mathrm{ft} / \mathrm{d}$ for the repeat test with the same value for $\mathrm{S}$. The Hvorslev analysis yielded a $\mathrm{K}$ of $4.57 \mathrm{ft} / \mathrm{d}$ for the initial test and $3.46 \mathrm{ft} / \mathrm{d}$ for the repeat test. Results obtained by both of these additional methods are comparable to those for Bouwer-Rice analysis.

Injection-test data for R-9i screen 2 were also analyzed by the Bouwer-Rice method (Figure 7). The figure shows an abrupt and steep downward curvature after the linear portion of the water-level decay plot. This shape sometimes results when pre-test water level is slightly higher than the static position. However, there is no indication of a higher water level on the field plot (Appendix A-4) and the reason for the response is unknown. Bouwer-Rice analysis yielded a $\mathrm{K}$ of $0.11 \mathrm{ft} / \mathrm{d}$ for the basalt behind the lower screen.

For comparison, we also analyzed test data from screen 2 by the C-B-P and Hvorslev methods. C-B-P analysis gave a $\mathrm{K}$ of $0.18 \mathrm{ft} / \mathrm{d}$, when $\mathrm{S}$ was fixed at $5 \times 10^{-6}$, while analysis by the Hvorslev method gave a $\mathrm{K}$ of $0.12 \mathrm{ft} / \mathrm{d}$. Results from these methods of analysis are comparable to those from Bouwer-Rice analysis.

Analysis/Pumping Test. Drawdown data from the pumping test at R-9i were analyzed by two different methods. Initially, we used the Theis method which yielded a T value of $49.4 \mathrm{ft}^{2} / \mathrm{d}(\mathrm{K}=4.75 \mathrm{ft} / \mathrm{d})$. The shape of the plot in the Theis analysis (Figure 8) suggested that application of the Neuman method for a phreatic aquifer was warranted. Thus, we also analyzed both early- and late-time drawdown data by the Neuman method. Analysis for early-time data is shown in Figure 9 and suggests that $T=315.3 \mathrm{ft}^{2} / \mathrm{d}$ $(K=30.3 \mathrm{ft} / \mathrm{d})$. These results are an order of magnitude greater than those for Bouwer-Rice analysis of the injection tests. When a reasonable curve match was obtained, the associated $S$ value was unreasonable, and when $S$ was constrained to a reasonable value, the curve match was poor. Analysis of late-time data is shown in Figure 10 and suggests that $T=13.2 \mathrm{ft}^{2} / \mathrm{d}(\mathrm{K}=1.3 \mathrm{ft} / \mathrm{d})$. These results are the same order of magnitude as the Bouwer-Rice results. However, although the late-time data fit the theoretical curve extremely well, specific yields obtained are too high, casting further doubt on the T value (Appendices A-10 and A-11). Some difference in anisotropy may be unaccounted for in the analysis. Furthermore, using the pumping well as the observation well is not ideal.

\section{WELL R-13}

$\mathrm{R}-13$ is located in Mortandad Canyon, just west of the eastern Laboratory boundary (Figure 1). Well R-13 was drilled to a TD of $1133 \mathrm{ft}$ within the Puye Formation and completed with a single 60-ft-long screen placed $125 \mathrm{ft}$ below the regional water table within the Puye (Figure 11).

\section{Hydrogeology}

Geologic units penetrated by well R-13 are shown in Figure 11. No perched water was detected. The regional water table was encountered at a depth of $834 \mathrm{ft}$ within the Puye Formation. The single screen straddles the contact between the typical Puye fanglomerate and the underlying pumiceous Puye. 


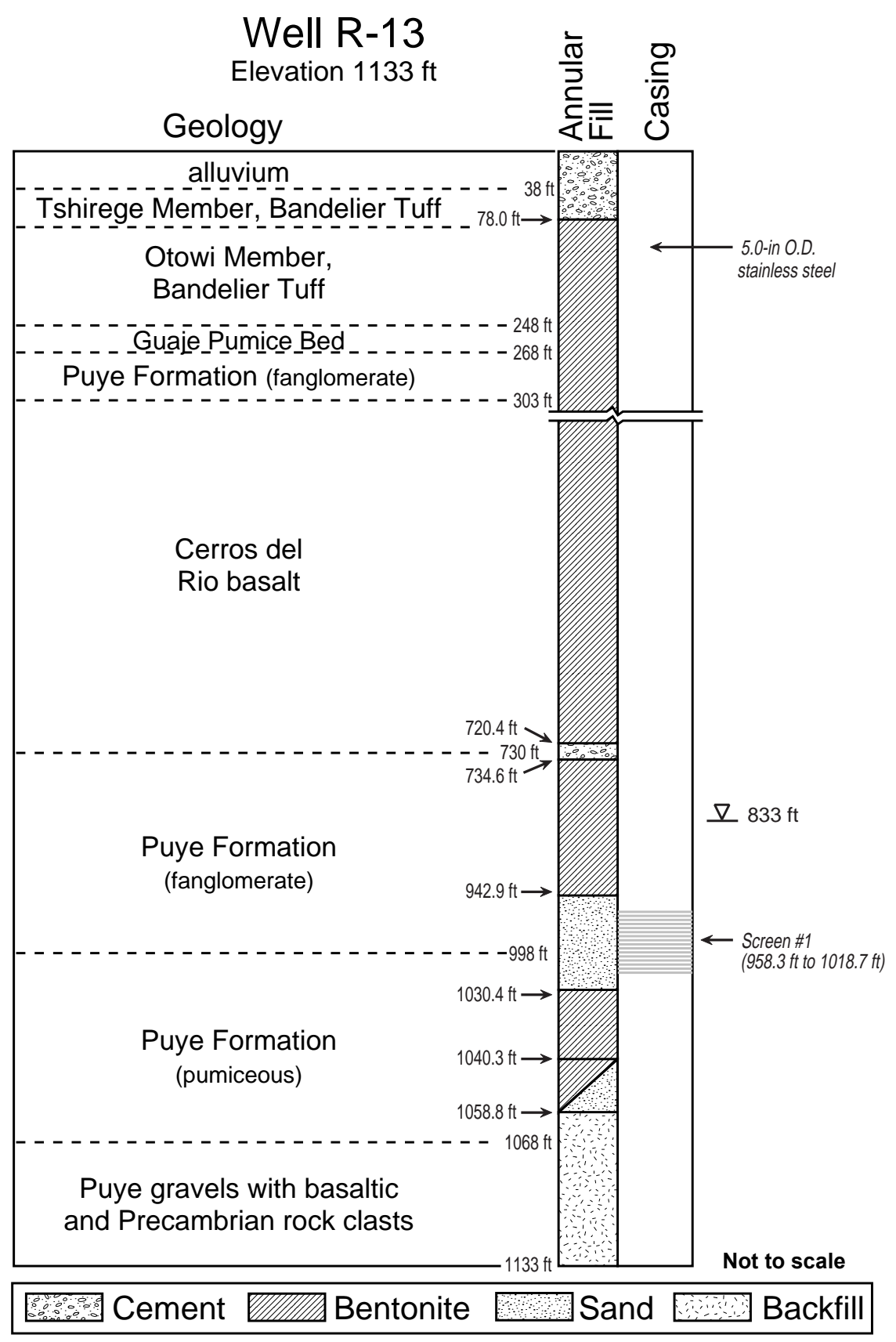

Figure 11. Hydrogeology and construction of R-13

\section{Pumping Test}

Two short single-well pumping tests were conducted at R-13 using a submersible pump inside the well casing. As drawdown and recovery data from the second (repeat) test were more uniform, it is the only one analyzed. Test design and results are summarized in Table 9. Analyses of the test data by the Hantush-Jacob method are shown in Figures 11 and 12. Field and analytical data for the repeat test are given in Appendix B. 


\begin{tabular}{|c|c|}
\hline \multicolumn{2}{|c|}{$\begin{array}{c}\text { Table } 9 \\
\text { Summary of Single-Well Pumping Tests at R-13 }\end{array}$} \\
\hline Geologic Unit & Puye Formation \\
\hline 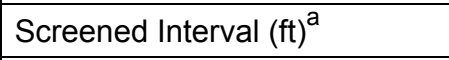 & 958.3-1018.7 \\
\hline Screen Length (ft) ${ }^{a}$ & 60.4 \\
\hline Saturated Thickness (ft) & 87.5 \\
\hline \multicolumn{2}{|l|}{ Test Design } \\
\hline Pre-Test Water Level (ft) & 833 \\
\hline Pump Type & 10 hp submersible \\
\hline Depth of Pump Intake (ft) & 931.34 \\
\hline Average Pumping Rate $(\mathrm{gpm})^{\mathrm{b}}$ & $\begin{array}{l}\text { a) } 18.9 \\
\text { b) } 19\end{array}$ \\
\hline Pumping Period (min) & $\begin{array}{l}\text { a) } 22 \\
\text { b) } 12\end{array}$ \\
\hline Volume Pumped (gal.) & $\begin{array}{l}\text { a) } 430 \\
\text { b) } 190\end{array}$ \\
\hline Conducted by ${ }^{\mathrm{c}}$ & WS \\
\hline Date & $10 / 31 / 01$ \\
\hline \multicolumn{2}{|c|}{$\begin{array}{l}\text { Comments: Pumping rate apparently not enough to stress aquifer; water } \\
\text { level during first test erratic }\end{array}$} \\
\hline \multicolumn{2}{|c|}{ Test Results } \\
\hline Analyzed by ${ }^{\mathrm{c}}$ & SM \\
\hline Analytical Method & Hantush-Jacob \\
\hline Transmissivity $\left(\mathrm{ft}^{2} / \mathrm{d}\right)$ & $\begin{array}{l}\text { a) not analyzed } \\
\text { b) } 1293.3 \text { (pumping), } \\
829.7 \text { (recovery) }\end{array}$ \\
\hline Hydraulic Conductivity (ft/d) $^{d}$ & $\begin{array}{l}\text { b) } 21.4 \text { (pumping), } \\
13.7 \text { (recovery) }\end{array}$ \\
\hline Storativity & Not valid from single-well tests \\
\hline \multicolumn{2}{|c|}{ Comments: Recovery analysis more reliable } \\
\hline \multicolumn{2}{|c|}{$\begin{array}{l}\text { a Length of open interval, not screen joints. } \\
\text { betermined by flowmeter and stopwatch; a and b refer to initial and repeat tests } \\
\text { throughout table. } \\
\text { C WS }=\text { W. Stone, SM }=\mathrm{S} \text {. McLin. } \\
\text { d Derived from transmissivity, using screen length because of shortness of test. }\end{array}$} \\
\hline
\end{tabular}




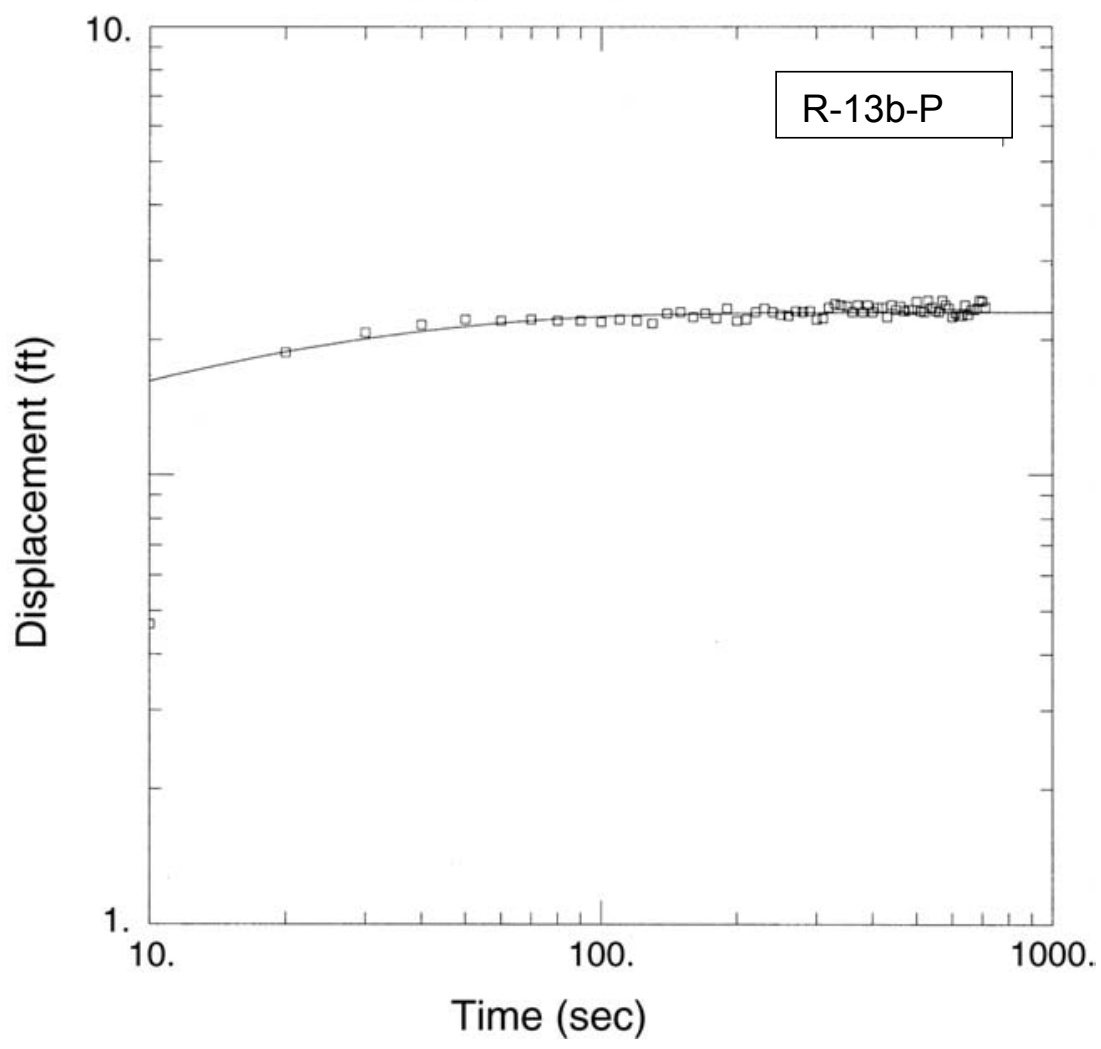

Figure 12. Hantush-Jacob analysis of pumping-test recovery data for R-13b

\section{Discussion}

Test. Because R-13 was constructed with a single screen situated below the water table, it provided an excellent opportunity for evaluating aquifer properties by means of a traditional single-well pumping test. Two tests were conducted. In the first test (R-13a), water level was erratic. In the second test (R-13b), after an initial drawdown of about $2.5 \mathrm{ft}$, the water level declined very gradually (Appendix B-1). Water level oscillated at this position on the order of 0.1 to $0.3 \mathrm{ft}$. This drawdown, in response to running a 10horsepower (hp) pump at a maximum discharge rate of 19 gallons per minute (gpm), suggests that a higher discharge rate, and perhaps a larger pump, are required to stress the regional aquifer at this location.

Analysis. As water level during the first test was erratic and the recovery curve had only a few data points, it was not analyzed. Both drawdown and recovery data for the repeat pumping test $(R-13 b)$ were more uniform and thus were analyzed. Data analysis by the Theis method suggested leaky aquifer conditions with partial penetration. Therefore, data were analyzed by the Hantush-Jacob technique for a leaky aquifer. While the duration of pumping was not optimal, analysis of pumping data yielded a $T$ value of $1293.3 \mathrm{ft}^{2} / \mathrm{d}(\mathrm{K}=21.4 \mathrm{ft} / \mathrm{d})$ and analysis of recovery data yielded a $T$ value of $829.7 \mathrm{ft} 2 / \mathrm{d}(\mathrm{K}=13.7 \mathrm{ft} / \mathrm{d})$. These values are consistent with the productivity of this zone.

As the screen straddles the contact between the pumiceous and fanglomerate units of the Puye Formation, the test result cannot be assigned to either one of these materials. The test yielded an average result that probably overestimates the permeability of one unit and underestimates the permeability of the other unit. 


\section{WELL R-19}

Well R-19 is located on the mesa between Threemile and Pajarito Canyons in TA-36 (Figure 1). It was drilled to a TD of $1902 \mathrm{ft}$, but the final depth is $1885 \mathrm{ft}$ in the Puye Formation because of sloughing in of the borehole (Broxton et al. 2001, 66603). It was completed with seven screens: two in possible perched zones, one across the water table, and four within the regional zone of saturation (Figure 13).

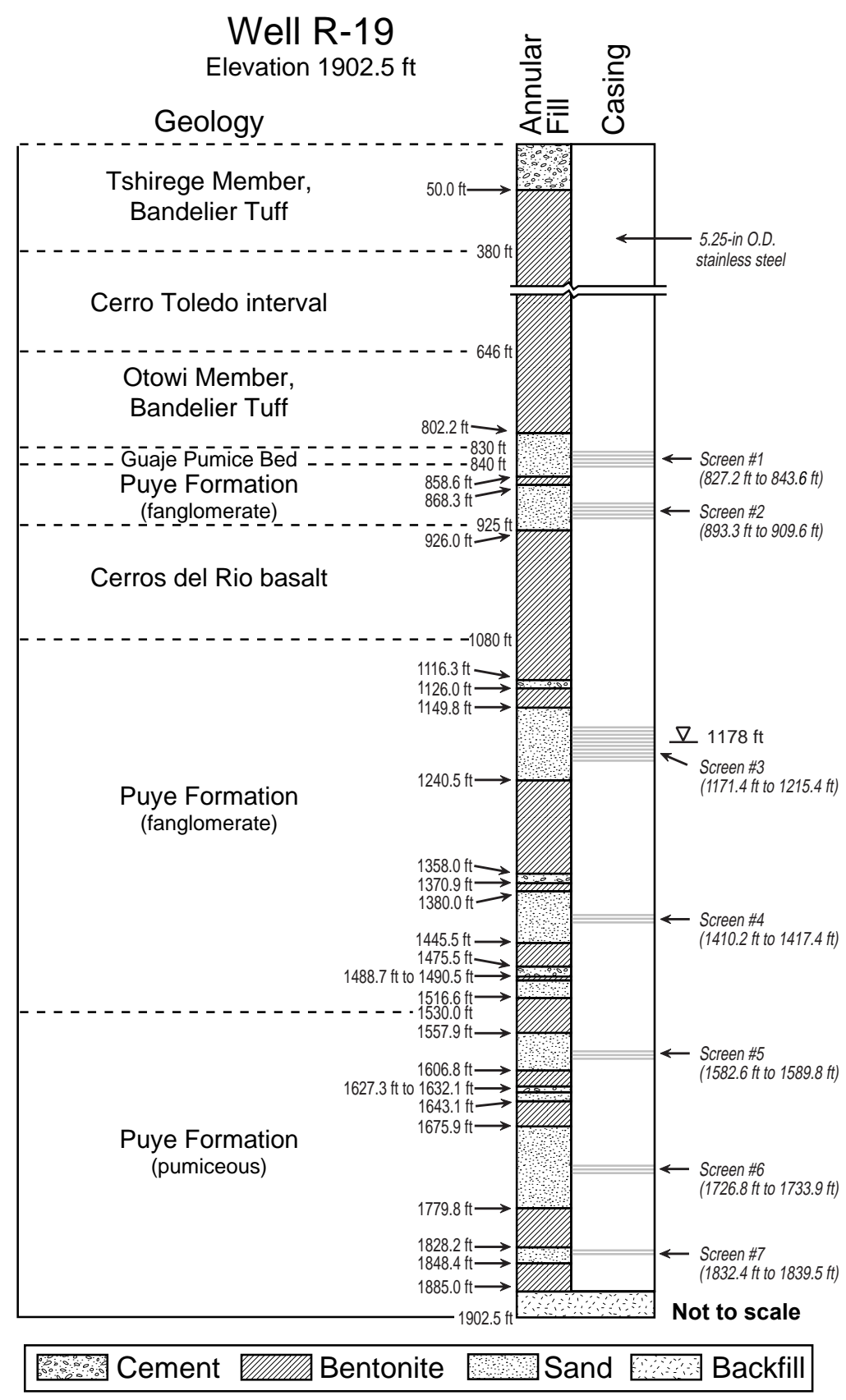

Figure 13. Hydrogeology and construction of R-19 


\section{Hydrogeology}

Geologic units penetrated by well R-19 are shown in Figure 13. Two possible zones of perched saturation were encountered at depths of 834 to $840 \mathrm{ft}$ in the Guaje Pumice Bed and at 894 to $912 \mathrm{ft}$ in the Puye Formation. The regional water table was encountered at a depth of $1178 \mathrm{ft}$ within the Puye Formation. Two head measurements made during testing indicate that a downward vertical gradient exists in the regional zone of saturation at well R-19.

\section{Injection Tests}

The lowermost two screened intervals (screens 6 and 7 ) were tested at well R-19. Test design and results are summarized in Table 10. Analyses of injection-test data are shown in Figures 14 and 15. Field and analytical data are given in Appendix C.

\begin{tabular}{|c|c|c|}
\hline \multicolumn{3}{|c|}{ Summary of Injection Testing at R-19 } \\
\hline Screen \# & 6 & 7 \\
\hline Geologic Unit $^{\mathrm{a}}$ & $\mathrm{Tp}$ & $\mathrm{Tp}$ \\
\hline Screened Interval (ft) ${ }^{b}$ & $1726.8-1733.9$ & 1832.4-1839.5 \\
\hline Screen Length (ft) & 7.1 & 7.1 \\
\hline Saturated Thickness (ft) & 103.9 & 20.2 \\
\hline \multicolumn{3}{|l|}{ Test Design } \\
\hline Pre-Test Water Level $(\mathrm{ft})^{\mathrm{c}}$ & 1177 & 1774 \\
\hline 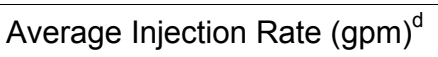 & 11.8 & 14.6 \\
\hline Injection-Rate Variation (\%) & $<10$ & $<10$ \\
\hline Injection Period (min) & 10 & 22 \\
\hline Volume Injected (gal) & 120 & 322 \\
\hline Conducted by & NT & NT \\
\hline Date & $7 / 27 / 00$ & $7 / 27 / 00$ \\
\hline Comments & - & - \\
\hline \multicolumn{3}{|l|}{ Test Results } \\
\hline Analyzed by ${ }^{\mathrm{e}}$ & SM & SM \\
\hline Analytical Method & $\begin{array}{l}\text { Bouwer-Rice } \\
\text { C-B-P } \\
\text { Hvorslev }\end{array}$ & $\begin{array}{l}\text { Bouwer-Rice } \\
\text { C-B-P } \\
\text { Hvorslev }\end{array}$ \\
\hline Hydraulic Conductivity $(\mathrm{ft} / \mathrm{d})^{\mathrm{f}}$ & $\begin{array}{l}1.10 \\
1.21 \\
1.36\end{array}$ & $\begin{array}{l}0.73 \\
1.30 \\
1.08\end{array}$ \\
\hline Comments & \multicolumn{2}{|c|}{ Analytical plots reasonable } \\
\hline \multicolumn{3}{|c|}{$\begin{array}{l}\text { a } \text { Tp = Puye Formation. } \\
\text { b For open interval, not screen joints. } \\
\text { c Depth below ground surface for packed-off interval, not well (composite static } \\
\text { water-level depth for well = } 1179 \mathrm{ft} \text { ). } \\
\text { d Determined by flowmeter and stopwatch or watch with second hand. } \\
\text { e } \mathrm{NT}=\text { Neal Tapia, SM = S. McLin. } \\
\text { f Results are for Bouwer-Rice, C-B-P, and Hvorslev, respectively. }\end{array}$} \\
\hline
\end{tabular}




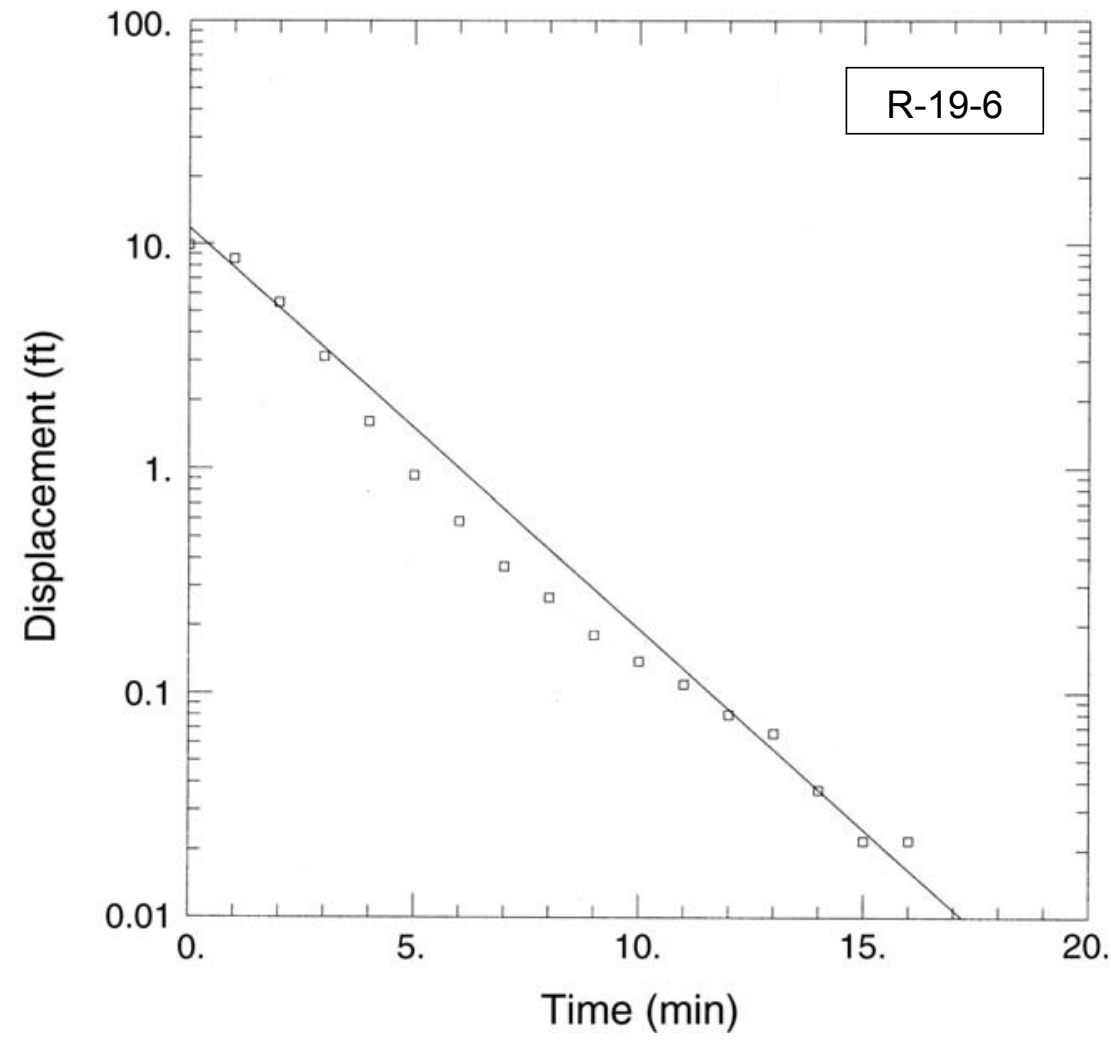

Figure 14. Bouwer-Rice analysis of injection-test recovery data for R-19, screen 6

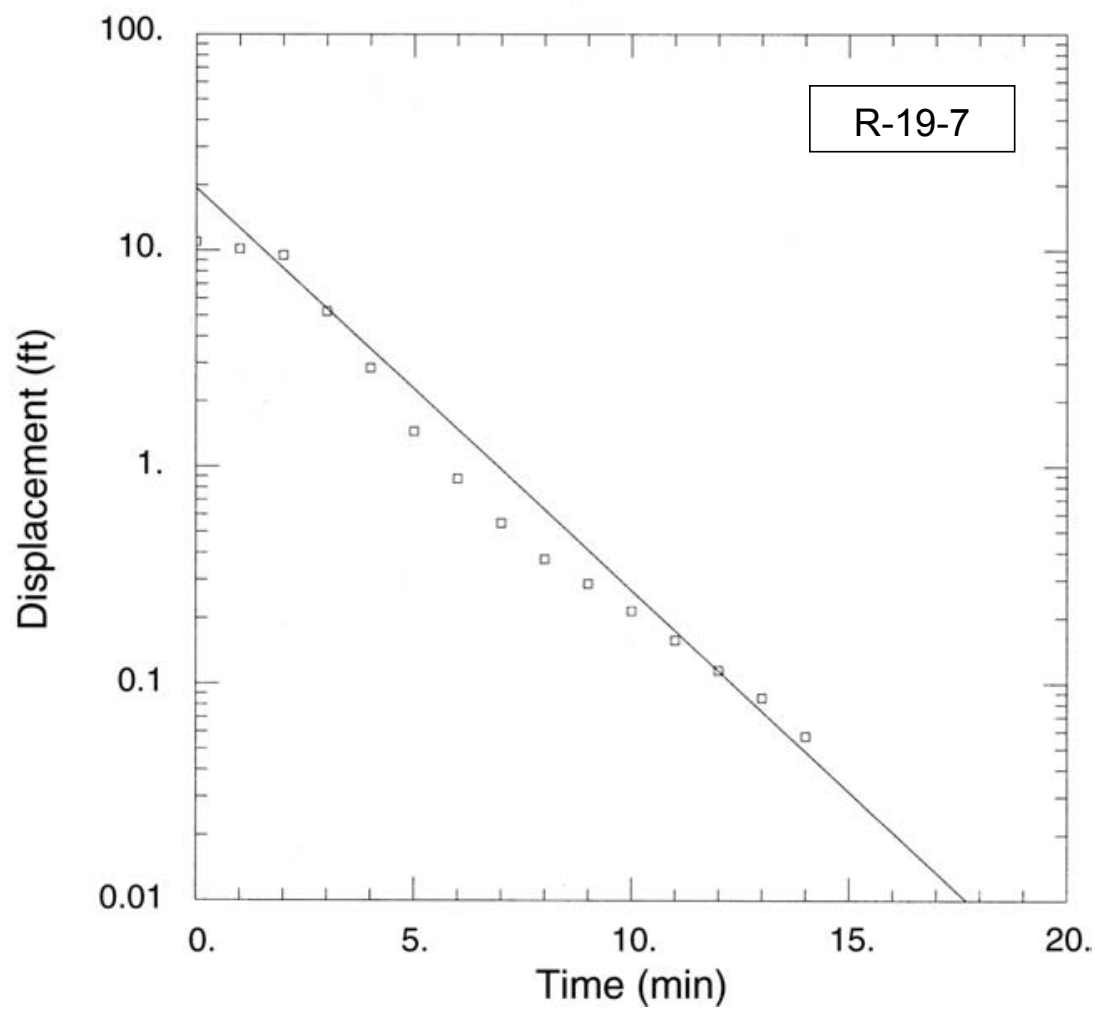

Figure 15. Bouwer-Rice analysis of injection-test recovery data for R-19, screen 7 


\section{Discussion}

Tests. Screen 3 at R-19 straddles the water table, so testing by injection was not appropriate. As both screens 4 and 5 were initially thought to be located within the fanglomerate unit of the Puye Formation, only one (screen 5) was tested. (Further geologic analysis has shown that only screen 4 is in the fanglomerate and screen 5 is in the newly recognized pumiceous unit of the Puye Formation.) However, the test of screen 5 was unsuccessful because water depth during injection exceeded the capacity of the transducer. If the material behind a screen does not readily take up the injected water, the water level can quickly rise above the rated depth of the transducer, rendering it inoperable. When testing was attempted at screen 5 , water level in the straddle-packer/injection apparatus and drill rods rose rapidly. After 30 gal. of water were injected, the capacity of the transducer was exceeded so testing was abandoned. Nonetheless, testing at well R-19 successfully characterized the newly recognized lower pumiceous unit in the Puye Formation, accessible in screens 6 and 7.

Analysis. As plots for the Bouwer-Rice analysis of data for tests of screens 6 and 7 are somewhat S-shaped, we passed a line through the data, approximating a straight-line fit. The results from the injection tests at screen 6 and 7 are similar as they evaluated similar geologic material (pumiceous Puye).

Bouwer-Rice analysis of data for the injection test at screen 6 yielded a $\mathrm{K}$ of $1.10 \mathrm{ft} / \mathrm{d}$ (Table 10). Analysis of the data by the C-B-P method gave a $\mathrm{K}$ of $1.21 \mathrm{ft} / \mathrm{d}$, with $\mathrm{S}=5 \times 10^{-5}$; however, the data fit the theoretical curve poorly. Hvorslev analysis of data from the test at screen 6 resulted in a $\mathrm{K}$ of $1.36 \mathrm{ft} / \mathrm{d}$. Results for the three methods are comparable.

Results of analysis of the test at screen 7 by all three methods are also similar. Bouwer-Rice analysis of the data from the test at screen 7 yielded a $\mathrm{K}$ of $0.73 \mathrm{ft} / \mathrm{d}$. Although data fit the theoretical curve poorly, analysis by the C-B-P method gave a $\mathrm{K}$ of $1.30 \mathrm{ft} / \mathrm{d}$. Hvorslev analysis gave a $\mathrm{K}$ of $1.08 \mathrm{ft} / \mathrm{d}$.

\section{WELL R-22}

Well R-22 is located east of MDA-G in Technical Area (TA)-54 on the mesa between Cañada del Buey and Pajarito Canyons (Figure 1). It was drilled by open-hole methods to a TD of $1489 \mathrm{ft}$ in the Santa Fe Group (Ball et al. 2001, 71471). The well was completed with five screens: one at the water table and four within the regional zone of saturation (Figure 16).

\section{Hydrogeology}

Geologic units penetrated by well R-22 are shown in Figure 16. No perched water was encountered at this location. The regional water table was penetrated at a depth of $883 \mathrm{ft}$ in the Cerros del Rio basalt (Ball et al. 2001, 71471). Of the four screens below water table, two provide access to basalt, one is situated in Puye Formation fanglomerate, and one is situated in older fanglomerate. Head measurements for each screened interval during testing indicate the vertical gradient is downward at R-22.

\section{Injection Tests}

Straddle-packer/injection tests were attempted at each of the screened intervals below the water table, that is, screens 2 through 5 . During the test at screen 3 , the rod to which the packer assembly was attached dropped $4.8 \mathrm{in}$. and stripped the coating off the transducer cable, so the test had to be halted. To make the best use of rig time while the cable was being repaired at the drilling yard, the packer assembly was moved down to screen 4 and a static water level was determined. When the cable had been repaired and returned to the site, testing resumed with screen 4 . A repeat test of screen 4 (R-22-4b) with the same injection rate and time was also run for comparison. Finally, screen 5 was tested. Test design and results for all tests are summarized in Table 11. Analyses of injection-test data are shown in Figures 17 through 20. Field and analytical data are given in Appendix D. 


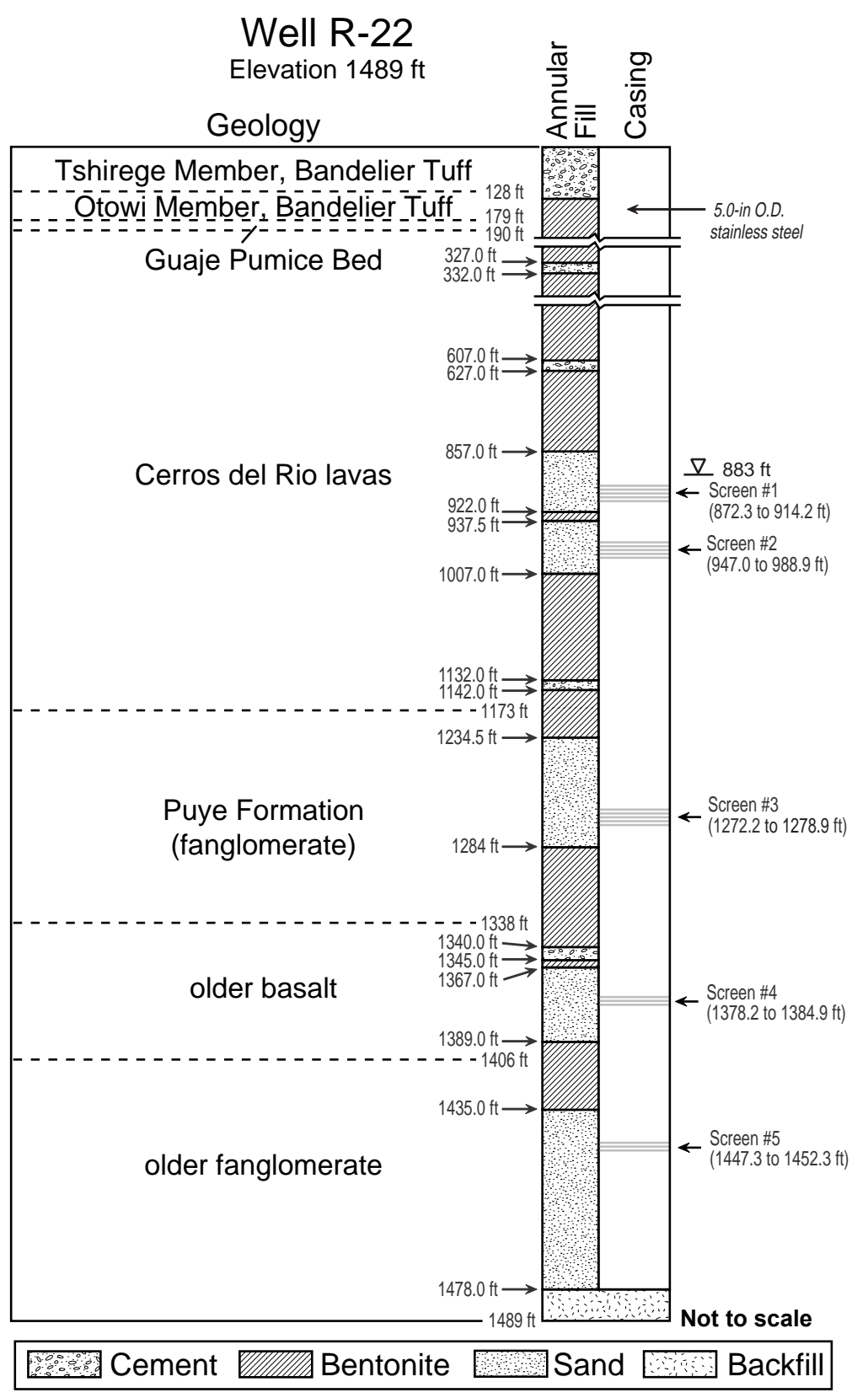

Figure 16. Hydrogeology and construction of R-22

\section{Discussion}

Tests. During injection tests of screens 2 and 3 at R-22, the peak water level exceeded the depth capacity of the transducer. Thus, plots in the appendix show a horizontal line for maximum water level instead of a peak (Appendix D-1 and D-5). As sufficient water-level observations had been made before capacity was exceeded, a procedure for reconstructing the peaks for these plots was successfully applied and the test data were analyzed.

A repeat injection test was conducted for the material behind screen 4 at $R-22$. Results were reproduced as the hydraulic-conductivity value obtained is of the same order of magnitude as that for the initial test (Table 11). 
The cause of a jump in the water-level plot during testing of screen 5 (near the end of the recovery curve in Appendix D-11) is not known. No equipment problem was detected. The drill rod to which the testing apparatus was attached had not slipped and packer-inflation pressure was normal.

\begin{tabular}{|c|c|c|c|c|}
\hline \multicolumn{5}{|c|}{$\begin{array}{c}\text { Table } 11 \\
\text { Summary of Injection Testing at R-22 }\end{array}$} \\
\hline Screen \# & 2 & 3 & $4^{a}$ & 5 \\
\hline Geologic Unit $^{\mathrm{b}}$ & $\mathrm{Tb}$ & Tpt & Tbo & Tfo \\
\hline Screened Interval $(\mathrm{ft})^{\mathrm{C}}$ & $947-988.9$ & $1272.2-1278.9$ & $1378.2-1384.9$ & $1447.3-1452.3$ \\
\hline Screen Length (ft) & 41.9 & 6.7 & 6.7 & 5.0 \\
\hline Saturated Thickness (ft) & 69.5 & 49.4 & 49.0 & 43.0 \\
\hline \multicolumn{5}{|l|}{ Test Design } \\
\hline Pre-Test Water Level (ft) $^{d}$ & 899.6 & 948.0 & \begin{tabular}{|l|l|}
955.5 \\
\end{tabular} & 955.5 \\
\hline $\begin{array}{l}\text { Average Injection Rate } \\
(\mathrm{gpm})^{\mathrm{e}}\end{array}$ & 9.12 & 12.0 & $\begin{array}{l}\text { a) } 16 \\
\text { b) } 16\end{array}$ & 17 \\
\hline Injection-Rate Variation (\%) & $<10$ & $<10$ & $<10$ & $<10$ \\
\hline Injection Period (min) & 19 & 10 & $\begin{array}{l}\text { a) } 3 \\
\text { b) } 3 \\
\end{array}$ & 3 \\
\hline Volume Injected (gal.) & 173 & 120 & $\begin{array}{l}\text { a) } 48 \\
\text { b) } 48\end{array}$ & 51 \\
\hline Conducted by $^{f}$ & WS & WS & WS & WS \\
\hline Date & $11 / 15 / 00$ & $11 / 16 / 00$ & $11 / 17 / 00$ & $11 / 17 / 00$ \\
\hline Comments: & - & $\begin{array}{l}\text { Drill rod slipped } \\
4.8 \text { in. during test } \\
\text { and stripped } \\
\text { transducer cable }\end{array}$ & $\begin{array}{l}\text { Two tests run with } \\
\text { identical parameters }\end{array}$ & - \\
\hline \multicolumn{5}{|l|}{ Test Results } \\
\hline Analyzed by ${ }^{f}$ & SM & SM & SM & SM \\
\hline Analytical Method & $\begin{array}{l}\text { Bouwer-Rice } \\
\text { C-B-P } \\
\text { Hvorslev }\end{array}$ & $\begin{array}{l}\text { Bouwer-Rice } \\
\text { C-B-P } \\
\text { Hvorslev }\end{array}$ & $\begin{array}{l}\text { Bouwer-Rice } \\
\text { C-B-P } \\
\text { Hvorslev } \\
\end{array}$ & $\begin{array}{l}\text { Bouwer-Rice } \\
\text { C-B-P } \\
\text { Hvorslev }\end{array}$ \\
\hline $\begin{array}{l}\text { Hydraulic Conductivity } \\
(\mathrm{ft} / \mathrm{d})^{\mathrm{g}}\end{array}$ & $\begin{array}{l}0.04 \\
0.06 \\
0.05\end{array}$ & $\begin{array}{l}0.21 \\
0.53 \\
0.25\end{array}$ & $\begin{array}{ll}\text { a) } & 0.54 \\
& 0.66 \\
& 0.61 \\
\text { b) } & 0.72 \\
& 0.66 \\
& 0.76 \\
\end{array}$ & $\begin{array}{l}0.27 \\
0.64 \\
0.39\end{array}$ \\
\hline Comments: & \multicolumn{4}{|c|}{ Tests fairly long for slug method } \\
\hline $\begin{array}{ll}\text { a } & \text { Two tests were conducte } \\
\text { b } & \text { Tb = Cerros del Rio base } \\
\text { c } & \text { For open interval, not scr } \\
\text { d } & \text { Depth bgs for packed-off } \\
\text { e } & \text { Determined by flowmete } \\
\text { f } & \text { WS }=\text { W. Stone, SM = S. } \\
\text { gesults are for Bouwer-R }\end{array}$ & $\begin{array}{l}\text { d for this screer } \\
\text { tt; Tpt = Puye F } \\
\text { een joints. } \\
\text { interval, not we } \\
\text { and watch with } \\
\text { McLin. } \\
\text { ce, C-B-P, and }\end{array}$ & $\begin{array}{l}\text { to check reproducibil } \\
\text { rmation, Totavi Lenti } \\
\text { (composite static wa } \\
\text { econd hand. } \\
\text { Ivorslev, respectively }\end{array}$ & $\begin{array}{l}\text { y of results. } \\
\text { Tbo = older basalt; Tfo } \\
\text { er-level depth for well = }\end{array}$ & $\begin{array}{l}=\text { older fanglomerate. } \\
390 \mathrm{ft}) .\end{array}$ \\
\hline
\end{tabular}




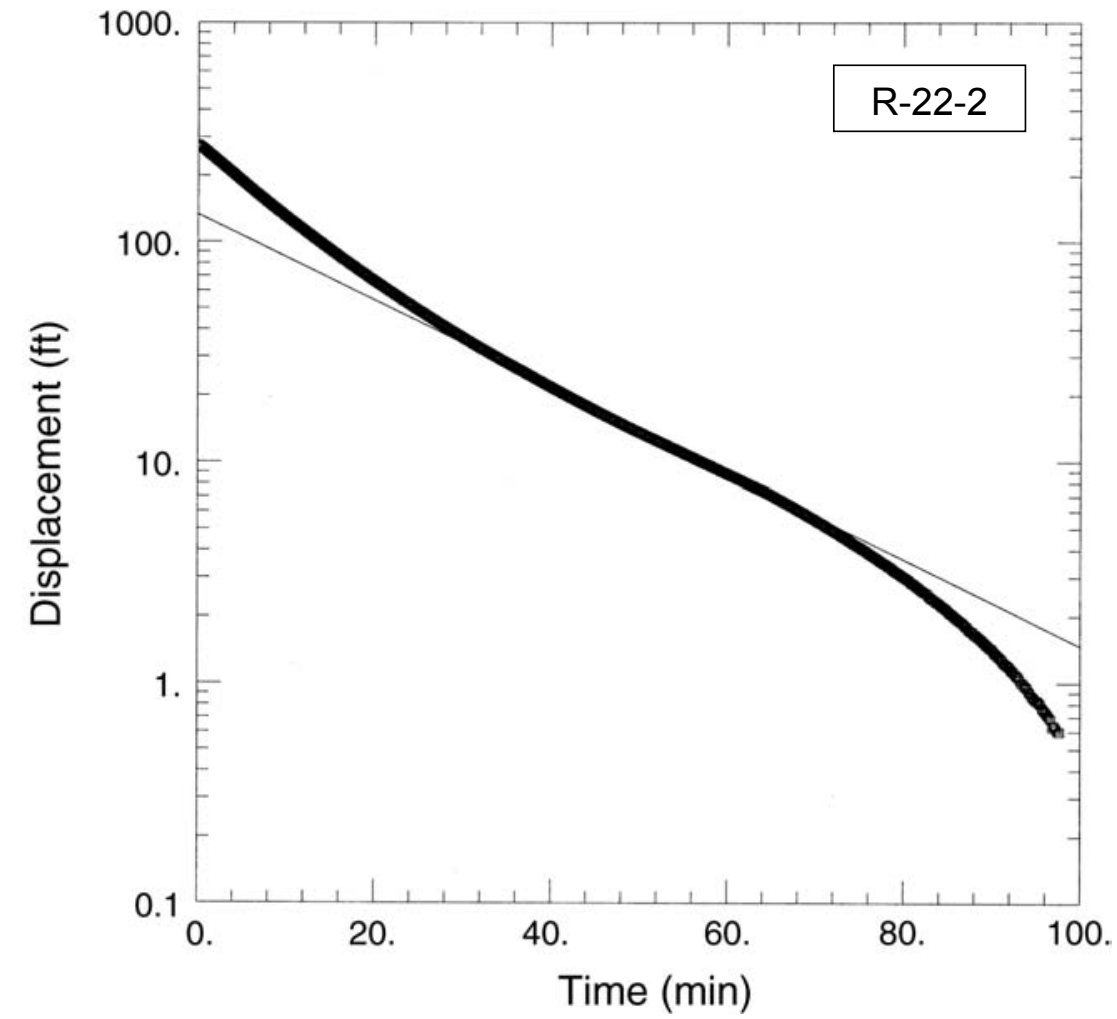

Figure 17. Bouwer-Rice analysis of injection-test recovery data for R-22, screen 2

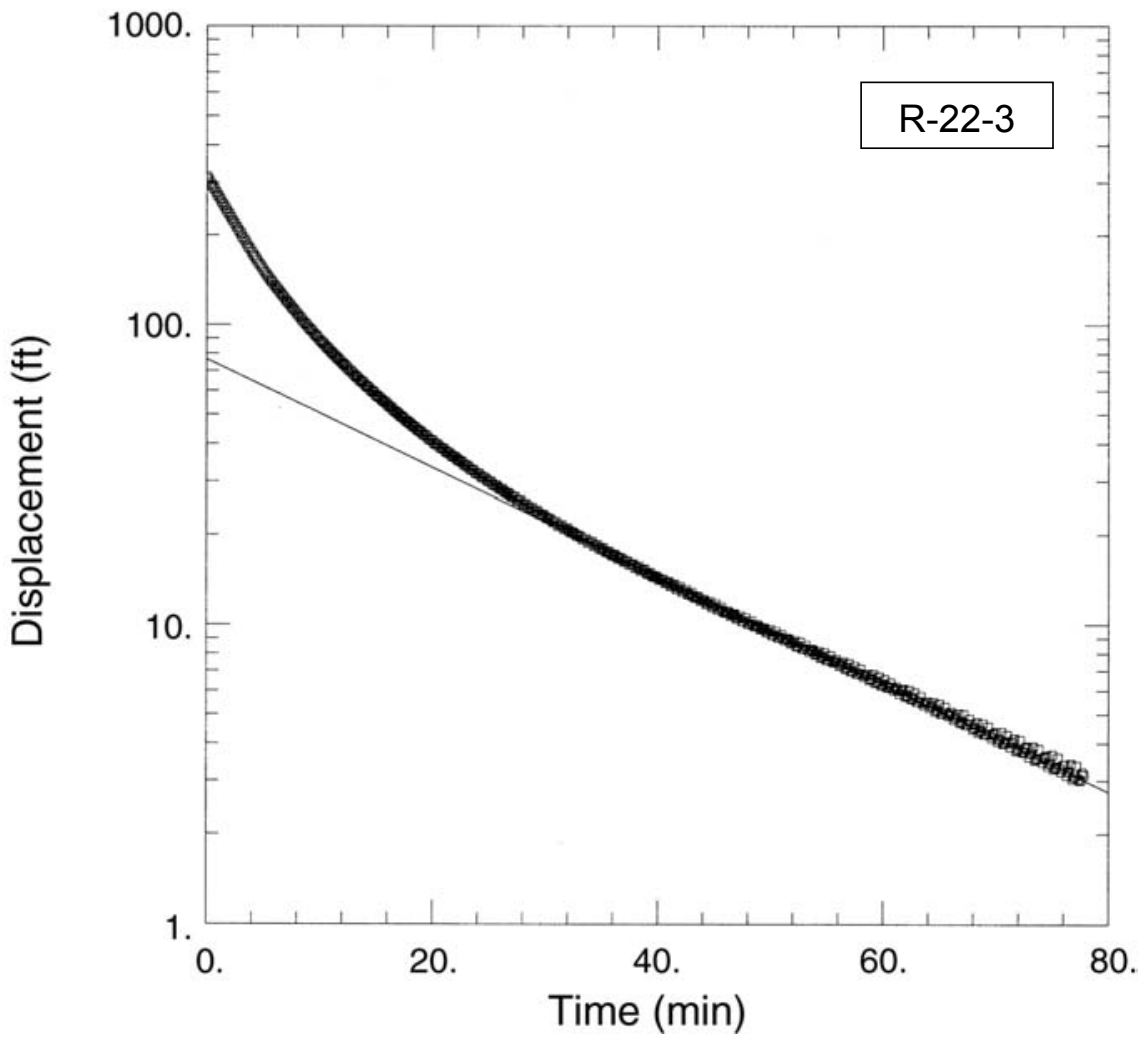

Figure 18. Bouwer-Rice analysis of injection-test recovery data for R-22, screen 3 


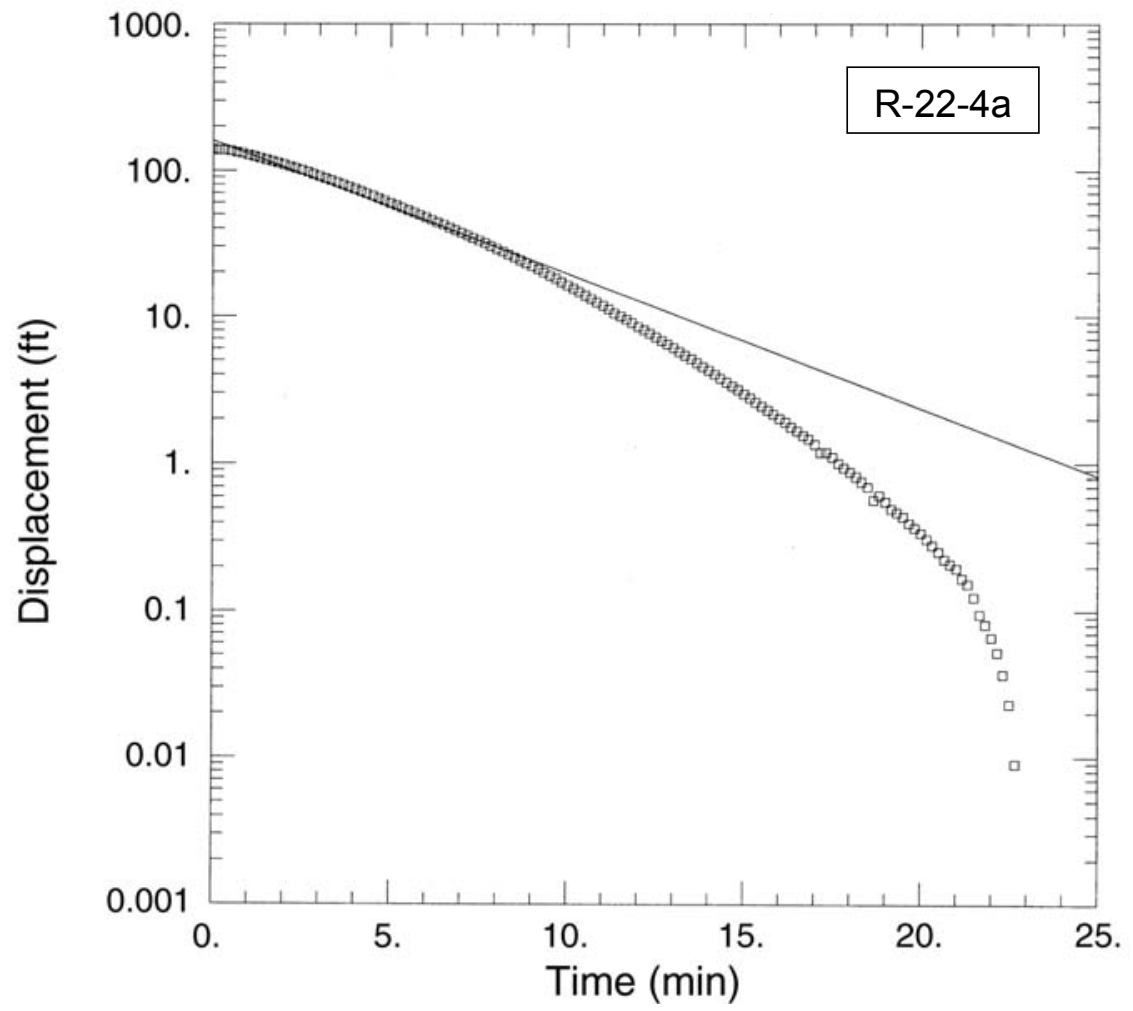

Figure 19. Bouwer-Rice analysis of injection-test recovery data for R-22, screen $4 a$

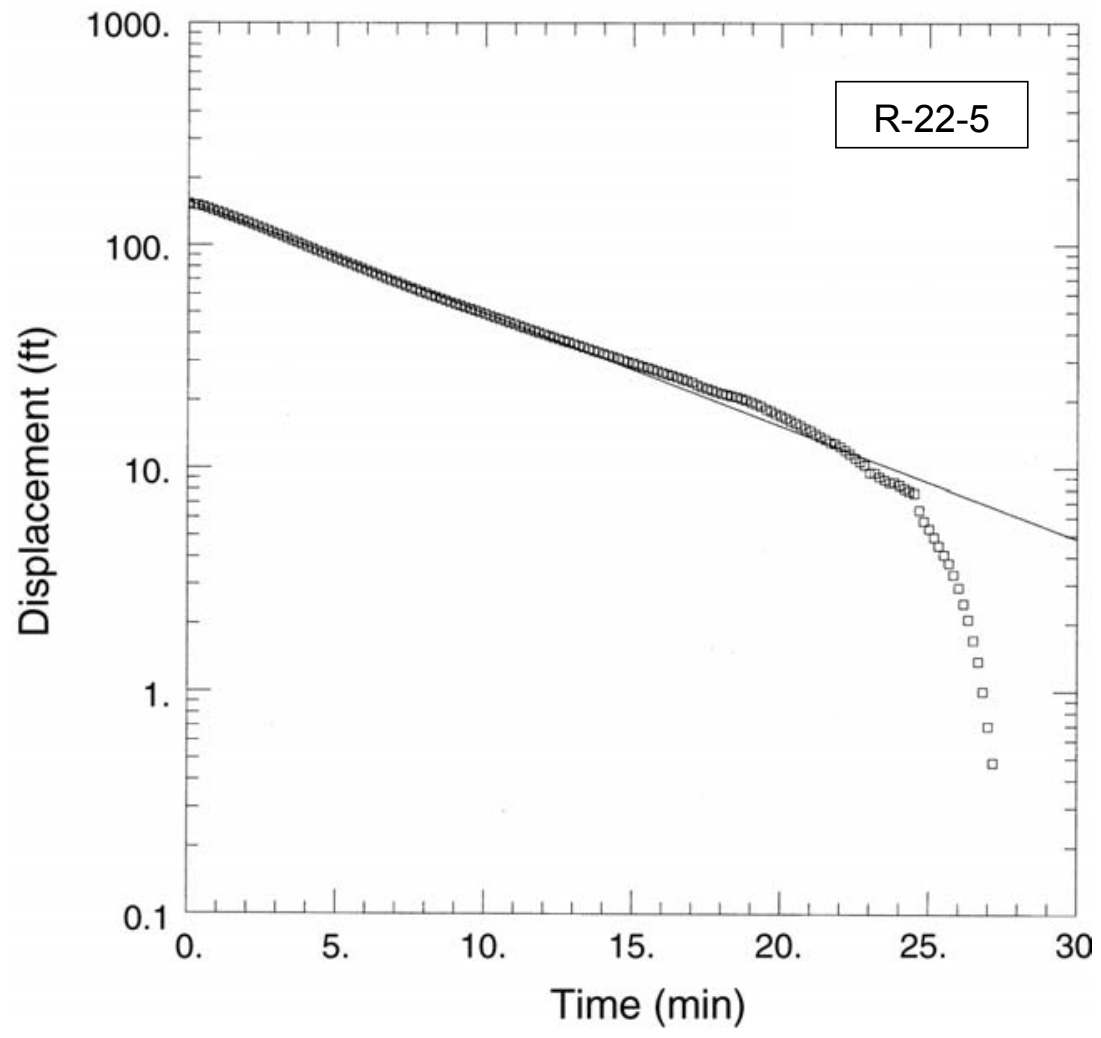

Figure 20. Bouwer-Rice analysis of injection-test recovery data for R-22, screen 5 
Analysis. Plots for Bouwer-Rice analyses of data for screens 2 and 3 are concave upward as is typical for the method. However, plots for screens 4 and 5 are convex upward. After a linear segment the plot turns sharply downward. This behavior often indicates that the pre-test water level was slightly higher than the static position. A difference of only a few hundredths of a foot can cause such a response. Graphs in Appendices D-8 and D-11 confirm this condition.

Analysis of data from the injection test at screen 2 by all three methods gave similar results (Table 11). Bouwer-Rice analysis yielded a K of $0.04 \mathrm{ft} / \mathrm{d}$. Analysis by the C-B-P method gave $0.06 \mathrm{ft} / \mathrm{d}$ (with $\mathrm{S}=5 \times 10^{-5}$ ). Hvorslev analysis gave $0.05 \mathrm{ft} / \mathrm{d}$.

Results of analyses of data from the injection test at screen 3 were less comparable. That is, BouwerRice and Hvorslev results agree $(K=0.21$ and $0.0 .25 \mathrm{ft} / \mathrm{d}$, respectively) whereas C-B-P analysis (with $\mathrm{S}=1 \times 10^{-4}$ ) gave $\mathrm{K}$ of $0.53 \mathrm{ft} / \mathrm{d}$.

Results of analysis of data from the injection test and repeat test at screen 4 differ slightly but are of the same order of magnitude. Bouwer-Rice analysis yielded a $\mathrm{K}$ of $0.54 \mathrm{ft} / \mathrm{d}$ in the initial test and $0.72 \mathrm{ft} / \mathrm{d}$ in the repeat test. C-B-P analysis (with $S=1 \times 10-4$ ) gave a $\mathrm{K}$ of $0.66 \mathrm{ft} / \mathrm{d}$ in the initial test and $0.66 \mathrm{ft} / \mathrm{d}$ in the repeat test. Hvorslev analysis yielded a $\mathrm{K}$ of $0.61 \mathrm{ft} / \mathrm{d}$ for the initial test and a $\mathrm{K}$ of $0.76 \mathrm{ft} / \mathrm{d}$ for the repeat test.

$\mathrm{K}$ values obtained by the three methods for the injection-test of screen 5 are also similar. The BouwerRice method gave a K of $0.27 \mathrm{ft} / \mathrm{d}$, the C-B-P method gave $0.64 \mathrm{ft} / \mathrm{d}$, and the Hvorslev method gave $0.39 \mathrm{ft} / \mathrm{d}$.

\section{WELL R-31}

Well R-31 is located in TA-39 in lower Ancho Canyon (Figure 1). It was drilled by the air-rotary casingadvance method (Table 1) to a TD of $1103 \mathrm{ft}$ in the Totavi Lentil (Vaniman et al. 2001, 72615). The well was completed with five screens: one in a possible perched zone of saturation, one across the water table, and three in the regional zone of saturation (Figure 21).

\section{Hydrogeology}

Geologic units penetrated by R-31 are shown in Figure 21. A possible zone of perched water was encountered in the Cerros del Rio basalt at a depth of $440 \mathrm{ft}$. The regional water table was encountered at a depth of $523 \mathrm{ft}$, also in the Cerros del Rio basalt. Preliminary head measurements from transducers in the Westbay ${ }^{\mathrm{TM}}$ monitoring system suggest either that the different screened intervals were not isolated or that well R-31 was drilled more or less parallel to an isopotential. In the latter case, groundwater flow at this location may be neither up nor down but horizontal.

\section{Injection Tests}

Soon after straddle-packer/injection testing had begun, we learned that the well (1) had not been developed according to guidance in the Field Implementation Plan and (2) was therefore only partially developed. Thus, two separate rounds of testing were performed. After three phases of additional development over 9 days, a second round of injection testing focused on screens 3 and 4 . We then compared results of the initial tests with those obtained after final well development. Screen 5 was not retested because of time constraints, so the result obtained is for the first round of testing in a partially developed well. Test design and results are summarized in Table 12. Analyses of injection-test data are shown in Figures 22 through 24. Field and analytical data are given in Appendix E. 


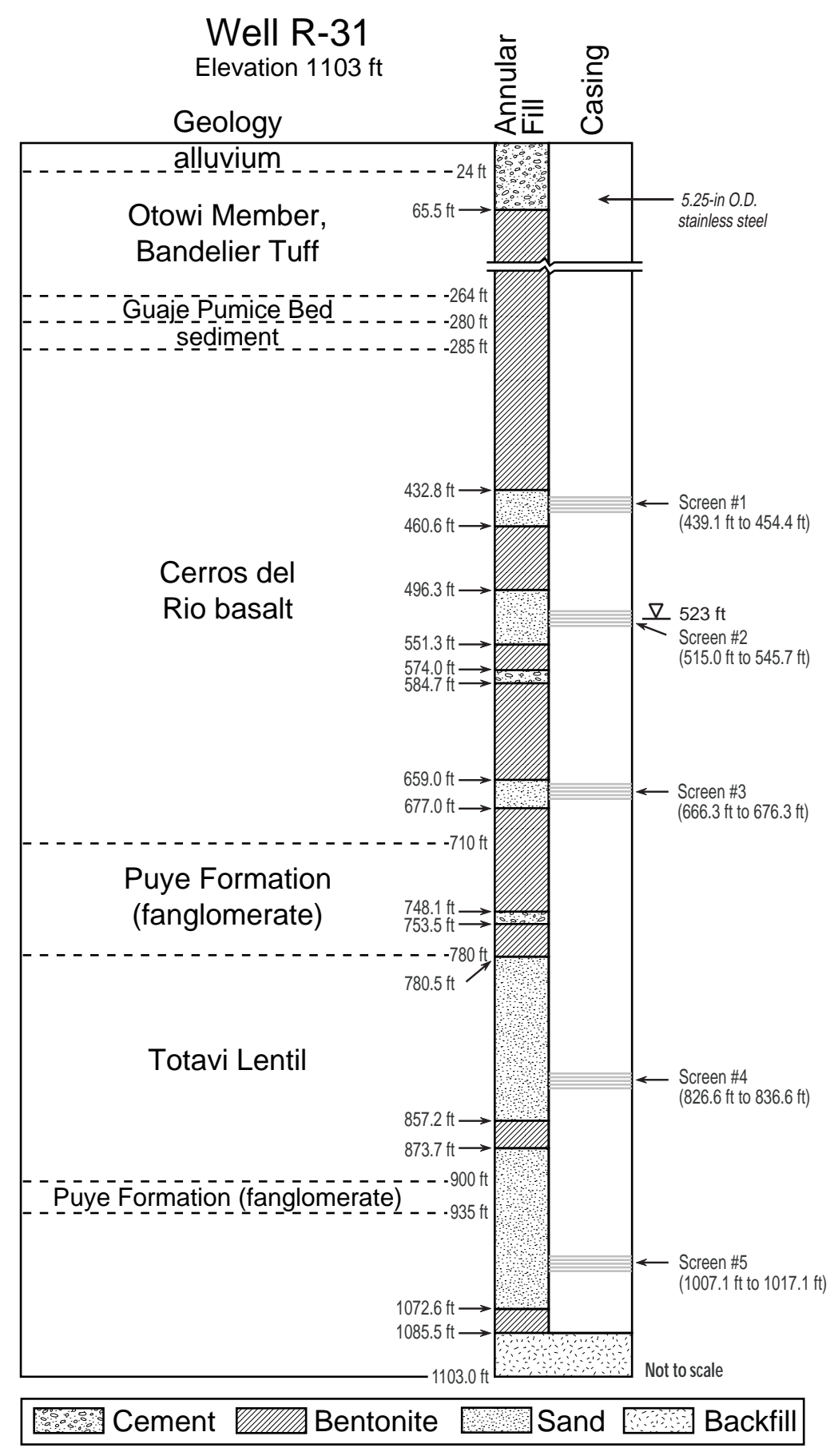

Figure 21. Hydrogeology and construction of R-31 


\begin{tabular}{|c|c|c|c|}
\hline \multicolumn{4}{|c|}{$\begin{array}{c}\text { Table } 12 \\
\text { Summary of Injection Testing at R-31 }\end{array}$} \\
\hline Screen \# & 3 & 4 & 5 \\
\hline Geologic Unit $^{\mathrm{a}}$ & $\mathrm{Tb}$ & Tpt & Tpt \\
\hline Screened Interval (ft) ${ }^{b}$ & $666.3-676.3$ & $826.6-836.6$ & $1007.1-1017.1$ \\
\hline Screen length $(\mathrm{ft})^{\mathrm{b}}$ & 10.0 & 10.0 & 10.0 \\
\hline Saturated Thickness (ft) & 18.0 & 77.2 & 198.9 \\
\hline \multicolumn{4}{|l|}{ Test Design } \\
\hline Pre-Test Water Level $(\mathrm{ft})^{\mathrm{c}}$ & 522.9 & 520.65 & 524.0 \\
\hline Average Injection Rate (gpm) ${ }^{\mathrm{d}}$ & 10.9 & 9.8 & 9.0 \\
\hline Injection-Rate Variation (\%) & $<10$ & $<10$ & $<10$ \\
\hline Injection Period (min) & 0.92 & 30.5 & 32 \\
\hline Volume Injected (gal.) & 10 & 300 & 270 \\
\hline Conducted by ${ }^{\mathrm{e}}$ & SM/WS & SM/WS & SM/WS \\
\hline Date & $3 / 28 / 00$ & $3 / 28 / 00$ & $3 / 10 / 00$ \\
\hline Comments: & $\begin{array}{l}\text { Two tests conducted after } \\
\text { second round of well } \\
\text { development; injection in } \\
\text { second test exceeded depth } \\
\text { capacity of transducer so } \\
\text { not reported }\end{array}$ & $\begin{array}{l}\text { Test } \\
\text { conducted } \\
\text { after second } \\
\text { round of well } \\
\text { development }\end{array}$ & $\begin{array}{l}\text { Test conducted after } \\
\text { only initial (incomplete) } \\
\text { well development }\end{array}$ \\
\hline \multicolumn{4}{|l|}{ Test Results } \\
\hline Analyzed by & SM & SM & SM \\
\hline Analytical Method & $\begin{array}{l}\text { Bouwer-Rice } \\
\text { C-B-P } \\
\text { Hvorslev } \\
\end{array}$ & $\begin{array}{l}\text { Bouwer-Rice } \\
\text { C-B-P } \\
\text { Hvorslev }\end{array}$ & $\begin{array}{l}\text { Bouwer-Rice } \\
\text { C-B-P } \\
\text { Hvorslev }\end{array}$ \\
\hline Hydraulic Conductivity (ft/d) ${ }^{\dagger}$ & $\begin{array}{l}0.41 \\
0.48 \\
0.53\end{array}$ & $\begin{array}{l}1.23 \\
1.40 \\
1.48\end{array}$ & $\begin{array}{l}0.75 \\
1.35 \\
0.88\end{array}$ \\
\hline Comments: & \multicolumn{3}{|l|}{ Analytical plots reasonable } \\
\hline \multicolumn{4}{|c|}{$\begin{array}{l}\text { a } \text { Tb = Cerros del Rio basalt; Tpt = Puye Formation, Totavi Lentil. } \\
\text { b Length of open interval, not screen joints. } \\
\text { c Depth bgs for packed-off interval, not well (composite static water-level depth for well = } 522.8 \mathrm{ft} \text { ). } \\
\text { d Determined by flowmeter and stopwatch or watch with second hand. } \\
\text { e } \mathrm{SM}=\mathrm{S} \text {. McLin, WS = W. Stone. } \\
\text { f Results are for Bouwer-Rice, C-B-P, Hvorslev, respectively. }\end{array}$} \\
\hline
\end{tabular}

\section{Discussion}

Tests. Comparison of results from two rounds of testing conducted at R-31 (one before and one after complete well development) provided an opportunity to evaluate the impact of development on hydraulic properties obtained in testing. The second round of testing, after full development gave different values for hydraulic properties. $\mathrm{K}$ for material behind screen 3 decreased from $1.95 \mathrm{ft} / \mathrm{d}$ to $0.41 \mathrm{ft} / \mathrm{d}$ and $\mathrm{K}$ for material behind screen 4 increased from $1.09 \mathrm{ft} / \mathrm{d}$ to $1.23 \mathrm{ft} / \mathrm{d}$ with further development.

Analysis. The Bouwer-Rice plot for the screen 3 test is linear over nearly the entire test period (Figure 22). Analysis of data from the injection test at screen 3 by all three methods gave similar results. Bouwer-Rice analysis yielded a K of $0.41 \mathrm{ft} / \mathrm{d}$, the C-B-P method gave a K of $0.48 \mathrm{ft} / \mathrm{d}$, and Hvorslev analysis gave $0.53 \mathrm{ft} / \mathrm{d}$.

The Bouwer-Rice plot for the test at screen 4 is concave upward, which is more typical (Figure 23). As in the case of screen 3 , results by various methods for screen 4 are comparable. Bouwer-Rice analysis gave a K of $1.23 \mathrm{ft} / \mathrm{d}$, C-B-P analysis (with $S=5 \times 10^{-5}$ ) gave $1.40 \mathrm{ft} / \mathrm{d}$, and Hvorslev analysis gave $1.48 \mathrm{ft} / \mathrm{d}$.

The Bouwer-Rice plot for the injection test at screen 5 is similar to that for screen 4 (Figure 24). Results of analysis of the injection test at screen 5 by three methods are similar. Bouwer-Rice analysis gave a $\mathrm{K}$ of $0.75 \mathrm{ft} / \mathrm{d}$, C-B-P analysis (with $\mathrm{S}=2.5 \times 10^{-6}$ ) gave a K of $1.35 \mathrm{ft} / \mathrm{d}$, and Hvorslev analysis yielded a $\mathrm{K}$ of $0.88 \mathrm{ft} / \mathrm{d}$. The results are slightly lower than those for screen 4 , completed in the same geologic unit, perhaps because screen 5 was not retested after the second round of well development. 


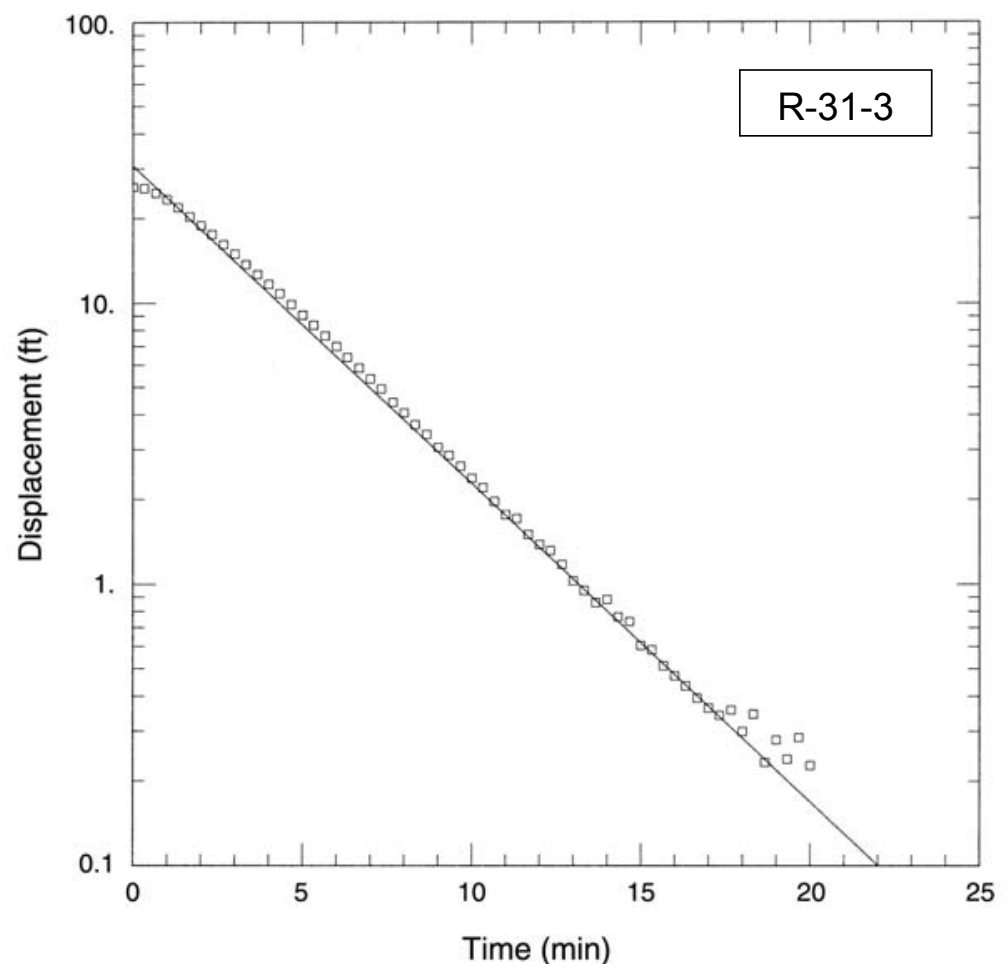

Figure 22. Bouwer-Rice analysis of injection-test recovery data for R-31, screen 3

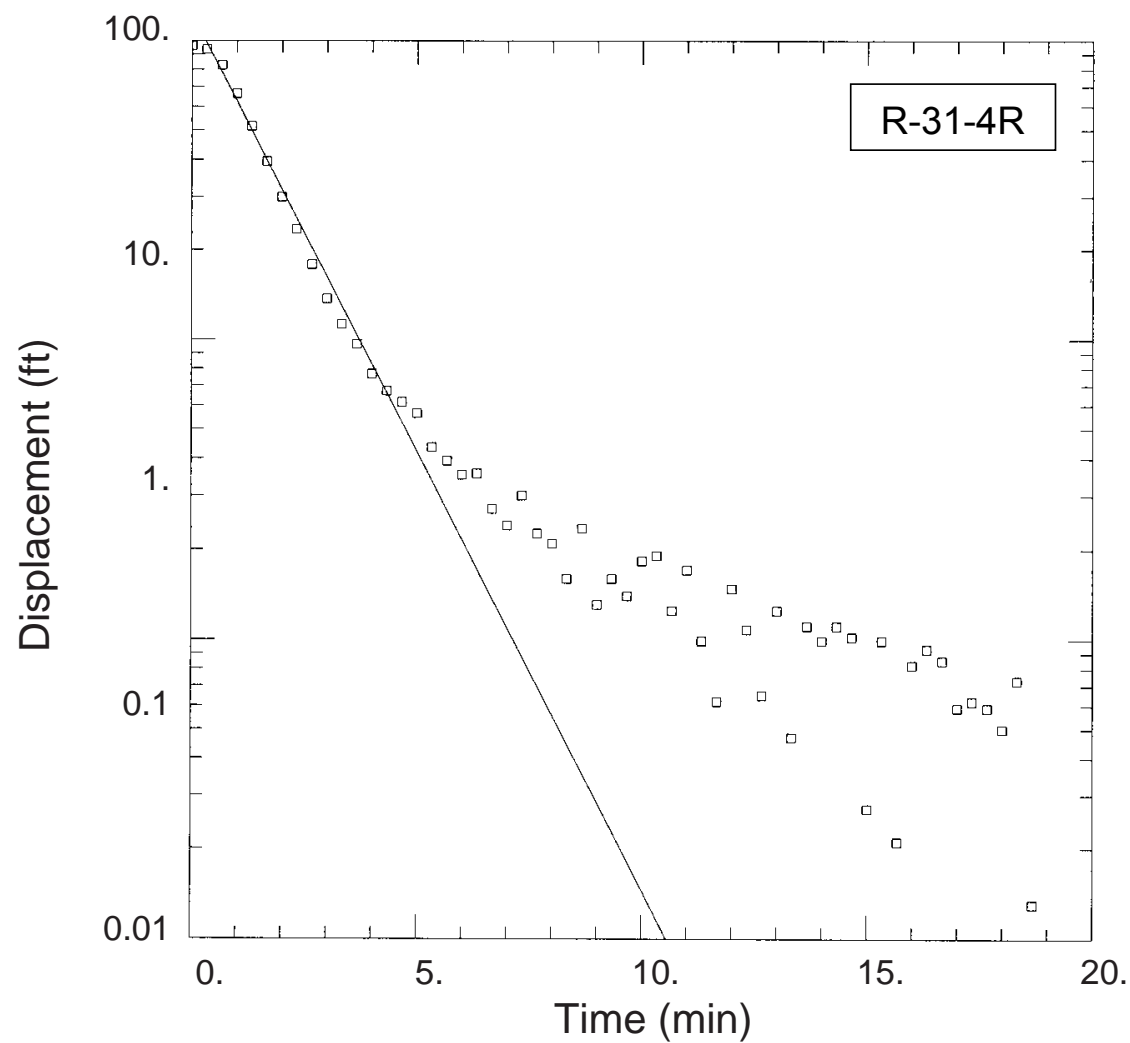

Figure 23. Bouwer-Rice analysis of injection-test recovery data for R-31, screen 4 


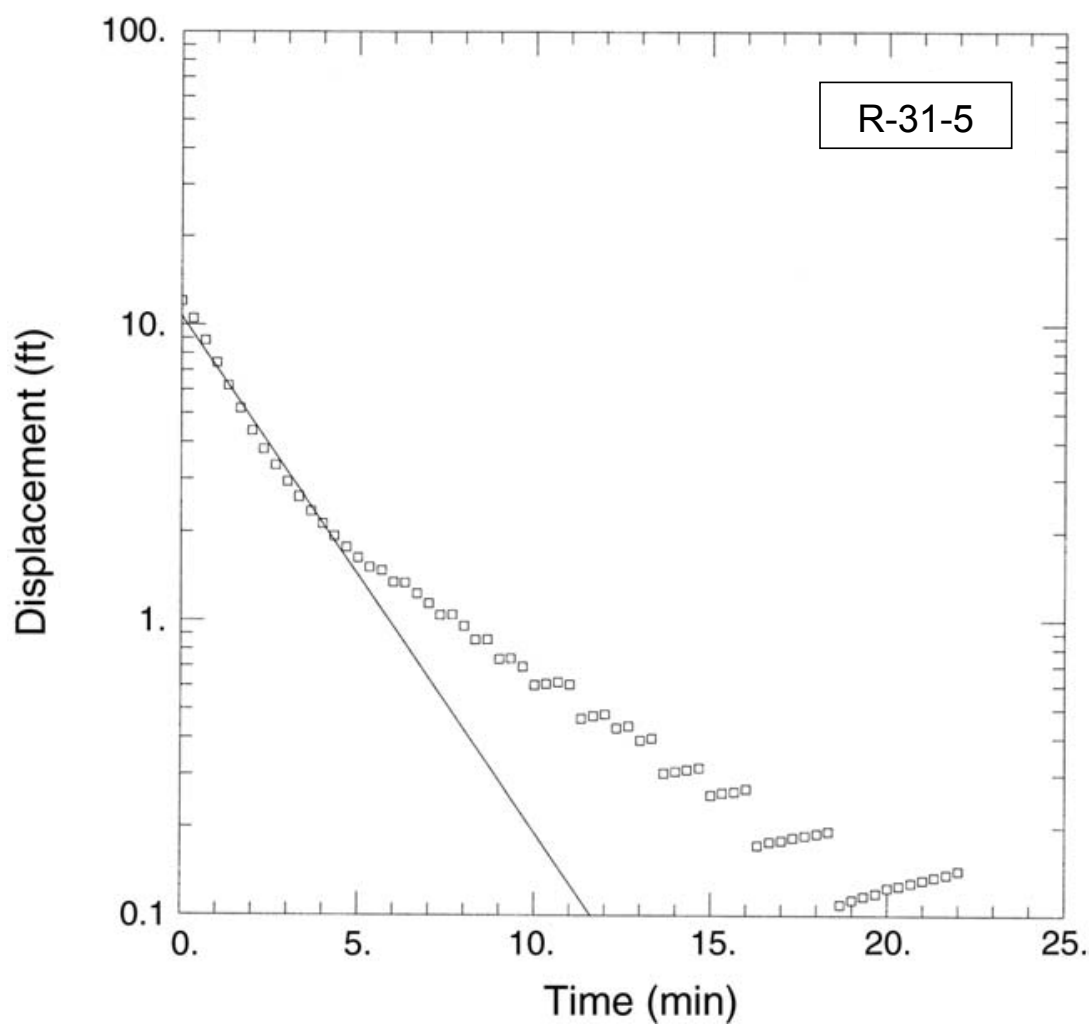

Figure 24. Bouwer-Rice analysis of injection-test recovery data for R-31, screen 5

\section{QUALITY OF TEST RESULTS}

This report not only presents the results of testing five of the $\mathrm{R}$ wells but also provides the details of test design, execution, and analysis necessary for users to judge the quality of test results for the $R$ wells. Quality of test results depends on the reliability of the field data collected and validity of the analytical methods used. Addressing a few basic questions about the tests permits even further evaluation of the results.

\section{Reliability of Test Data}

The type of test conducted is an important consideration. With two exceptions (wells R-9i and R-13), testing was limited to a straddle-packer/injection method, a hybrid form of test. It is not strictly a slug test as water is not injected instantaneously. Rather, the introduction of a volume of water takes a number of minutes. Thus, the plots of water level versus time for the injection tests differ slightly from those for traditional slug tests: the slope of the initial water-level rise on the plots is not always vertical.

The reliability of hydrologic-test data depends on the uniformity of the stress applied during testing and the reliable operation of test equipment. Stress during the test, that is, the rate of water injection or withdrawal, must not vary significantly. In other words, the pump used must deliver or withdraw water at a fairly constant rate. In multi-screened wells, screens must be isolated by the packers during injection tests. Data reliability also depends on the correct functioning of all the equipment involved in measurements, including water-level probes, transducers, data loggers, flow meters, and packers. Overall, stress was applied uniformly and the testing equipment employed functioned reliably. Any exceptions are noted in the summary tables and discussion sections for the tests described herein. 


\section{Validity of Analytical Methods}

Hydraulic properties are derived by analysis of test data using any of various established methods. These methods vary with hydrologic condition or aquifer type: unconfined, leaky confined, and confined. Software permits plotting data against type curves for the various methods. The type curve yielding the best fit presumably identifies the hydrologic condition prevailing for the material tested and gives the most representative result. However, the results should not be accepted uncritically but should be evaluated in view of what is known of the hydrogeology of the area.

As many analytical methods are graphical (they involve curve matching), there will always be some variation in the results. However, slight differences in curve matching yield only slight differences in results.

More important, however, is the suitability of the method used to analyze the data. Suitability is determined by the similarity of both the site and test conditions to those specified for the method. In other words, assumptions made for the method must be met. Table 13 summarizes the basic conditions assumed for the analytical methods used in this report.

Table 13

Major Assumptions for Analytical Methods Used

\begin{tabular}{|c|c|c|c|}
\hline Method & $\begin{array}{l}\text { Well Penetration } \\
\text { of Aquifer }\end{array}$ & Hydraulic Condition & Application of Stress \\
\hline \multicolumn{4}{|l|}{ Slug Tests } \\
\hline Bouwer-Rice $(1976,64056)$ & Partial or complete & Unconfined or confined & Addition or withdrawal \\
\hline $\begin{array}{l}\text { Cooper-Bredehoeft-Papadopulos } \\
(1967,70108)\end{array}$ & Complete & Confined & Addition or withdrawal \\
\hline Hvorslev $(1951,70101)$ & Partial & Unconfined or confined & Addition or withdrawal \\
\hline \multicolumn{4}{|l|}{ Pumping Tests } \\
\hline Theis $(1935,70102)$ & Complete & Unconfined or confined & Pumping \& recovery \\
\hline Hantush-Jacob $(1954,70115)$ & Complete & Leaky confined & Pumping \& recovery \\
\hline Neuman $(1975,73479)$ & Partial or complete & Unconfined & Pumping \& recovery \\
\hline
\end{tabular}

\section{Evaluating Test Results}

It is beyond the scope of this report to review the field of well hydraulics. Excellent coverage can be found in standard hydrology textbooks (for example, Driscoll 1986, 70108, and Fetter 1994, 70942). However, for a quick quality-assurance check of hydrologic tests, one can ask a few basic questions:

1. How much did flow rate vary during the test? All analytical methods assume it was constant. However, maintaining a constant flow rate is difficult. For the test to be valid, flow rate should not have varied by more than $10 \%$; less variation is desirable (Fetter 1994, 70942). The Bean pumps used provided remarkably constant flow rates. In all the tests reported on here, flow-rate variation was much less than $10 \%$ (typically $2-4 \%$ ).

2. Are there indications that any equipment was unreliable? Did drill rod slip, packers deflate, the flow meter behave erratically, etc.? Obviously, unreliable equipment produces unreliable data. Whenever equipment problems occurred, testing was halted until they could be resolved.

3. Did testing evaluate the formation or the filter pack? Since the filter packs in some wells are long (Table 3 ) and the tests are short, this question seems reasonable. However, as the filter packs 
are saturated when testing begins, it is not. The injection of any amount of water causes an equal amount of water to be displaced from the filter pack into the adjacent formation. If $5 \mathrm{gal}$. are injected, 5 gal. enter the formation, even if the pore volume of the filter pack is 25 gal. The greater the volume of water injected, the greater the volume of water going into the formation, but the formation is evaluated in all cases.

Nonetheless, comparing the volume of water injected to the pore volume of the filter pack may be of interest to some readers. To evaluate this amount, we first estimated the total volumes of the filter packs, assuming ideal cylinders (Table 14). Next, we compared the volumes of water injected with estimated pore volumes of the filter packs behind the various screens tested (Table 15). In all cases, more water was injected during testing than was needed to displace all the water in the pores of the filter pack (assuming 25\% porosity). In fact, in the 11 injection tests documented in this report, injected water represented at least four times the estimated filter-pack pore volume. In nine of the tests, the volume of water injected was at least ten times the estimated pore volume. In four of the tests, the volume injected was 50 times the pore volume. In one test, the water injected represented 110 times the pore volume.

Table 14

Estimated Volume of Filter Packs in Wells Tested

\begin{tabular}{|c|c|c|c|c|c|c|c|c|c|c|c|}
\hline$\overline{\overline{0}}$ & 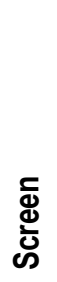 & 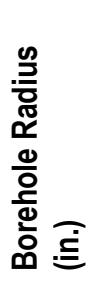 & 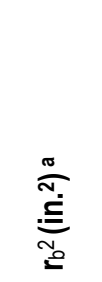 & 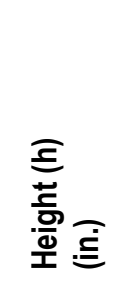 & 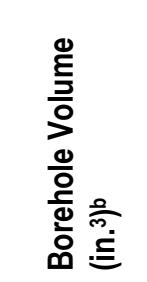 & 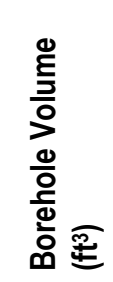 & 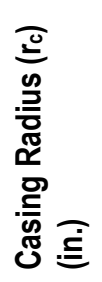 & 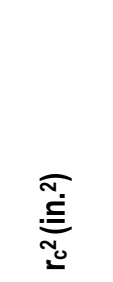 & 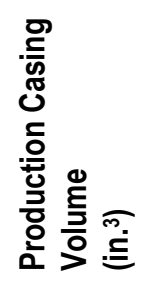 & 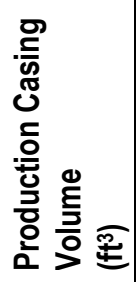 & 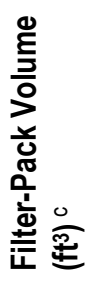 \\
\hline \multirow[t]{2}{*}{ R-9i } & 1 & 6.12 & 37.45 & 20.7 & 2435.70 & 1.41 & 2.5 & 6.25 & 406.44 & 0.24 & 1.17 \\
\hline & 2 & 6.12 & 37.45 & 18.5 & 2176.83 & 1.26 & 2.5 & 6.25 & 363.25 & 0.21 & 1.05 \\
\hline$R-13$ & 1 & 6.37 & 40.58 & 87.5 & 11154.16 & 6.45 & 2.78 & 7.7284 & 2124.45 & 1.23 & 5.23 \\
\hline \multirow[t]{2}{*}{ R-19 } & 6 & 7.00 & 49.00 & 103.9 & 15994.16 & 9.26 & 2.5 & 6.25 & 2040.07 & 1.18 & 8.08 \\
\hline & 7 & 7.00 & 49.00 & 20.2 & 3109.55 & 1.80 & 2.5 & 6.25 & 396.63 & 0.23 & 1.57 \\
\hline \multirow[t]{4}{*}{$\mathrm{R}-22$} & 2 & 7.25 & 52.56 & 69.5 & 11476.53 & 6.64 & 2.5 & 6.25 & 1364.63 & 0.79 & 5.85 \\
\hline & 3 & 7.25 & 52.56 & 49.5 & 8173.93 & 4.73 & 2.5 & 6.25 & 971.93 & 0.56 & 4.17 \\
\hline & 4 & 5.25 & 27.56 & 19.5 & 1688.51 & 0.98 & 2.5 & 6.25 & 382.88 & 0.22 & 0.76 \\
\hline & 5 & 5.25 & 27.56 & 41 & 3550.20 & 2.05 & 2.5 & 6.25 & 805.03 & 0.47 & 1.59 \\
\hline \multirow[t]{3}{*}{ R-31 } & 3 & 6.56 & 43.03 & 18 & 2433.49 & 1.41 & 2.6 & 6.76 & 382.27 & 0.22 & 1.19 \\
\hline & 4 & 5.37 & 28.84 & 61.5 & 5571.52 & 3.22 & 2.6 & 6.76 & 1306.09 & 0.76 & 2.47 \\
\hline & 5 & 5.37 & 28.84 & 198.9 & 18019.11 & 10.43 & 2.6 & 6.76 & 4224.07 & 2.44 & 7.98 \\
\hline
\end{tabular}

a $r_{b}=$ borehole radius.

b Calculations required assumption that borehole is an ideal cylinder for which volume $=\pi r^{2} h$.

c Filter-pack volume $=$ borehole volume - production-casing volume . 
Table 15

Volume of Water Injected vs. Pore Volume of Filter Packs in Wells Tested

\begin{tabular}{|c|c|c|c|c|c|c|c|}
\hline Well & Screen & $\begin{array}{c}\text { Borehole } \\
\text { Volume } \\
\quad\left(\mathrm{ft}^{3}\right)\end{array}$ & $\begin{array}{l}\text { Casing } \\
\text { Volume } \\
\left.\text { (ft }^{3}\right)\end{array}$ & $\begin{array}{c}\text { Filter-Pack } \\
\text { Volume } \\
\left(\mathrm{ft}^{3}\right)\end{array}$ & $\begin{array}{c}\text { Pore } \\
\text { Volume } \\
\left(\mathrm{ft}^{3}\right)\end{array}$ & $\begin{array}{c}\text { Volume of } \\
\text { Water Injected } \\
\text { (gal.) }\end{array}$ & $\begin{array}{c}\text { Volume of } \\
\text { Water Injected } \\
\left(\mathrm{ft}^{3}\right)\end{array}$ \\
\hline \multirow[t]{2}{*}{ R-9i } & 1 & 1.41 & 0.24 & 1.17 & 0.29 & 120 & 16.04 \\
\hline & 2 & 1.26 & 0.21 & 1.05 & 0.26 & 30 & 4.01 \\
\hline \multirow[t]{2}{*}{ R-19 } & 6 & 9.26 & 1.18 & 8.08 & 2.02 & 120 & 16.04 \\
\hline & 7 & 1.80 & 0.23 & 1.57 & 0.39 & 322 & 43.05 \\
\hline \multirow[t]{4}{*}{ R-22 } & 2 & 6.64 & 0.79 & 5.85 & 1.46 & 140 & 18.72 \\
\hline & 3 & 4.73 & 0.56 & 4.17 & 1.04 & 140 & 18.72 \\
\hline & 4 & 0.98 & 0.22 & 0.76 & 0.19 & 50 & 6.69 \\
\hline & 5 & 2.05 & 0.47 & 1.59 & 0.40 & 50 & 6.69 \\
\hline \multirow[t]{3}{*}{ R-31 } & 3 & 1.41 & 0.22 & 1.19 & 0.30 & 10 & 1.34 \\
\hline & 4 & 3.22 & 0.76 & 2.47 & 0.62 & 300 & 40.11 \\
\hline & 5 & 10.43 & 2.44 & 7.98 & 2.00 & 270 & 36.10 \\
\hline
\end{tabular}

${ }^{a}$ Borehole, casing and filter-pack volumes are as derived in Table 14.

${ }^{b}$ Pore volume based on assumption of $25 \%$ porosity; primary and secondary filter-pack sands not distinguished for this estimate.

4. Were the assumptions for the analytical method used actually met at the site? Unrealistic or erroneous hydraulic properties are often attributed to the inadequacy of the analytical equation used. It is more likely that any of several field conditions did not match those on which the equation is based:

Screen Position. Tests for screens straddling the water table are not ideal, as discussed under "Constraints." Although a few methods specifically state that they apply only to tests of screens below the water table (for example, Bouwer and Rice), that assumption is inherent for all methods.

Well Penetration of Aquifer. Ideally, a well to be tested fully penetrates the thickness of an aquifer. Some methods are suitable for partially penetrating wells, others require fully penetrating wells, and some apply to either case, especially if certain conditions are met. If a screen covers less than $70 \%$ of the total thickness of the saturated material, the well is considered to be partially penetrating (Kruseman and de Ridder 2000, 70110). The multiscreen completion of most of the wells epitomizes partial penetration. Short single-screen completions also represent only partial penetration. Well penetration is a concern in test analysis. What saturated thickness should be applied to each screen? Is it the interval between seals (filter-pack length) or that between the lower seal and the composite static water level for the entire well? For consistency, we usually defined the saturated thickness as the filter-pack length.

Hydraulic Condition. Some methods apply only to confined conditions, others apply only to unconfined conditions, while still others apply to leaky-confined conditions. Some apply to either confined or unconfined conditions, if certain provisions apply. If an analytical plot looks good for a given condition, one should consider whether that condition is likely for the location and material behind the screen.

Flow Conditions. Each analytical method corresponds to a specific flow condition. Flow to the well is assumed to be radial. For pumping tests, flow may also be further described as steady (in equilibrium) or nonsteady (not in equilibrium). In steady flow, the cone of depression continues to 
grow with time. In nonsteady flow, the cone of depression has reached a recharge boundary and stopped growing.

Method of Applying Stress. Some methods evaluate the response to removal of water (as by pumping), while others address the response to addition of water. Alternatively, the same results can be generated by introducing or removing a solid slugger of known volume to or from the water column in the well (conventional slug tests).

Major assumptions for the methods used to analyze data from the five wells tested are summarized in Table 13.

5. Do the test results for the various geologic units compare favorably with those obtained previously? Figure 25 permits a comparison of the results of the injection testing described herein and those obtained for the same geologic unit by various other methods. In most cases, injectiontest results fall within the distribution of values. In general, however, results of injection tests tend to be lower than those of pumping tests.

6. Do the results seem reasonable for the geologic materials tested? That is, are the hydraulic properties within the range commonly reported for the rock types tested? Table 16 gives the lithology of the material tested, the results obtained from testing $(\mathrm{K})$, and the range of textbook $\mathrm{K}$ values for the same or most similar material. All of the test results fall within reported ranges of $K$ for the geologic materials tested.

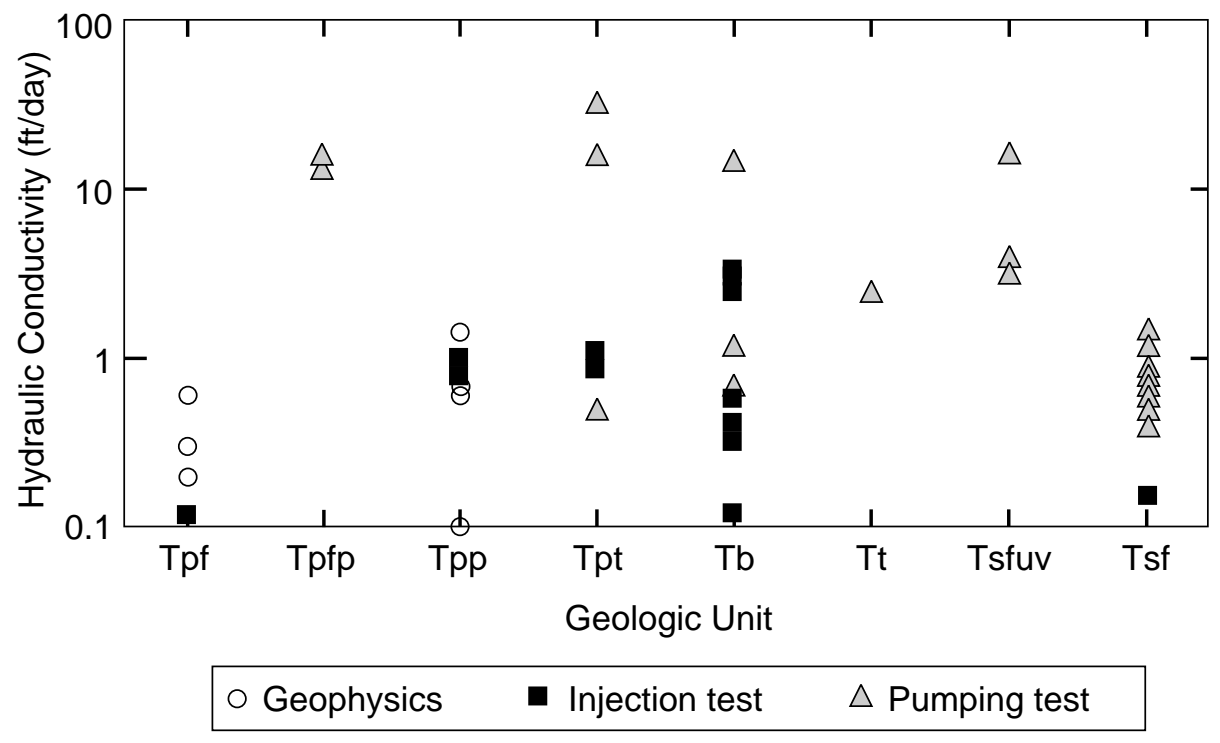

Figure 25. Comparison of results for various test methods. $\mathbf{T p f}=$ Puye Formation (fanglomerate); $\mathrm{Tpp}=$ Puye Formation (pumiceous); $\mathrm{Tpfp}=$ Puye Formation (fanglomerate and pumiceous); Tpt $=$ Puye Formation, Totavi Lentil; $\mathrm{Tb}=$ Cerros del Rio basalt; $\mathrm{Tt}=$ Tschicoma Formation; Tsfuv = upper Santa Fe Group; and Tsf = Santa Fe Group 
Table 16

Hydraulic Properties vs. Geology

\begin{tabular}{|c|c|c|c|c|}
\hline $\begin{array}{c}\text { Material Tested } \\
\text { (well-screen/test) }\end{array}$ & $\begin{array}{l}\text { Test } \\
\text { (ft/d) }\end{array}$ & $\begin{array}{l}\text { esults K } \\
\left(\mathrm{gpd} / \mathrm{ft}^{2}\right)^{\mathrm{b}}\end{array}$ & $\begin{array}{c}\text { Comparable Textbook } \\
\text { Materialc }\end{array}$ & $\begin{array}{c}\text { Textbook K } \\
\text { Range }\left(\mathrm{gpd} / \mathrm{ft}^{2}\right)^{\mathrm{c}}\end{array}$ \\
\hline $\begin{array}{l}\text { Clayey flow base } \\
\text { (R-9i-2) }\end{array}$ & 0.11 & 0.82 & Glacial till & $10^{-5}$ to 10 \\
\hline $\begin{array}{l}\text { Massive/somewhat } \\
\text { fractured basalt } \\
\text { (R-22-2) } \\
\text { (R-31-3) } \\
\text { (R-22-4a) } \\
\text { (R-22-4b) }\end{array}$ & $\begin{array}{l}0.04 \\
0.41 \\
0.54 \\
0.72\end{array}$ & $\begin{array}{l}0.30 \\
3.07 \\
4.04 \\
5.39\end{array}$ & $\begin{array}{l}\text { Fractured igneous and } \\
\text { metamorphic rock }\end{array}$ & $10^{-1}$ to $10^{3}$ \\
\hline $\begin{array}{l}\text { Highly fractured } \\
\text { basalt } \\
\text { (R-9i-1a) } \\
(\mathrm{R}-9 \mathrm{i}-1)^{*}\end{array}$ & $\begin{array}{l}4.87 \\
4.75 \\
\end{array}$ & $\begin{array}{l}36.43 \\
35.53\end{array}$ & Permeable basalt & 1 to $10^{5}$ \\
\hline $\begin{array}{l}\text { Fanglomerate and } \\
\text { axial gravel } \\
\text { (R-22-3) } \\
\text { (R-22-5) } \\
\text { (R-19-7)p } \\
\text { (R-31-5)g } \\
\text { (R-19-6)p } \\
\text { (R-31-4)g } \\
(\mathrm{R}-13 \mathrm{~b})^{*}\end{array}$ & $\begin{array}{r}0.21 \\
0.27 \\
0.73 \\
0.75 \\
1.10 \\
1.23 \\
13.70\end{array}$ & $\begin{array}{r}1.57 \\
2.02 \\
5.46 \\
5.61 \\
8.23 \\
9.20 \\
102.48\end{array}$ & Silty sand & 1 to $10^{3}$ \\
\hline
\end{tabular}

a * = pumping test and $\mathrm{K}=\mathrm{T}$ /saturated thickness; $\mathrm{p}=$ pumiceous fanglomerate (Puye Formation), $\mathrm{g}=$ gravel (Totavi Lentil).

b Calculated as $\mathrm{ft} / \mathrm{d}$ value (Table 5$) \times 7.48$

c From Freeze and Cherry $(1979,64057)$ Table 2.2.

Despite the care taken in the design, execution, and analysis of tests, results obtained are not unique. Kruseman and DeRidder (2000, p. 13, 70110) summed up the reason succinctly:

Analyzing and evaluating pumping test data...is as much an art as a science. It is science because it is based on theoretical models that the geologist or engineer must understand and on thorough investigations that he [/she] must conduct into the geologic formations in the area of interest. It is an art because different types of aquifers can exhibit similar drawdown behaviors, which demand interpretation...on the part of the geologist or engineer.

This dual nature of hydrologic testing should be kept in mind when evaluating or using test results.

\section{RECOMMENDATIONS}

As noted in the "Constraints" section, the R wells present several challenges to hydrologic testing. We offer the following suggestions for overcoming these challenges and optimizing opportunities for evaluating hydraulic properties of the saturated materials beneath the Pajarito Plateau.

Avoid Placing Screens Across Water Table. Designing wells with testing in mind maximizes both testing opportunities and results. Most analytical methods assume the screen is below the water table. NMED has specified that the uppermost screen must straddle the water table to facilitate detection of organic contaminants floating at the top of the saturated zone, despite the fact that organics are not the principal contaminants at LANL. Furthermore, such a well design hinders development of the uppermost screen. Thus, we recommend that screens not be paced across the water table, unless there is a reason to suspect organic contaminants in the area. 
Avoid Placing Screens Across Geologic Contacts. Hydrologic testing is usually conducted to learn the properties of a single geologic unit or type of material within a geologic unit. When screens are placed across contacts between geologic units, the test result is an average that is not representative of either unit. Thus, we recommend that placing screens across geologic contacts or contacts between material types within units should be avoided wherever possible.

Avoid Oversized Filter Packs. Oversized filter packs should be avoided as they hinder focused hydrologic testing and water-quality sampling. One usually assumes that the interval of geologic material targeted by a screen is similar to the length of the screen. Thus, it is not only misleading but also counterproductive to have a 7-ft screen and a 100-ft filter pack (as at R-19, screen 6; Table 4). Results of testing such a screen installation are biased by the amount of permeable material in such a long interval. Furthermore, many of the $\mathrm{R}$ wells are destined to become monitoring wells. Such wells usually target certain intervals in the saturated zone. Oversized filter packs permit the mixing of water over long intervals. It is not possible to characterize the quality of water associated with material behind a 7 -ft screen if the water sample actually came from a bracketing 100-ft interval.

Employ Alternative Test Methods. Ideally, a given saturated material would be tested by as many methods as possible and the results compared. For example, injection tests, slug tests, and pumping tests could be conducted in the same well. Testing of the multiscreened $R$ wells has been by a straddlepacker/injection method. Slug and pumping tests between straddle packers should also be performed. However, equipment for such testing was not available for wells discussed in this report. The added expense of applying multiple methods would be minimal as equipment is already at the well site. Costs would also be minimized by employing multiple methods only until the relationship of results is determined.

Tests employing a solid slugger would not only be simpler but would have the advantage of eliminating the need to introduce foreign water. As equipment is not readily available, an assembly must be fabricated to permit such testing between straddle packers. A major design challenge, however, is accommodating a transducer and a solid slugger in the small production casing, without tangling/damaging the transducer cable or compromising the seal provided by the packer.

One possible alternative approach to traditional slug testing in the multiscreened wells would be to add a valve to the straddle-packer/injection assembly currently used that could be tripped from the surface. In this case one would add a known volume of water to the rods above the valve and then trip it for instantaneous delivery to the screened interval, as assumed in slug testing. Another alternative is to use a pulse of air as the "slug." In these and the solid-slugger cases, analytical methods intended for slug tests would be directly applicable.

Screen-specific pumping tests, in which water is withdrawn from between a pair of packers isolating screens, would also be ideal. Such tests would provide additional hydraulic-property results for comparison with those from straddle-packer/injection or slug tests. For such tests, a pump must (1) fit inside a 4.5-in. production casing, (2) lift water against the heads involved in these deep wells, and (3) discharge at a rate great enough to stress the saturated zones. However, we have not succeeded in obtaining a pump that will do all three. Where hydrologic data are an objective, larger diameter wells should be installed.

Hydraulic properties can also be evaluated by means of water-level time-series analysis, especially with respect to the response to atmospheric pressure and earth tides (Ritzi et al. 1991, 73645; McLin 2000, 73735). The water levels collected to date by LANL's transducer network are a valuable source of data for such analysis. Results would complement and provide a further check of field-test results.

Employ Alternative Test Designs. The results reported here are all based on single-well tests. It could be argued that such tests interrogate only a small portion of the saturated material next to the well and that 
material may have been damaged during drilling and well construction. Multiwell tests, involving a pumping well and one or more observation wells, cover a larger portion of the saturated medium (that between the pumping and observation wells) and thus give more representative results (Kruseman and de Ridder 2000, 70110). Such tests also permit the calculation of storativity and anisotropy. The Hydrogeologic Workplan (LANL 1998, 59599) recognizes the need for multiwell tests, and it is hoped that some will be conducted before the program is concluded.

Pumping tests should involve as many observation wells (piezometers) as possible. Kruseman and de Ridder $(2000,70110)$ recommend employing at least three. Spacing and orientation depend on site conditions. Placing piezometers 30 to $300 \mathrm{ft}$ from the pumping well is sufficient in most cases; however, a spacing on the order of 300 to $800 \mathrm{ft}$ may be required for thick or stratified, confined aquifers. A well or piezometer located outside the radius of influence of the pumping well is also useful. Any water-level changes related to natural recharge or discharge detected in such a well can be used to correct drawdowns induced by pumping.

If funding permits only two-well tests, they could be most economically accomplished by locating selected $\mathrm{R}$ wells near existing water-supply wells. In such an arrangement, the supply well could be the pumping well and the $\mathrm{R}$ well could be the observation well. The use of a municipal well solves the problem of disposal of produced water: it would go into the supply line. However, the construction of supply wells is not always ideal for hydrologic testing. That is, screens may be long and extend over multiple hydrostratigraphic units.

If no supply well exists where a test is needed or if the construction of existing supply wells is not appropriate, an $\mathrm{R}$ well can be installed to be either the pumping well or an observation well. If the $\mathrm{R}$ well is completed with a single screen and used as the pumping well, the observation well(s) can be a smalldiameter piezometer(s). The piezometer(s) must be constructed so as to be compatible with the pumping well (same unit screened, etc.) or with the test objective.

Repeat Tests When Practical. Conducting more than one test using the same method on the same screen and comparing results is instructive and should be done where feasible. Some repeat tests were made for the wells reported here but not consistently. Retesting should become routine practice, at least until it is shown that results are reproducible. In the case of injection or pumping tests, a second test can be run after water level has returned to the pre-test static position. In the second round of testing, flow rate and duration can be kept the same or changed. The additional expense amounts to a few hours of rig, crew, and LANL-staff time, which is small when compared to the total cost of a well.

Verify Development With Testing. Hydrologic testing assumes the well has been completely developed. Even if field parameters reach acceptable levels, the two-layer screen (as currently in use), the filter pack or the adjacent formation may not be completely open. A series of tests can be performed to verify that well development has completely removed all drilling fluids or that borehole skin effects do not dominate the flow regime (Butler 1997, 73641). Ideally, at least three tests are employed sequentially: slug withdrawal first, then slug injection, and finally slug withdrawal. The resulting impact on the well is much like surging during well development. Generally, during the final test, the maximum slug-injection head is about twice the initial slug-injection head. This series gives results for flow both into and out of the formation. If these tests replicate one another, then one has high confidence that well development was adequate, and that the reported hydraulic conductivity values represent the undisturbed formation surrounding the well screen.

Even if the exact series of tests described above cannot be performed, repeat tests can tell something about development. For example, if the recovery curve for the initial falling-head test is rough but that for subsequent tests is smooth, one may conclude that the initial injection accomplished some development. 
Target Selected Hydrostratigraphic Units. Figure 25 shows that the injection tests reported here have not included the deeper geologic units (Tt, Tsfuv, and Tsf). This can be explained by the fact that the R wells do not usually penetrate these units. Results of recent numerical modeling of the groundwater system beneath the Pajarito Plateau suggest that existing data adequately characterize the hydraulic properties for the Santa Fe Group. Thus, future testing in the deep wells should focus on other units for which aquifer properties are poorly constrained, namely, the Cerros del Rio basalt and the Puye Formation. Hydraulic conductivity data obtained from testing to date vary considerably for both of these units (Stone et al. 2001, 70090).

Testing every screen in every well may not be necessary or economical. As noted above, testing screens straddling the water table is not appropriate. Additionally, if a given unit has been fairly well characterized by previous testing or if several screens are set in the same unit in the well, testing may be limited to selected screens.

\section{SUMMARY AND CONCLUSIONS}

The key findings of the tests and conclusions based on them are summarized below.

1. Eleven straddle-packer/injection tests and two pumping tests have been conducted at five wells: R-9i, R-13, R-19, R-22, R-31.

2. Although testing by injection between straddle packers is a hybrid method, it was the only one available for the deep, multiscreened wells being installed on the Pajarito Plateau.

3. Four of the eleven injection tests evaluated the Cerros del Rio basalt. $\mathrm{K}$ values for the basalt range from 0.04 to $4.87 \mathrm{ft} / \mathrm{d}$. Such a range of values is expected given the variability of porosity and permeability within basalts.

4. Two of the eleven injection tests involved the Puye Formation, pumiceous unit, in the same well (R-19). Results of the tests are very similar: 0.73 and $1.10 \mathrm{ft} / \mathrm{d}$, no doubt a result of similar depositional conditions, and thus similar porosity and permeability, for this unit of the Puye lying behind the two screens tested.

5. Two other tests involve the Totavi Lentil of the Puye Formation, in the same well (R-31). K values determined from these tests are $1.23 \mathrm{ft} / \mathrm{d}$ (screen 4 ) and $0.75 \mathrm{ft} / \mathrm{d}$ (screen 5).

6. The remaining three injection tests each targeted a different geologic unit. $\mathrm{K}$ for the Puye Formation at R-22, screen $3=0.21 \mathrm{ft} / \mathrm{d}$; $\mathrm{K}$ for older basalt at R-22, screen $4=0.54 \mathrm{ft} / \mathrm{d}$; and $\mathrm{K}$ for older fanglomerate at R-22, screen $5=0.27 \mathrm{ft} / \mathrm{d}$.

7. Hydraulic properties at two wells were evaluated by pumping tests: R-9i and R-13. For Cerros del Rio basalt at R-9i, screen $1, T=49.4 \mathrm{ft}^{2} / \mathrm{d}$ or $\mathrm{K}=4.75 \mathrm{ft} / \mathrm{d}$. This $\mathrm{K}$ is very similar to that obtained in the injection test $(K=4.87 \mathrm{ft} / \mathrm{d})$. For the Puye Formation at $\mathrm{R}-13, \mathrm{~T}$ is at least $829.7 \mathrm{ft}^{2} / \mathrm{d}$ $(\mathrm{K}=13.7 \mathrm{ft} / \mathrm{d})$. As the screen straddles the contact between fanglomerate and pumiceous Puye, this is a composite value. Discharge was too low with the pump available to stress the regional aquifer at R-13 and the test was cut short.

8. In spite of constraints imposed by hydrogeology and well design, hydrologic testing yielded reasonable order-of-magnitude results when compared both with those of previous testing on the Pajarito Plateau and with values commonly reported for similar materials outside the area.

9. We recommend that screens not be placed across the water table or geologic contacts and that oversized filter packs be avoided.

10. Alternative test methods and designs should be employed and results compared, at least until relationships have been determined.

11. Development could be verified by a series of slug tests, as used elsewhere.

12. Testing should be focused on selected hydrostratigraphic units for which data are sparse. 
Although major saturated materials beneath the Pajarito Plateau have been previously tested, especially in the water-supply wells, details of some such tests have not been preserved, and those for others are incomplete or not readily available. Thus, the validity of many of the previous tests cannot be determined. It is hoped that since this document not only presents results of testing at five of the new $\mathrm{R}$ wells but also captures and preserves information about the test design, implementation, and analysis needed to evaluate the quality of these results, it will be even more useful to readers.

\section{ACKNOWLEDGEMENTS}

Personnel of Dynatec Drilling, Inc., supported testing operations at all the wells. Chad Johannsen (S.M. Stoller Corp.) assisted with testing at well R-13. Neal Tapia (RRES) conducted the tests at well R-19. Paula Schuh (Daniel B. Stephens and Associates) assisted with the testing at well R-22. Richard Koch (SAIC) assisted with the testing at well R-31. David Vaniman (EES-6) updated the geology portion of the well diagrams. Elizabeth Keating (EES-6) provided Figure 27. Anthony Garcia (EES-6) prepared the well diagrams as well as Figures 2, 3, and 27. Christy Flaming (IM-1/RRES) scanned the field and analytical plots and prepared the cover illustration. Randi Moore (IM-1/RRES) prepared the final versions of all figures in the report. Ann Lee (RRES) assisted with the construction of Tables 14 and 15. Meena Sachdeva (RRES/IM-1) edited the document. Pam Maestas (Neptune) and Randi Moore were the compositors. Review comments by Roy Bohn (RRES), Ellen Louderbough (Legal), Steve Pearson (RRES), David Rogers (RRES), Dave Schafer (David Schafer \& Associates), Kelly Summers (retired groundwater scientist), as well as Tom Whitacre and Bob Enz (both DOE) are gratefully acknowledged.

\section{REFERENCES}

Aller, L., T.W. Bennett, G. Hackett, R.J. Petty, J.H. Lehr, H. Sedoris, D.M. Nielsen, and J.E. Denne, 1991. Handbook of Suggested Practices for the Design and Installation of Ground-Water Monitoring Wells, US Environmental Protection Agency Report, EPA 160014-891034. (Aller et al. 1991, 70112)

ASTM, 1994. Standards on Ground Water and Vadose Zone Investigations, sponsored by Committee D-18 on Soil and Rock ( $2^{\text {nd }}$ edition), ASTM Publication Code Number 03-418094-38. (ASTM 1994, 70099)

ASTM, 1996. Standards on Analysis of Hydrologic Parameters and Ground Water Modeling, sponsored by Committee D-18 on Soil and Rock, ASTM Publication Code Number 03-41096-38. (ASTM 1996, 70100)

Ball, T., M. Everett, P. Longmire, D. Vaniman, W. Stone, D. Larssen, K. Greene, N. Clayton, and S. McLin, February 2001. "Characterization Well R-22 Completion Report," Los Alamos National Laboratory Report LA-13893-MS, Los Alamos, New Mexico. (Ball et al. 2001, 71471)

Bouwer, H., 1978. Groundwater Hydrology, McGraw-Hill, New York. (Bouwer 1978, 73678)

Bouwer, H., and R.C. Rice, 1976. "A Slug Test for Determining Hydraulic Conductivity of Unconfined Aquifers with Completely or Partially Penetrating Wells, "Water Resources Research, Vol. 12, pp. 423-428. (Bouwer and Rice 1976, 64056)

Broxton, D., R. Gilkeson, P. Longmire, J. Marin, R. Warren, D. Vaniman, A Crowder, B. Newman, B. Lowry, D. Rogers, W. Stone, S. McLin, G. WoldeGabriel, D. Daymon, and D. Wycoff, May 2001. "Characterization Well R-9 Completion Report," Los Alamos National Laboratory Report LA-13742-MS, Los Alamos, New Mexico. (Broxton et al. 2001, 66599)

Broxton, D., D. Vaniman, W. Stone, S. McLin, M. Everett and A. Crowder, September 2000.

"Characterization Well R-9i Completion Report," Los Alamos National Laboratory Report LA-13821-MS, Los Alamos, New Mexico. (Broxton et al. 2001, 66600)

Broxton, D., D. Vaniman, W. Stone, S. McLin, J. Marin, R. Koch, R. Warren, P. Longmire, D. Rogers, and N. Tapia, May 2001. "Characterization Well R-19 Completion Report," Los Alamos National Laboratory Report LA-13823-MS, Los Alamos, New Mexico. (Broxton et al. 2001, 71253) 
Butler, J.J., 1997. The Design, Performance, and Analysis of Slug Tests, Lewis Publishers, New York. (Butler 1997, 73641)

Cooper, H.H., J. D. Bredehoeft and I.S. Papadopulos, 1967. "Response of a Finite-Diameter Well to an Instantaneous Charge of Water," Water Resources Research, Vol. 3, pp. 263-269. (Cooper et al. 1967, 70108)

Driscoll, F.G., 1986. Groundwater and Wells, Johnson Division, St. Paul, Minnesota. (Driscoll 1986, 70111)

Earlougher, R.C., 1977. Advances in Well Test Analysis, Society of Petroleum Engineers of AIME, New York. (Earlougher 1977, 73478)

Fetter, C.W., 1994. Applied Hydrogeology, $3^{\text {rd }}$ edition, Prentice Hall, Upper Saddle River, New Jersey. (Fetter 1994, 70942)

Freeze, R.A., and J.A. Cherry, 1979. Groundwater, Prentice Hall, Englewood Cliffs, New Jersey. (Freeze and Cherry 1979, 64057)

Hantush, S., and C.E. Jacob, 1954. "Plane Potential Flow of Ground Water With Linear Leakage," Transactions, American Geophysical Union, Vol. 35, No. 6, pp 917-936. (Hantush and Jacob 1954, 70115)

Hvorslev, M.J., 1951. "Time Lag and Soil Permeability in Ground Water Observations," U.S. Army Corps of Engineers, Waterways Experiment Station Bulletin 36. (Hvorslev 1951, 70101)

Kruseman, G.P. and N.A. de Ridder, 2000. Analysis and Evaluation of Pumping Test Data, International Institute for Land Reclamation and Improvement, Publication 47, Wageningen, The Netherlands.

(Kruseman and de Ridder 2000, 70110)

LANL (Los Alamos National Laboratory), September 1998. "Hydrogeologic Workplan," Los Alamos, New Mexico. (LANL 1998, 59599)

McLin, S.G., April 2000. "Estimating Hydraulic Parameters from Water-Level Fluctuations (abstract)," New Mexico Geological Society, Proceedings of Annual Spring Meeting, Socorro, New Mexico. (McLin 2000, 73735)

Neuman, S.P., 1975. "Analysis of Pumping Test Data From Anisotropic Unconfined Aquifers Considering Delayed Gravity Response," Water Resources Research, Vol. 11, No. 2, pp. 329-342. (Neuman 1975, 73544)

Ritzi, R.W., P.A. Hsieh, and S. Sorooshian, 1991. "The Estimation of Fluid Flow Properties from the Response of Water Levels in Wells to the Combined Atmospheric and Earth Tide Forces," Water Resources Research, Vol. 27, No. 5, pp. 883-893. (Ritzi et al 1991, 73645)

Stone, W., G. Cole, W. Carey, and M. Jones, 2001. "Expanded Hydrogeologic Atlas for Los Alamos National Laboratory," Los Alamos National Laboratory Document, LA-UR-01-70, Los Alamos, New Mexico. (Stone et al. 2001, 69830)

Stone, W., S. McLin, and D. Vaniman, April 2001. "Hydraulic Conductivity vs Geology in New Los Alamos Wells" (abstract), New Mexico Geological Society, Proceedings of Annual Spring Meeting, Socorro, New Mexico. (Stone et al. 2001, 70090)

Theis, C.V., 1935. "The Relation Between the Lowering of the Piezometric Surface and the Rate and Duration of Discharge of a Well Using Groundwater Storage," American Geophysical Union Transactions, Vol. 16, pp. 519-52. (Theis 1935, 70102)

Vaniman, D., J. Marin, W. Stone, B. Newman, P. Longmire, N. Clayton, R. Lewis, R. Koch, S. McLin, G. WoldeGabriel, D. Counce, R. Rogers, R. Warren, E. Kluk, S. Chipera, D. Larssen, and W. Kopp, March 2002. "Characterization Well R-31 Completion Report," Los Alamos National Laboratory Report, LA-13910-MS, Los Alamos, New Mexico. (Vaniman et al. 2001, 72615) 


\section{Appendix A}

\section{Well R-9i Test Data}

Contents

A-1 Plots for Injection Tests, Screen 1

A-2 Recovery Data for Injection Test, Screen 1a

A-3 Analysis of Injection Test, Screen 1a

A-4 Plot for Injection Test, Screen 2

A-5 Recovery Data for Injection Test, Screen 2

A-6 Analysis of Injection Test, Screen 2

A-7 Plot for Pumping Test

A-8 Drawdown Data for Pumping Test

A-9 Analysis of Pumping Test (Theis)

A-10 Analysis of Pumping Test (Neuman, early-time data)

A-11 Analysis of Pumping Test (Neuman, late-time data) 



\section{A-1. Plots for Injection Tests, R-9i, Screen 1}

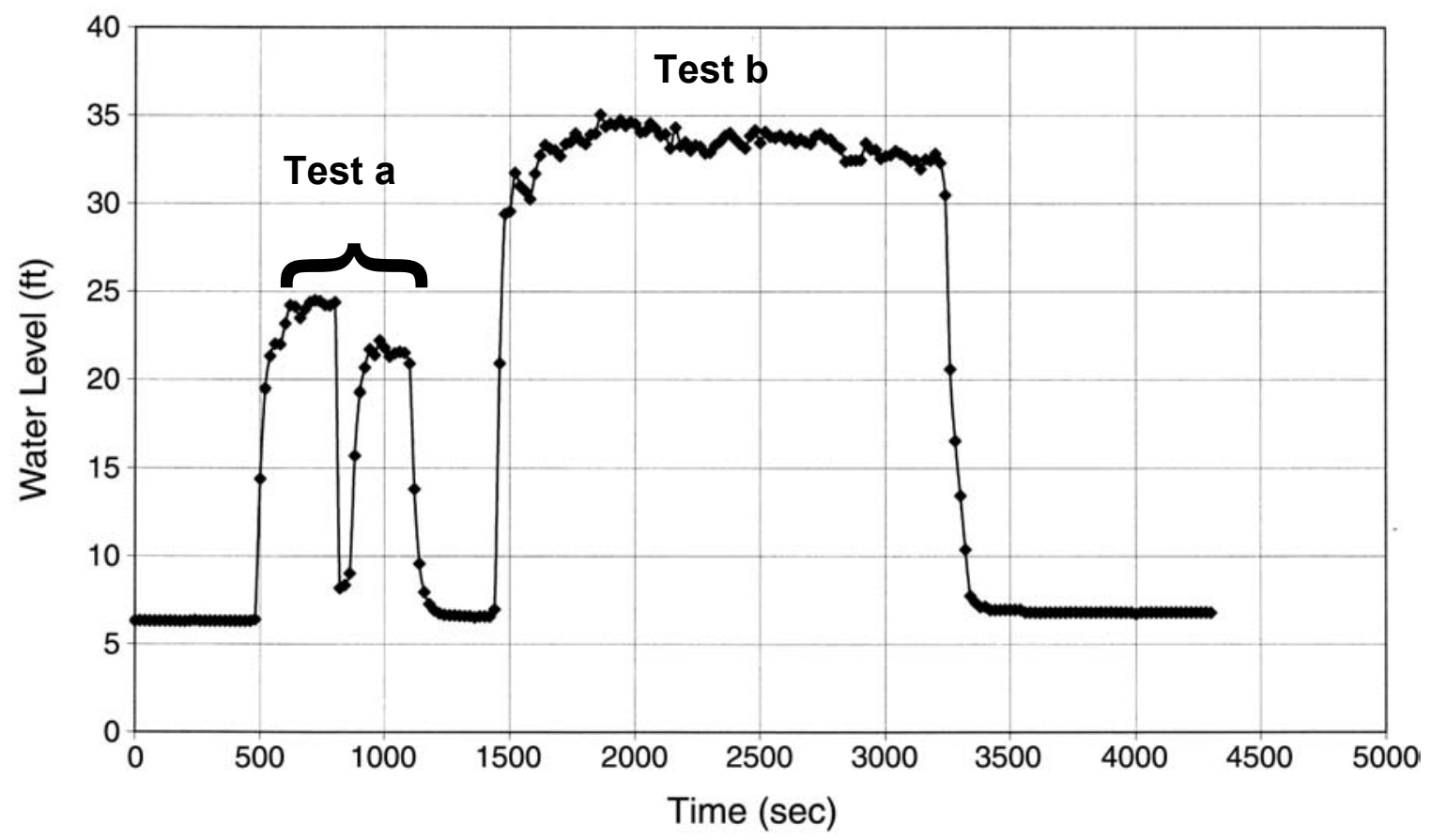

A-2. Recovery Data for Injection Test, R-9i, Screen 1a

\begin{tabular}{|c|c|}
\hline $\mathbf{t}(\mathbf{s e c})$ & $\mathbf{s}(\mathbf{f t})$ \\
\hline 20.00 & 14.32 \\
\hline 40.00 & 7.23 \\
\hline 60.00 & 2.99 \\
\hline 80.00 & 1.38 \\
\hline 100.00 & 0.69 \\
\hline 120.00 & 0.34 \\
\hline 140.00 & 0.16 \\
\hline 160.00 & 0.09 \\
\hline 180.00 & 0.06 \\
\hline 200.00 & 0.06 \\
\hline 220.00 & 0.04 \\
\hline 240.00 & 0.02 \\
\hline
\end{tabular}

A-3. Analysis of Injection Test, R-9i, Screen 1a

Test Date: 10 Apr 00

Aquifer Data

Saturated thickness:

Anisotropy ratio $(\mathrm{Kz} / \mathrm{Kr})$ :

$61.9 \mathrm{ft}$

1

\section{Well Data}

Initial displacement:

$14.9 \mathrm{ft}$

Depth of penetration:

$61.9 \mathrm{ft}$

Casing radius:

$0.0990 \mathrm{ft}$

Borehole radius:

$0.5104 \mathrm{ft}$

Screen length:

$10.4 \mathrm{ft}$

Filter pack porosity:

0.25

\section{Solution}

Analytical method: Bouwer-Rice Conceptual model: unconfined
$\mathrm{K}=$
$4.87 \mathrm{ft} / \mathrm{d}$
$\mathrm{y}_{0}=$
$30.36 \mathrm{ft}$ 


\section{A-4. Plot for Injection Test, R-9i, Screen 2}

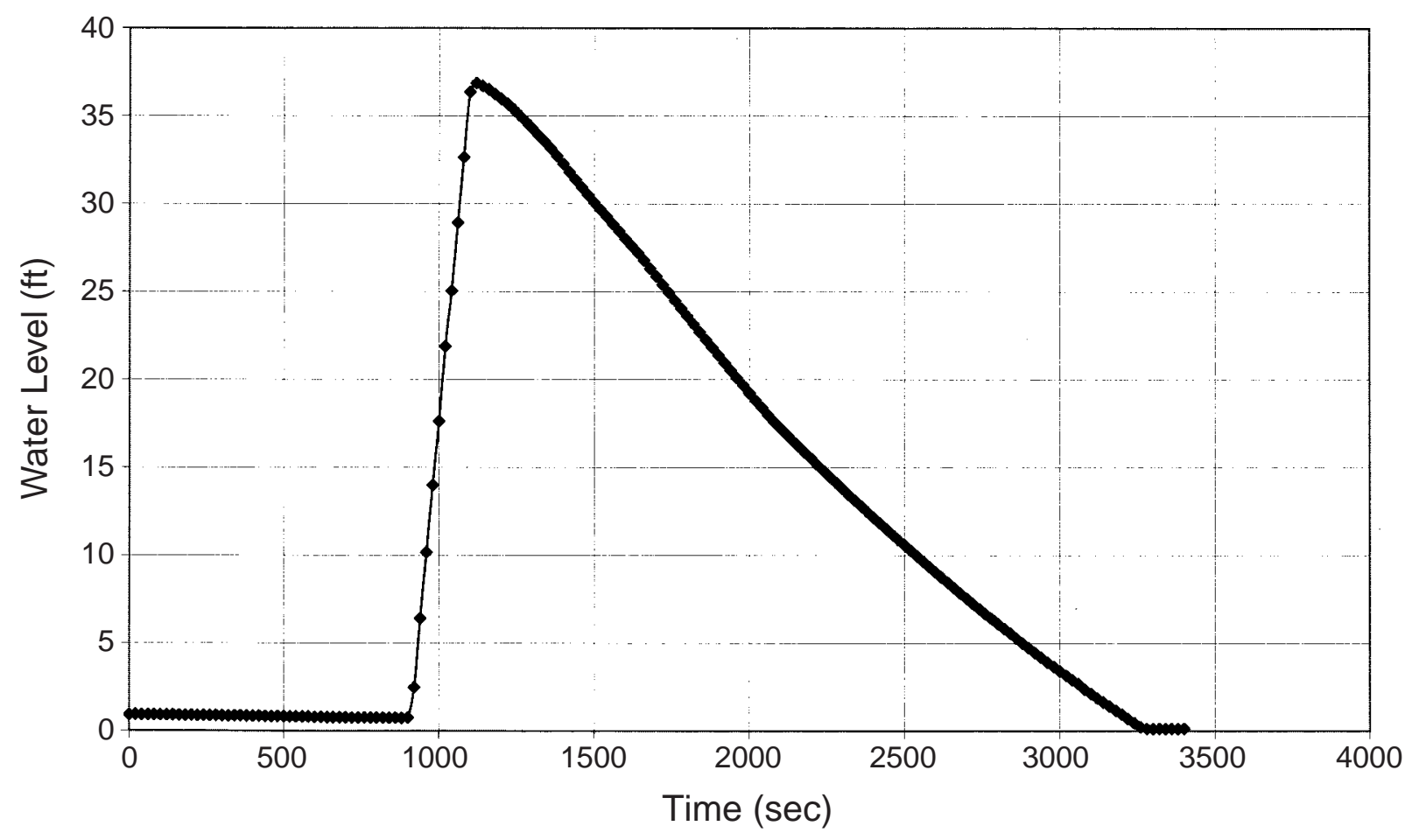

A-5. Recovery Data for Injection Test, R-9i, Screen 2

\begin{tabular}{|l|l|}
\hline $\mathbf{t}(\mathbf{m i n})$ & $\mathbf{s}(\mathbf{f t})$ \\
\hline 0.33 & 144.13 \\
\hline 0.67 & 143.53 \\
\hline 1.00 & 142.73 \\
\hline 1.33 & 141.65 \\
\hline 1.67 & 140.55 \\
\hline 2.00 & 139.46 \\
\hline 2.33 & 138.21 \\
\hline 2.67 & 136.76 \\
\hline 3.00 & 135.34 \\
\hline 3.33 & 133.81 \\
\hline 3.67 & 132.29 \\
\hline 4.00 & 130.78 \\
\hline 4.33 & 129.22 \\
\hline 4.67 & 127.59 \\
\hline 5.00 & 125.70 \\
\hline 5.33 & 123.87 \\
\hline 5.67 & 122.10 \\
\hline 6.00 & 120.37 \\
\hline
\end{tabular}

\begin{tabular}{|l|l|}
\hline $\mathbf{t}(\mathbf{m i n})$ & $\mathbf{s}(\mathbf{f t})$ \\
\hline 6.33 & 118.61 \\
\hline 6.67 & 116.95 \\
\hline 7.00 & 115.28 \\
\hline 7.33 & 113.70 \\
\hline 7.67 & 112.06 \\
\hline 8.00 & 110.38 \\
\hline 8.33 & 108.64 \\
\hline 8.67 & 107.09 \\
\hline 9.00 & 105.57 \\
\hline 9.33 & 103.81 \\
\hline 9.67 & 101.94 \\
\hline 10.00 & 100.10 \\
\hline 10.33 & 98.26 \\
\hline 10.67 & 96.43 \\
\hline 11.00 & 94.62 \\
\hline 11.33 & 92.82 \\
\hline 11.67 & 91.06 \\
\hline 12.00 & 89.28 \\
\hline
\end{tabular}

\begin{tabular}{|c|l|}
\hline $\mathbf{t}(\mathbf{m i n})$ & $\mathbf{s}(\mathbf{f t})$ \\
\hline 12.33 & 87.50 \\
\hline 12.67 & 85.69 \\
\hline 13.00 & 83.95 \\
\hline 13.33 & 82.20 \\
\hline 13.67 & 80.48 \\
\hline 14.00 & 78.74 \\
\hline 14.33 & 77.02 \\
\hline 14.67 & 75.27 \\
\hline 15.00 & 73.59 \\
\hline 15.33 & 71.91 \\
\hline 15.67 & 70.29 \\
\hline 16.00 & 68.65 \\
\hline 16.33 & 67.09 \\
\hline 16.67 & 65.64 \\
\hline 17.00 & 64.22 \\
\hline 17.33 & 62.80 \\
\hline 17.67 & 61.45 \\
\hline 18.00 & 60.03 \\
\hline
\end{tabular}

\begin{tabular}{|c|c|}
\hline $\mathbf{t}(\mathbf{m i n})$ & $\mathbf{s}(\mathbf{f t})$ \\
\hline 18.33 & 58.67 \\
\hline 18.67 & 57.29 \\
\hline 19.00 & 55.92 \\
\hline 19.33 & 54.54 \\
\hline 19.67 & 53.18 \\
\hline 20.00 & 51.83 \\
\hline 20.33 & 50.50 \\
\hline 20.67 & 49.18 \\
\hline 21.00 & 47.93 \\
\hline 21.33 & 46.61 \\
\hline 21.67 & 45.32 \\
\hline 22.00 & 44.06 \\
\hline 22.33 & 42.80 \\
\hline 22.67 & 41.45 \\
\hline 23.00 & 40.25 \\
\hline 23.33 & 39.01 \\
\hline 23.67 & 37.78 \\
\hline 24.00 & 36.52 \\
\hline
\end{tabular}




\begin{tabular}{|l|l|}
\hline $\mathbf{t}$ (min) & $\mathbf{s}$ (ft) \\
\hline 24.33 & 35.30 \\
\hline 24.67 & 34.07 \\
\hline 25.00 & 32.83 \\
\hline 25.33 & 31.63 \\
\hline 25.67 & 30.41 \\
\hline 26.00 & 29.22 \\
\hline 26.33 & 28.05 \\
\hline 26.67 & 26.83 \\
\hline 27.00 & 25.66 \\
\hline
\end{tabular}

\begin{tabular}{|l|l|}
\hline $\mathbf{t}(\mathbf{m i n})$ & $\mathbf{s}(\mathbf{f t})$ \\
\hline 27.33 & 24.48 \\
\hline 27.67 & 23.36 \\
\hline 28.00 & 22.26 \\
\hline 28.33 & 21.13 \\
\hline 28.67 & 20.01 \\
\hline 29.00 & 18.91 \\
\hline 29.33 & 17.82 \\
\hline 29.67 & 16.66 \\
\hline
\end{tabular}

\begin{tabular}{|l|l|}
\hline $\mathbf{t}$ (min) & $\mathbf{s}(\mathbf{f t})$ \\
\hline 30.00 & 15.58 \\
\hline 30.33 & 14.49 \\
\hline 30.67 & 13.42 \\
\hline 31.00 & 12.34 \\
\hline 31.33 & 11.33 \\
\hline 31.67 & 10.33 \\
\hline 32.00 & 9.31 \\
\hline 32.33 & 8.29 \\
\hline
\end{tabular}

\begin{tabular}{|l|l|}
\hline $\mathbf{t}$ (min) & $\mathbf{s}(\mathbf{f t})$ \\
\hline 32.67 & 7.43 \\
\hline 33.00 & 6.17 \\
\hline 33.33 & 5.18 \\
\hline 33.67 & 4.18 \\
\hline 34.00 & 3.22 \\
\hline 34.33 & 2.25 \\
\hline 34.67 & 1.30 \\
\hline 35.00 & 0.40 \\
\hline
\end{tabular}

A-6. Analysis of Injection Test, R-9i, Screen 2

Test Date: 10 Apr 00

\section{Aquifer Data}

Saturated thickness: $\quad 18.8 \mathrm{ft}$

Anisotropy ratio $(\mathrm{Kz} / \mathrm{Kr})$ : $\quad 1$

\section{Well Data}

Initial displacement: $\quad 145 \mathrm{ft}$

Depth of penetration: $\quad 18.8 \mathrm{ft}$

Casing radius: $\quad 0.0990 \mathrm{ft}$

Borehole radius: $\quad 0.5104 \mathrm{ft}$

Screen length: $\quad 10.7 \mathrm{ft}$

Filter pack porosity: $\quad 0.25$

\section{Solution}

Analytical method: Bouwer-Rice

Conceptual model: $\quad$ unconfined

$\mathrm{K}=$

$0.11 \mathrm{ft} / \mathrm{d}$

$\mathrm{y}_{0}=$

$167.9 \mathrm{ft}$ 


\section{A-7. Plot for Pumping Test, R-9i}

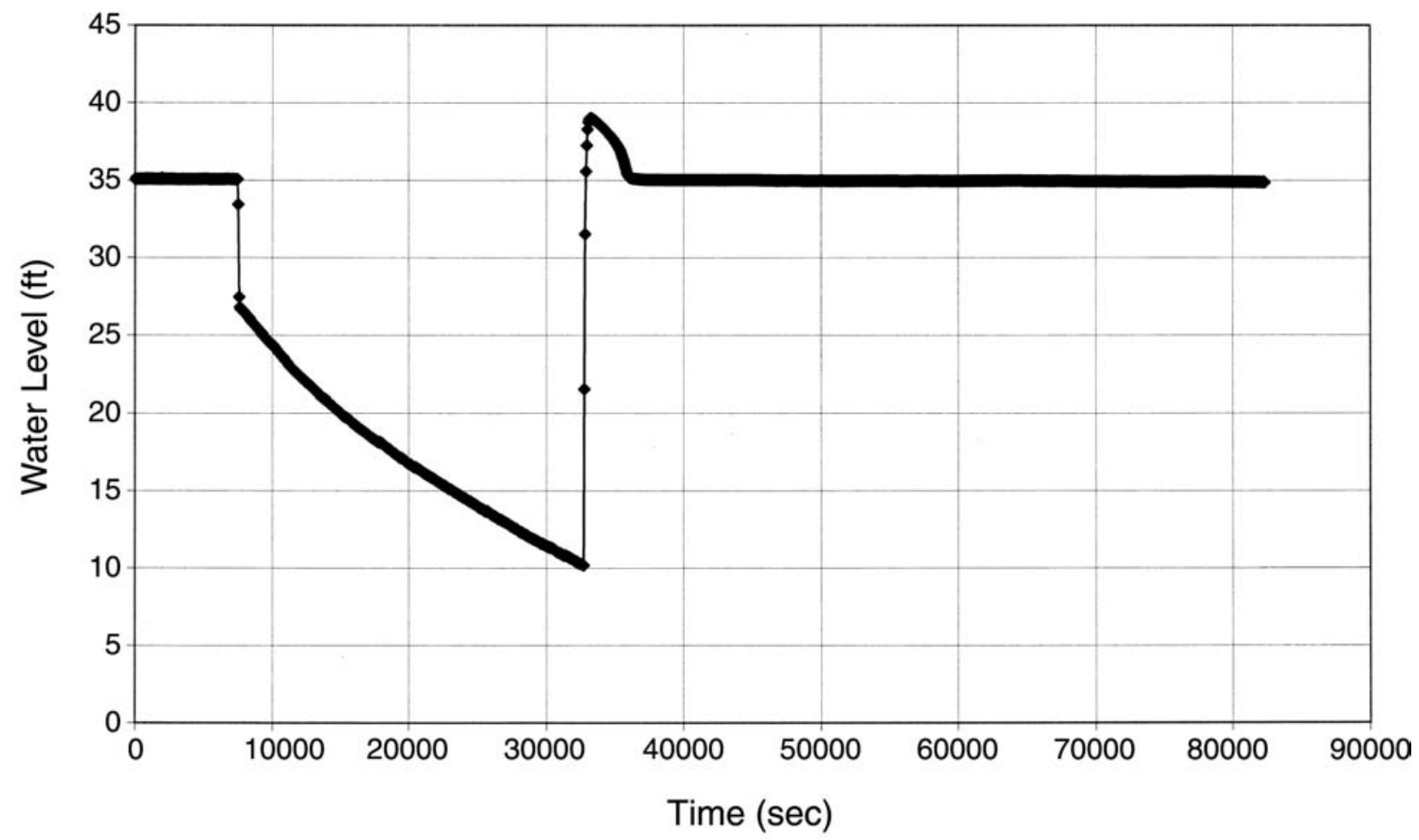

A-8. Drawdown Data for Pumping Test, R-9i

\begin{tabular}{|c|c|}
\hline $\mathbf{t}(\mathbf{m i n})$ & $\mathbf{s}(\mathbf{f t})$ \\
\hline 3 & 8.27 \\
\hline 4 & 8.39 \\
\hline 5 & 8.42 \\
\hline 6 & 8.43 \\
\hline 7 & 8.49 \\
\hline 8 & 8.54 \\
\hline 9 & 8.66 \\
\hline 10 & 8.69 \\
\hline 11 & 8.76 \\
\hline 12 & 8.82 \\
\hline 13 & 8.90 \\
\hline 14 & 8.93 \\
\hline 15 & 9.02 \\
\hline 16 & 9.12 \\
\hline 17 & 9.19 \\
\hline 18 & 9.25 \\
\hline 19 & 9.30 \\
\hline
\end{tabular}

\begin{tabular}{|c|c|}
\hline $\mathbf{t}(\mathbf{m i n})$ & $\mathbf{s}(\mathbf{f t})$ \\
\hline 20 & 9.36 \\
\hline 21 & 9.42 \\
\hline 22 & 9.49 \\
\hline 23 & 9.53 \\
\hline 24 & 9.59 \\
\hline 25 & 9.68 \\
\hline 26 & 9.73 \\
\hline 27 & 9.79 \\
\hline 28 & 9.82 \\
\hline 29 & 9.95 \\
\hline 30 & 9.95 \\
\hline 31 & 10.09 \\
\hline 32 & 10.14 \\
\hline 33 & 10.18 \\
\hline 34 & 10.24 \\
\hline 35 & 10.34 \\
\hline 36 & 10.39 \\
\hline
\end{tabular}

\begin{tabular}{|c|c|}
\hline $\mathbf{t}(\mathbf{m i n})$ & $\mathbf{s}$ (ft) \\
\hline 37 & 10.44 \\
\hline 38 & 10.49 \\
\hline 39 & 10.55 \\
\hline 40 & 10.62 \\
\hline 41 & 10.68 \\
\hline 42 & 10.65 \\
\hline 43 & 10.68 \\
\hline 44 & 10.75 \\
\hline 45 & 10.87 \\
\hline 46 & 10.89 \\
\hline 47 & 10.97 \\
\hline 48 & 11.02 \\
\hline 49 & 11.10 \\
\hline 50 & 11.21 \\
\hline 51 & 11.22 \\
\hline 52 & 11.28 \\
\hline 53 & 11.35 \\
\hline
\end{tabular}

\begin{tabular}{|c|c|}
\hline $\mathbf{t}(\mathbf{m i n})$ & $\mathbf{s}(\mathbf{f t})$ \\
\hline 54 & 11.41 \\
\hline 55 & 11.50 \\
\hline 56 & 11.51 \\
\hline 57 & 11.57 \\
\hline 58 & 11.70 \\
\hline 59 & 11.75 \\
\hline 60 & 11.80 \\
\hline 61 & 11.85 \\
\hline 62 & 11.95 \\
\hline 63 & 12.04 \\
\hline 64 & 12.08 \\
\hline 65 & 12.17 \\
\hline 66 & 12.20 \\
\hline 67 & 12.26 \\
\hline 68 & 12.28 \\
\hline 69 & 12.37 \\
\hline 70 & 12.44 \\
\hline
\end{tabular}




\begin{tabular}{|c|c|}
\hline$t(\min )$ & $s$ (ft) \\
\hline 71 & 12.44 \\
\hline 72 & 12.50 \\
\hline 73 & 12.53 \\
\hline 74 & 12.61 \\
\hline 75 & 12.66 \\
\hline 76 & 12.73 \\
\hline 77 & 12.76 \\
\hline 78 & 12.83 \\
\hline 79 & 12.87 \\
\hline 80 & 12.90 \\
\hline 81 & 12.96 \\
\hline 82 & 12.99 \\
\hline 83 & 13.04 \\
\hline 84 & 13.13 \\
\hline 85 & 13.14 \\
\hline 86 & 13.22 \\
\hline 87 & 13.23 \\
\hline 88 & 13.29 \\
\hline 89 & 13.32 \\
\hline 90 & 13.37 \\
\hline 91 & 13.44 \\
\hline 92 & 13.49 \\
\hline 93 & 13.52 \\
\hline 94 & 13.62 \\
\hline 95 & 13.63 \\
\hline 96 & 13.72 \\
\hline 97 & 13.75 \\
\hline 98 & 13.83 \\
\hline 99 & 13.85 \\
\hline 100 & 13.87 \\
\hline 101 & 13.95 \\
\hline 102 & 14.02 \\
\hline 103 & 14.03 \\
\hline 104 & 14.09 \\
\hline 105 & 14.13 \\
\hline 106 & 14.18 \\
\hline 107 & 14.20 \\
\hline 108 & 14.23 \\
\hline 109 & 14.30 \\
\hline 110 & 14.32 \\
\hline 111 & 14.39 \\
\hline
\end{tabular}

\begin{tabular}{|c|c|}
\hline $\mathbf{t}(\mathbf{m i n})$ & $\mathbf{s}(\mathbf{f t})$ \\
\hline $\mathrm{n} 112$ & 14.45 \\
\hline 113 & 14.49 \\
\hline 114 & 14.52 \\
\hline 115 & 14.58 \\
\hline 116 & 14.59 \\
\hline 117 & 14.66 \\
\hline 118 & 14.69 \\
\hline 119 & 14.75 \\
\hline 120 & 14.81 \\
\hline 121 & 14.83 \\
\hline 122 & 14.89 \\
\hline 123 & 14.92 \\
\hline 124 & 14.98 \\
\hline 125 & 15.01 \\
\hline 126 & 15.06 \\
\hline 127 & 15.14 \\
\hline 128 & 15.15 \\
\hline 129 & 15.24 \\
\hline 130 & 15.28 \\
\hline 131 & 15.29 \\
\hline 132 & 15.32 \\
\hline 133 & 15.36 \\
\hline 134 & 15.38 \\
\hline 135 & 15.41 \\
\hline 136 & 15.46 \\
\hline 137 & 15.51 \\
\hline 138 & 15.55 \\
\hline 139 & 15.62 \\
\hline 140 & 15.68 \\
\hline 141 & 15.74 \\
\hline 142 & 15.77 \\
\hline 143 & 15.79 \\
\hline 144 & 15.82 \\
\hline 145 & 15.91 \\
\hline 146 & 15.92 \\
\hline 147 & 15.95 \\
\hline 148 & 16.02 \\
\hline 149 & 16.05 \\
\hline 150 & 16.10 \\
\hline 151 & 16.12 \\
\hline 152 & 16.17 \\
\hline & \\
\hline 139
\end{tabular}

\begin{tabular}{|c|c|}
\hline $\mathbf{t}(\mathbf{m i n})$ & $\mathbf{s}(\mathbf{f t})$ \\
\hline 153 & 16.20 \\
\hline 154 & 16.24 \\
\hline 155 & 16.28 \\
\hline 156 & 16.32 \\
\hline 157 & 16.35 \\
\hline 158 & 16.40 \\
\hline 159 & 16.44 \\
\hline 160 & 16.48 \\
\hline 161 & 16.53 \\
\hline 162 & 16.58 \\
\hline 163 & 16.61 \\
\hline 164 & 16.65 \\
\hline 165 & 16.70 \\
\hline 166 & 16.73 \\
\hline 167 & 16.77 \\
\hline 168 & 16.80 \\
\hline 169 & 16.81 \\
\hline 170 & 16.87 \\
\hline 171 & 16.91 \\
\hline 172 & 16.95 \\
\hline 173 & 16.94 \\
\hline 174 & 16.93 \\
\hline 175 & 16.95 \\
\hline 176 & 17.03 \\
\hline 177 & 17.03 \\
\hline 178 & 17.07 \\
\hline 179 & 17.13 \\
\hline 180 & 17.18 \\
\hline 181 & 17.23 \\
\hline 182 & 17.28 \\
\hline 183 & 17.31 \\
\hline 184 & 17.34 \\
\hline 185 & 17.38 \\
\hline 186 & 17.41 \\
\hline 187 & 17.46 \\
\hline 188 & 17.50 \\
\hline 189 & 17.56 \\
\hline 190 & 17.59 \\
\hline 191 & 17.64 \\
\hline 192 & 17.69 \\
\hline 193 & 17.70 \\
\hline & \\
\hline
\end{tabular}

\begin{tabular}{|c|c|}
\hline $\mathbf{t}$ (min) & $\mathbf{s}$ (ft) \\
\hline 194 & 17.74 \\
\hline 195 & 17.79 \\
\hline 196 & 17.86 \\
\hline 197 & 17.89 \\
\hline 198 & 17.94 \\
\hline 199 & 17.93 \\
\hline 200 & 17.94 \\
\hline 201 & 18.00 \\
\hline 202 & 18.03 \\
\hline 203 & 18.04 \\
\hline 204 & 18.10 \\
\hline 205 & 18.13 \\
\hline 206 & 18.22 \\
\hline 207 & 18.24 \\
\hline 208 & 18.30 \\
\hline 209 & 18.33 \\
\hline 210 & 18.34 \\
\hline 211 & 18.39 \\
\hline 212 & 18.40 \\
\hline 213 & 18.46 \\
\hline 214 & 18.49 \\
\hline 215 & 18.53 \\
\hline 216 & 18.57 \\
\hline 217 & 18.57 \\
\hline 218 & 18.56 \\
\hline 219 & 18.62 \\
\hline 220 & 18.65 \\
\hline 221 & 18.69 \\
\hline 222 & 18.72 \\
\hline 223 & 18.73 \\
\hline 224 & 18.77 \\
\hline 225 & 18.82 \\
\hline 226 & 18.87 \\
\hline 227 & 18.92 \\
\hline 228 & 18.95 \\
\hline 229 & 18.97 \\
\hline 230 & 19.02 \\
\hline 231 & 19.03 \\
\hline 232 & 19.07 \\
\hline 233 & 19.09 \\
\hline 234 & 19.15 \\
\hline & \\
\hline
\end{tabular}




\begin{tabular}{|c|c|c|c|c|c|c|c|}
\hline$t(\min )$ & $s(f t)$ & $t(\min )$ & $s(f t)$ & $t(\min )$ & $s(f t)$ & $t(\min )$ & $s(f t)$ \\
\hline 235 & 19.18 & 276 & 20.55 & 317 & 21.88 & 358 & 23.16 \\
\hline 236 & 19.20 & 277 & 20.56 & 318 & 21.90 & 359 & 23.19 \\
\hline 237 & 19.26 & 278 & 20.59 & 319 & 21.93 & 360 & 23.21 \\
\hline 238 & 19.26 & 279 & 20.62 & 320 & 21.93 & 361 & 23.23 \\
\hline 239 & 19.28 & 280 & 20.67 & 321 & 21.97 & 362 & 23.26 \\
\hline 240 & 19.33 & 281 & 20.71 & 322 & 22.01 & 363 & 23.29 \\
\hline 241 & 19.35 & 282 & 20.74 & 323 & 22.01 & 364 & 23.30 \\
\hline 242 & 19.39 & 283 & 20.78 & 324 & 22.05 & 365 & 23.34 \\
\hline 243 & 19.45 & 284 & 20.77 & 325 & 22.08 & 366 & 23.37 \\
\hline 244 & 19.48 & 285 & 20.81 & 326 & 22.13 & 367 & 23.42 \\
\hline 245 & 19.52 & 286 & 20.87 & 327 & 22.14 & 368 & 23.44 \\
\hline 246 & 19.55 & 287 & 20.89 & 328 & 22.18 & 369 & 23.49 \\
\hline 247 & 19.59 & 288 & 20.91 & 329 & 22.21 & 370 & 23.50 \\
\hline 248 & 19.61 & 289 & 20.95 & 330 & 22.24 & 371 & 23.52 \\
\hline 249 & 19.65 & 290 & 20.98 & 331 & 22.30 & 372 & 23.52 \\
\hline 250 & 19.68 & 291 & 21.04 & 332 & 22.31 & 373 & 23.57 \\
\hline 251 & 19.71 & 292 & 21.05 & 333 & 22.37 & 374 & 23.59 \\
\hline 252 & 19.78 & 293 & 21.09 & 334 & 22.38 & 375 & 23.63 \\
\hline 253 & 19.75 & 294 & 21.17 & 335 & 22.43 & 376 & 23.66 \\
\hline 254 & 19.82 & 295 & 21.20 & 336 & 22.46 & 377 & 23.67 \\
\hline 255 & 19.85 & 296 & 21.20 & 337 & 22.51 & 378 & 23.70 \\
\hline 256 & 19.88 & 297 & 21.24 & 338 & 22.51 & 379 & 23.72 \\
\hline 257 & 19.93 & 298 & 21.27 & 339 & 22.54 & 380 & 23.76 \\
\hline 258 & 19.96 & 299 & 21.31 & 340 & 22.57 & 381 & 23.76 \\
\hline 259 & 19.98 & 300 & 21.31 & 341 & 22.60 & 382 & 23.76 \\
\hline 260 & 19.99 & 301 & 21.37 & 342 & 22.64 & 383 & 23.80 \\
\hline 261 & 20.03 & 302 & 21.42 & 343 & 22.73 & 384 & 23.82 \\
\hline 262 & 20.06 & 303 & 21.42 & 344 & 22.74 & 385 & 23.87 \\
\hline 263 & 20.12 & 304 & 21.40 & 345 & 22.76 & 386 & 23.92 \\
\hline 264 & 20.15 & 305 & 21.41 & 346 & 22.76 & 387 & 23.95 \\
\hline 265 & 20.19 & 306 & 21.48 & 347 & 22.83 & 388 & 24.02 \\
\hline 266 & 20.21 & 307 & 21.52 & 348 & 22.84 & 389 & 24.03 \\
\hline 267 & 20.24 & 308 & 21.54 & 349 & 22.89 & 390 & 24.06 \\
\hline 268 & 20.28 & 309 & 21.61 & 350 & 22.90 & 391 & 24.10 \\
\hline 269 & 20.31 & 310 & 21.64 & 351 & 22.96 & 392 & 24.12 \\
\hline 270 & 20.36 & 311 & 21.67 & 352 & 22.96 & 393 & 24.13 \\
\hline 271 & 20.39 & 312 & 21.71 & 353 & 22.99 & 394 & 24.16 \\
\hline 272 & 20.38 & 313 & 21.71 & 354 & 23.04 & 395 & 24.19 \\
\hline 273 & 20.44 & 314 & 21.75 & 355 & 23.07 & 396 & 24.25 \\
\hline 274 & 20.48 & 315 & 21.78 & 356 & 23.10 & 397 & 24.27 \\
\hline 275 & 20.52 & 316 & 21.83 & 357 & 23.13 & 398 & 24.27 \\
\hline
\end{tabular}




\begin{tabular}{|c|c|}
\hline $\mathbf{t}$ (min) & $\mathbf{s}$ (ft) \\
\hline 399 & 24.25 \\
\hline 400 & 24.29 \\
\hline 401 & 24.32 \\
\hline 402 & 24.35 \\
\hline 403 & 24.36 \\
\hline 404 & 24.42 \\
\hline
\end{tabular}

\begin{tabular}{|c|c|}
\hline $\mathbf{t}$ (min) & $\mathbf{s}$ (ft) \\
\hline 405 & 24.42 \\
\hline 406 & 24.46 \\
\hline 407 & 24.48 \\
\hline 408 & 24.52 \\
\hline 409 & 24.56 \\
\hline 410 & 24.59 \\
\hline
\end{tabular}

\begin{tabular}{|c|c|}
\hline $\mathbf{t}$ (min) & $\mathbf{s}(\mathrm{ft})$ \\
\hline 411 & 24.63 \\
\hline 412 & 24.65 \\
\hline 413 & 24.66 \\
\hline 414 & 24.73 \\
\hline 415 & 24.76 \\
\hline 416 & 24.76 \\
\hline
\end{tabular}

\begin{tabular}{|c|c|}
\hline $\mathbf{t}$ (min) & $\mathbf{s}$ (ft) \\
\hline 417 & 24.79 \\
\hline 418 & 24.80 \\
\hline 419 & 24.83 \\
\hline 420 & 24.86 \\
\hline 421 & 24.89 \\
\hline
\end{tabular}

A-9. Analysis of Pumping Test, R-9i (Theis)

Test date: 11 Apr 00

\section{Aquifer Data}

Saturated thickness:

$61.9 \mathrm{ft}$

Anisotropy ratio $(\mathrm{Kz} / \mathrm{Kr})$ :

\section{Well Data}

Pumping well:

$X=$

R-9iP

$\mathrm{Y}=$

$0 \mathrm{ft}$

$0 \mathrm{ft}$

\section{Solution}

Analytical method:

Conceptual model:

$\mathrm{T}=$

$S=$

Theis

unconfined $49.4 \mathrm{ft}^{2} / \mathrm{d}$

0.58

A-10. Analysis of Pumping Test, R-9i

(Neuman, early-time data)

Test Date: 11 Apr 00

Aquifer Data

Saturated thickness:

$61.9 \mathrm{ft}$

Anisotropy ratio $(\mathrm{Kz} / \mathrm{Kr})$ :

\section{Well Data}

Pumping well: $R-9 i$

$$
\begin{array}{ll}
X= & 0 \mathrm{ft} \\
Y= & 0 \mathrm{ft}
\end{array}
$$

Observation well: $\mathrm{R}-9 \mathrm{i}$

$$
\begin{array}{lr}
X= & 1.0 \mathrm{ft} \\
Y= & 0 \mathrm{ft}
\end{array}
$$

\section{Solution}

Analytical method: Neuman

Conceptual model: unconfined

$\mathrm{T}=$

$\mathrm{S}=$

Sy $=$

$B=$
$315.3 \mathrm{ft}^{2} / \mathrm{d}$

$6.0 \times 10^{-3}$

0.038

0.004
A-11. Analysis of Pumping Test, R-9i

(Neuman, late-time data)

Test Date: 11 Apr 00

Aquifer Data

Saturated thickness:

$61.9 \mathrm{ft}$

Anisotropy ratio $(\mathrm{Kz} / \mathrm{Kr})$ :

Well Data

Pumping well: $\mathrm{R}-9 \mathrm{i}$

$$
\begin{array}{ll}
X= & 0 \mathrm{ft} \\
Y= & 0 \mathrm{ft}
\end{array}
$$

Observation well: R-9i

$$
\begin{aligned}
& X= \\
& Y=
\end{aligned}
$$

$0 \mathrm{ft}$

\section{Solution}

Analytical method: Neuman Conceptual model: unconfined

$\mathrm{T}=$

$S=$

$13.2 \mathrm{ft}^{2} / \mathrm{d}$

Sy $=$

0.009

$B=$

3.16

1.5 



\section{Appendix B}

\section{Well R-13 Test Data}

Contents

B-1 Plot for Pumping Test

B-2 Recovery Data for Pumping Test

B-3 Analysis of Pumping Test 

B-1. Plot for Pumping Test, R-13b

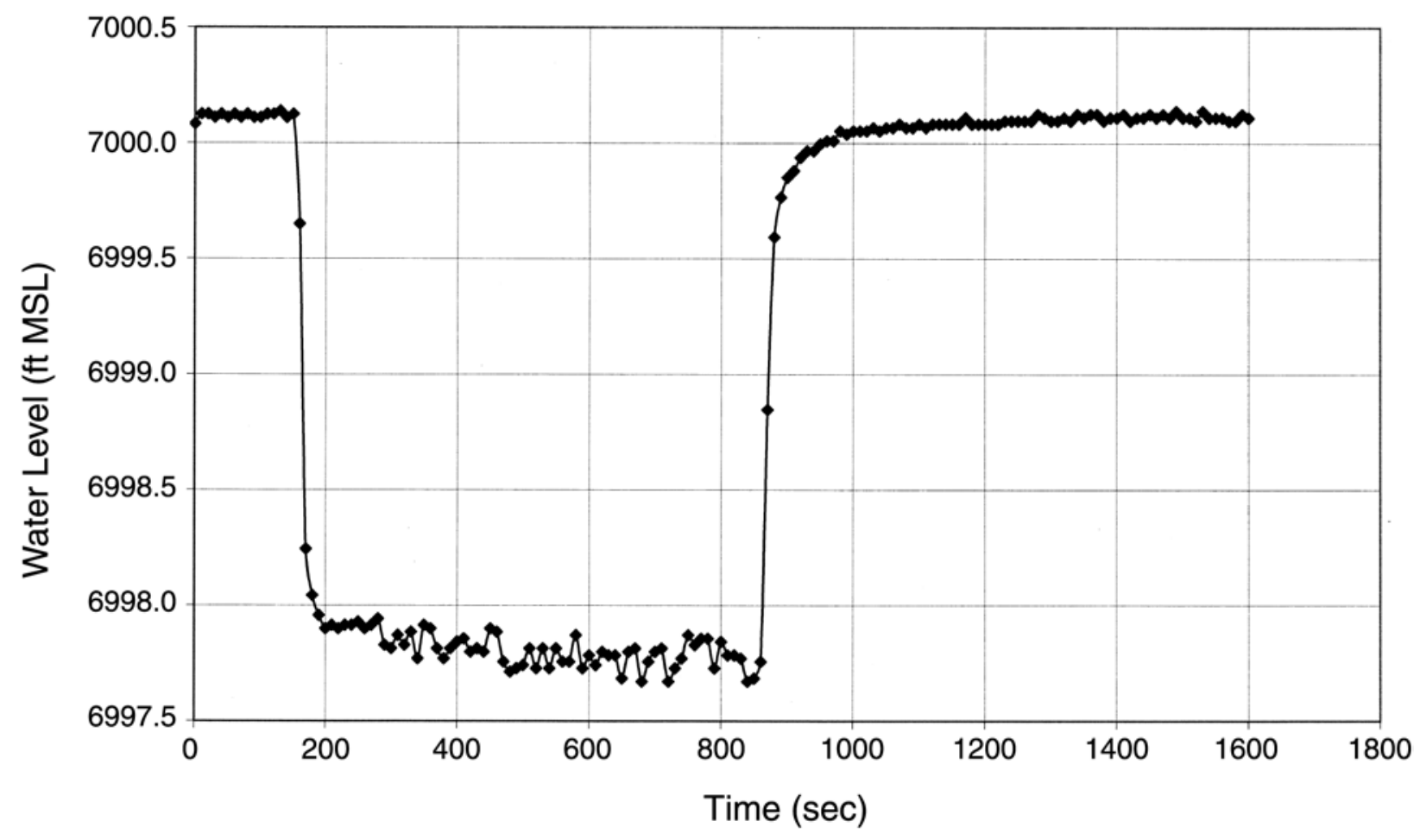

B-2. Recovery Data for Pumping Test, R-13b

\begin{tabular}{|c|c|c|c|}
\hline$t(\sec )$ & $s(\mathrm{ft})$ & $t(\sec )$ & $\mathrm{s}(\mathrm{ft})$ \\
\hline 10.000 & 1.069 & 200.000 & 2.289 \\
\hline 20.000 & 1.816 & 210.000 & 2.304 \\
\hline 30.000 & 1.988 & 220.000 & 2.289 \\
\hline 40.000 & 2.074 & 230.000 & 2.289 \\
\hline 50.000 & 2.103 & 240.000 & 2.304 \\
\hline 60.000 & 2.160 & 250.000 & 2.289 \\
\hline 70.000 & 2.189 & 260.000 & 2.304 \\
\hline 80.000 & 2.189 & 270.000 & 2.304 \\
\hline 90.000 & 2.218 & 280.000 & 2.304 \\
\hline 100.000 & 2.232 & 290.000 & 2.304 \\
\hline 110.000 & 2.232 & 300.000 & 2.304 \\
\hline 120.000 & 2.275 & 310.000 & 2.332 \\
\hline 130.000 & 2.261 & 320.000 & 2.304 \\
\hline 140.000 & 2.275 & 330.000 & 2.304 \\
\hline 150.000 & 2.275 & 370.000 & 2.318 \\
\hline 190.000 & 2.289 & 380.000 & 2.318 \\
\hline
\end{tabular}

\begin{tabular}{|c|c|}
\hline $\mathbf{t}(\mathbf{s e c})$ & $\mathbf{s}$ (ft) \\
\hline 390.000 & 2.318 \\
\hline 400.000 & 2.318 \\
\hline 410.000 & 2.318 \\
\hline 420.000 & 2.347 \\
\hline 430.000 & 2.332 \\
\hline 440.000 & 2.318 \\
\hline 450.000 & 2.318 \\
\hline 460.000 & 2.332 \\
\hline 470.000 & 2.318 \\
\hline 480.000 & 2.347 \\
\hline 490.000 & 2.332 \\
\hline 500.000 & 2.347 \\
\hline 510.000 & 2.347 \\
\hline 550.000 & 2.347 \\
\hline 560.000 & 2.318 \\
\hline
\end{tabular}

\begin{tabular}{|c|c|}
\hline $\mathbf{t}(\mathbf{s e c})$ & $\mathbf{s}(\mathbf{f t})$ \\
\hline 570.000 & 2.332 \\
\hline 580.000 & 2.332 \\
\hline 590.000 & 2.347 \\
\hline 600.000 & 2.332 \\
\hline 610.000 & 2.347 \\
\hline 620.000 & 2.332 \\
\hline 630.000 & 2.361 \\
\hline 640.000 & 2.332 \\
\hline 650.000 & 2.332 \\
\hline 660.000 & 2.318 \\
\hline 670.000 & 2.361 \\
\hline 680.000 & 2.332 \\
\hline 690.000 & 2.332 \\
\hline 730.000 & 2.347 \\
\hline 740.000 & 2.332 \\
\hline
\end{tabular}


B-3. Analysis of Pumping Test, R-13b

Test Date: 27 July 00

Aquifer Data

Saturated thickness:

$87.5 \mathrm{ft}$

Anisotropy ratio $(\mathrm{Kz} / \mathrm{Kr})$ :

1

Well Data

Pumping well: $\quad \mathrm{R}-13$

$X=\quad 0 \mathrm{ft}$

$Y=\quad 0 \mathrm{ft}$

Observation well: $\quad$ R-13

$\begin{array}{ll}X= & 1.0 \mathrm{ft}\end{array}$

$Y=\quad 0 \mathrm{ft}$

\section{Solution}

Analytical method: Hantush-Jacob

Conceptual model: leaky confined

Pumping:

$$
\begin{aligned}
& T=1293.3 \mathrm{ft}^{2} / \mathrm{d} \\
& \mathrm{S}=1.43 \times 10^{-3} \\
& \mathrm{r} / \mathrm{B}=0.0166 \\
& \mathrm{~b}=87.5
\end{aligned}
$$

Recovery:

$$
\begin{aligned}
& T=829.7 \mathrm{ft}^{2} / \mathrm{d} \\
& \mathrm{S}=8.8 \times 10^{-3} \\
& \mathrm{R} / \mathrm{B}=0.10 \\
& \mathrm{~b}=87.5
\end{aligned}
$$

Note: Drawdown and recovery data for the pumping test at $R-13$ appear almost identical, except the drawdown data are more "noisy." As only data for which an analytical plot appears in the text are included in the appendix, drawdown data for $R-13$ are not presented. 


\section{Appendix C}

\section{Well R-19 Test Data}

Contents

C-1 Plot for Injection Test, Screen 6

C-2 Recovery Data for Injection Test, Screen 6

C-3 Analysis of Injection Test, Screen 6

C-4 Plot for Injection Test, Screen 7

C-5 Recovery Data for Injection Test, Screen 7

C-6 Analysis of Injection Test, Screen 7 



\section{C-1. Plot for Injection Test, R-19, Screen 6}

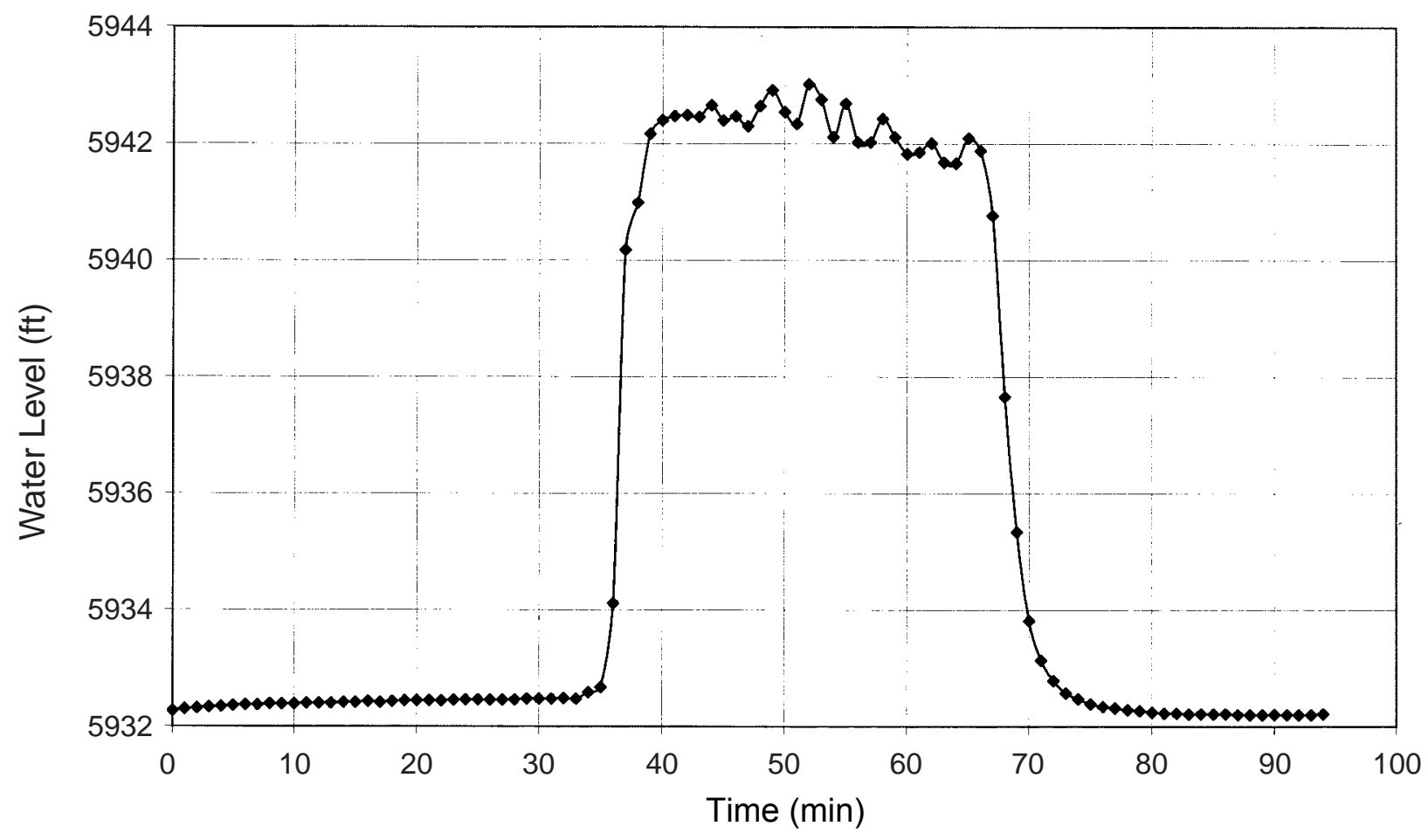

C-2. Recovery Data for Injection Test, R-19, Screen 6

\begin{tabular}{|c|c|}
\hline $\mathbf{t}(\mathbf{m i n})$ & $\mathbf{s}(\mathbf{f t})$ \\
\hline 1 & 8.564 \\
\hline 2 & 5.452 \\
\hline 3 & 3.133 \\
\hline 4 & 1.607 \\
\hline 5 & 0.930 \\
\hline 6 & 0.584 \\
\hline 7 & 0.368 \\
\hline 8 & 0.267 \\
\hline 9 & 0.181 \\
\hline 10 & 0.138 \\
\hline 11 & 0.109 \\
\hline 12 & 0.080 \\
\hline 13 & 0.066 \\
\hline 14 & 0.037 \\
\hline 15 & 0.022 \\
\hline 16 & 0.022 \\
\hline
\end{tabular}

C-3. Analysis of Injection Test, R-19, Screen 6

Test Date: 26 July 00

Aquifer Data

Saturated thickness:

Anisotropy ratio $(\mathrm{Kz} / \mathrm{Kr})$ :

$103.9 \mathrm{ft}$

1

\section{Well Data}

Initial displacement:

$9.9 \mathrm{ft}$

Depth of penetration:

Casing radius:

$58.0 \mathrm{ft}$

Borehole radius:

Screen length:

$0.0990 \mathrm{ft}$

$0.5104 \mathrm{ft}$

$7.1 \mathrm{ft}$

Filter pack porosity:

0.25

\section{Solution}

Analytical method: Bouwer-Rice Conceptual model: confined

$\mathrm{K}=$

$1.10 \mathrm{ft} / \mathrm{d}$

$\mathrm{y}_{0}=$

$14.62 \mathrm{ft}$ 


\section{C-4. Plot of Injection Test, R-19, Screen 7}

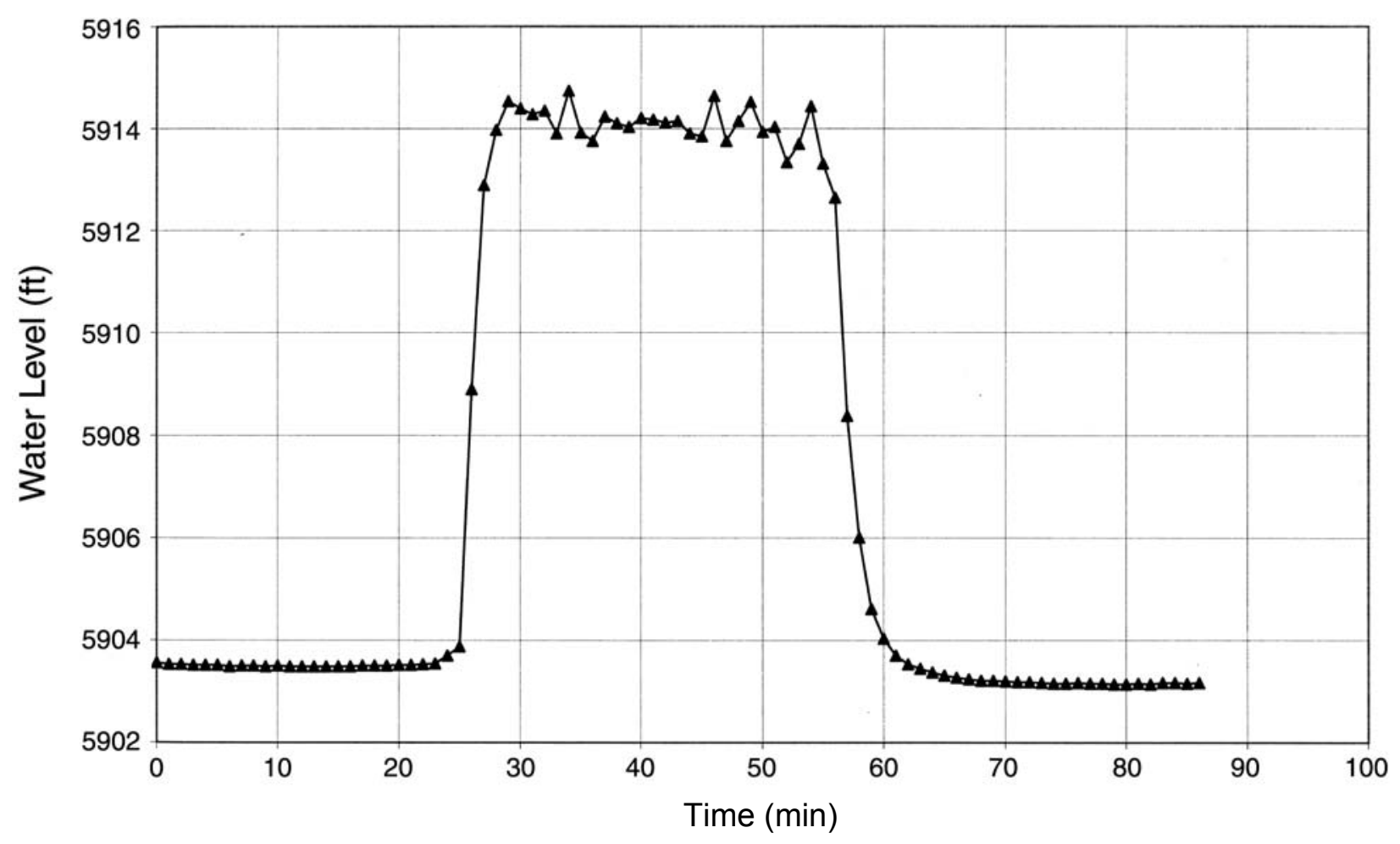

\section{C-5. Recovery Data for Injection Test, R-19,} Screen 7

\begin{tabular}{|c|c|}
\hline $\mathbf{t}(\mathbf{m i n})$ & $\mathbf{s}(\mathbf{f t})$ \\
\hline 1 & 10.155 \\
\hline 2 & 9.492 \\
\hline 3 & 5.228 \\
\hline 4 & 2.852 \\
\hline 5 & 1.454 \\
\hline 6 & 0.878 \\
\hline 7 & 0.547 \\
\hline 8 & 0.374 \\
\hline 9 & 0.288 \\
\hline 10 & 0.216 \\
\hline 11 & 0.158 \\
\hline 12 & 0.115 \\
\hline 13 & 0.086 \\
\hline 14 & 0.057 \\
\hline
\end{tabular}

\section{C-6. Analysis of Injection Test, R-19, Screen 7}

Test Date: 26 July 00

Aquifer Data

Saturated thickness:

Anisotropy ratio $(\mathrm{Kz} / \mathrm{Kr})$ :

$20.2 \mathrm{ft}$

1

Well Data

Initial displacement:

$10.9 \mathrm{ft}$

Depth of penetration:

Casing radius:

$11.3 \mathrm{ft}$

Borehole radius:

$0.0990 \mathrm{ft}$

Screen length:

$0.5104 \mathrm{ft}$

$7.1 \mathrm{ft}$

Filter pack porosity:

0.25

\section{Solution}

Analytical method: Bouwer-Rice Conceptual model: confined

$\mathrm{K}=$

$0.73 \mathrm{ft} / \mathrm{d}$

$\mathrm{y}_{0}=$

$12.95 \mathrm{ft}$ 


\section{Appendix D}

\section{Well R-22 Test Data}

Contents

D-1 Plot for Injection Test, Screen 2

D-2 Recovery Data for Injection Test, Screen 2

D-3 Analysis of Injection Test, Screen 2

D-4 Plot for Injection Test, Screen 3

D-5 Recovery Data for Injection Test, Screen 3

D-6 Analysis of Injection Test, Screen 3

D-7 Plot for Injection Test, Screen 4a

D-8 Recovery Data for Injection Test, Screen 4a

D-9 Analysis of Injection Test, Screen 4a

D-10 Plot for Injection Test, Screen 5

D-11 Recovery Data for Injection Test, Screen 5

D-12 Analysis of Injection Test, Screen 5 



\section{D-1. Plot for Injection Test, R-22, Screen 2}

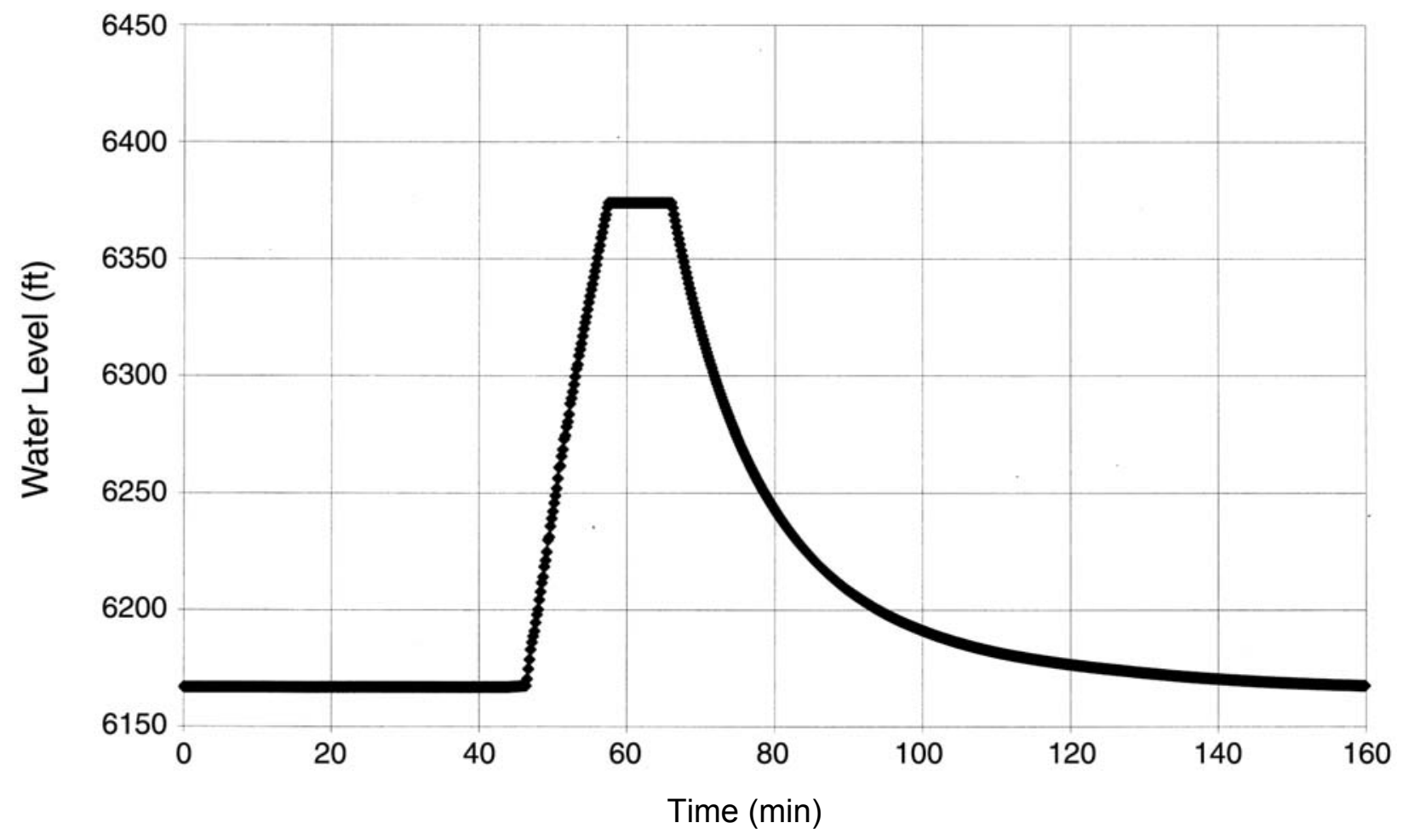

D-2. Recovery Data for Injection Test, R-22, Screen 2

\begin{tabular}{|c|c|}
\hline $\mathbf{t}$ (min) & $\mathbf{s}$ (ft) \\
\hline 0.000 & 276.862 \\
\hline 0.167 & 275.004 \\
\hline 0.333 & 271.576 \\
\hline 0.500 & 268.182 \\
\hline 0.667 & 264.823 \\
\hline 0.833 & 261.496 \\
\hline 1.000 & 258.203 \\
\hline 1.167 & 254.945 \\
\hline 1.333 & 251.718 \\
\hline 1.500 & 248.525 \\
\hline 1.667 & 245.368 \\
\hline 1.833 & 242.242 \\
\hline 2.000 & 239.150 \\
\hline 2.167 & 236.093 \\
\hline 2.333 & 233.067 \\
\hline 2.500 & 230.075 \\
\hline 2.667 & 227.119 \\
\hline 11.333 & 118.051 \\
\hline 11.500 & 116.679 \\
\hline
\end{tabular}

\begin{tabular}{|c|c|}
\hline $\mathbf{t}(\mathbf{m i n})$ & $\mathbf{s}(\mathbf{f t})$ \\
\hline 2.833 & 224.194 \\
\hline 3.000 & 221.303 \\
\hline 3.167 & 218.447 \\
\hline 3.333 & 215.623 \\
\hline 3.500 & 212.832 \\
\hline 3.667 & 210.076 \\
\hline 3.833 & 207.353 \\
\hline 4.000 & 204.891 \\
\hline 4.167 & 202.114 \\
\hline 4.333 & 199.438 \\
\hline 4.500 & 196.806 \\
\hline 4.667 & 194.203 \\
\hline 4.833 & 191.643 \\
\hline 5.000 & 189.156 \\
\hline 5.167 & 186.712 \\
\hline 5.333 & 184.254 \\
\hline 5.500 & 181.840 \\
\hline 18.167 & 74.248 \\
\hline 18.333 & 73.454 \\
\hline
\end{tabular}

\begin{tabular}{|c|c|}
\hline $\mathbf{t}(\mathbf{m i n})$ & $\mathbf{s}(\mathbf{f t})$ \\
\hline 5.667 & 179.527 \\
\hline 5.833 & 177.214 \\
\hline 6.000 & 174.944 \\
\hline 6.167 & 172.660 \\
\hline 6.333 & 170.477 \\
\hline 6.500 & 168.309 \\
\hline 6.667 & 166.199 \\
\hline 6.833 & 164.046 \\
\hline 7.000 & 161.994 \\
\hline 7.167 & 159.970 \\
\hline 7.333 & 157.976 \\
\hline 7.500 & 156.025 \\
\hline 7.667 & 154.031 \\
\hline 7.833 & 152.124 \\
\hline 8.000 & 150.246 \\
\hline 8.167 & 148.411 \\
\hline 8.333 & 146.605 \\
\hline 25.000 & 48.662 \\
\hline 25.167 & 48.187 \\
\hline
\end{tabular}

\begin{tabular}{|c|c|}
\hline $\mathbf{t}(\mathbf{m i n})$ & $\mathbf{s}(\mathbf{f t})$ \\
\hline 8.500 & 144.799 \\
\hline 8.667 & 143.007 \\
\hline 8.833 & 141.274 \\
\hline 9.000 & 139.584 \\
\hline 9.167 & 137.879 \\
\hline 9.333 & 136.363 \\
\hline 9.500 & 134.557 \\
\hline 9.667 & 132.925 \\
\hline 9.833 & 131.365 \\
\hline 10.000 & 129.805 \\
\hline 10.167 & 128.260 \\
\hline 10.333 & 126.744 \\
\hline 10.500 & 125.242 \\
\hline 10.667 & 123.740 \\
\hline 10.833 & 122.267 \\
\hline 11.000 & 120.852 \\
\hline 11.167 & 119.437 \\
\hline 31.833 & 33.035 \\
\hline 32.000 & 32.747 \\
\hline
\end{tabular}




\begin{tabular}{|c|c|c|c|c|c|c|c|}
\hline$t(\min )$ & $s(\mathrm{ft})$ & $t(\min )$ & $s(\mathrm{ft})$ & $t(\min )$ & $s(\mathrm{ft})$ & $t(\min )$ & $s(\mathrm{ft})$ \\
\hline 11.667 & 115.322 & 18.500 & 72.675 & 25.333 & 47.740 & 32.167 & 32.459 \\
\hline 11.833 & 113.878 & 18.667 & 71.911 & 25.500 & 47.264 & 32.333 & 32.185 \\
\hline 12.000 & 112.607 & 18.833 & 71.146 & 25.667 & 46.803 & 32.500 & 31.897 \\
\hline 12.167 & 111.279 & 19.000 & 70.396 & 25.833 & 46.356 & 32.667 & 31.608 \\
\hline 12.333 & 109.994 & 19.167 & 69.660 & 26.000 & 45.909 & 32.833 & 31.334 \\
\hline 12.500 & 108.738 & 19.333 & 68.925 & 26.167 & 45.462 & 33.000 & 31.075 \\
\hline 12.667 & 107.468 & 19.500 & 68.218 & 26.333 & 45.015 & 33.167 & 30.801 \\
\hline 12.833 & 106.226 & 19.667 & 67.497 & 26.500 & 44.553 & 33.333 & 30.513 \\
\hline 13.000 & 104.999 & 19.833 & 66.804 & 26.667 & 44.121 & 33.500 & 30.253 \\
\hline 13.167 & 103.772 & 20.000 & 66.112 & 26.833 & 43.674 & 33.667 & 30.008 \\
\hline 13.333 & 102.589 & 20.167 & 65.405 & 27.000 & 43.270 & 33.833 & 29.735 \\
\hline 13.500 & 101.434 & 20.333 & 64.713 & 27.167 & 42.852 & 34.000 & 29.489 \\
\hline 13.667 & 100.279 & 20.500 & 64.021 & 27.333 & 42.448 & 34.167 & 29.230 \\
\hline 13.833 & 99.139 & 20.667 & 63.357 & 27.500 & 42.030 & 34.333 & 28.971 \\
\hline 14.000 & 98.013 & 20.833 & 62.708 & 27.667 & 41.641 & 34.500 & 28.740 \\
\hline 14.167 & 96.916 & 21.000 & 62.059 & 27.833 & 41.252 & 34.667 & 28.495 \\
\hline 14.333 & 95.834 & 21.167 & 61.410 & 28.000 & 40.863 & 34.833 & 28.250 \\
\hline 14.500 & 94.737 & 21.333 & 60.776 & 28.167 & 40.488 & 35.000 & 28.034 \\
\hline 14.667 & 93.640 & 21.500 & 60.170 & 28.333 & 40.099 & 35.167 & 27.789 \\
\hline 14.833 & 92.587 & 21.667 & 59.535 & 28.500 & 39.738 & 35.333 & 27.558 \\
\hline 15.000 & 91.562 & 21.833 & 58.944 & 28.667 & 39.363 & 35.500 & 27.328 \\
\hline 15.167 & 90.538 & 22.000 & 58.338 & 28.833 & 39.003 & 35.667 & 27.111 \\
\hline 15.333 & 89.527 & 22.167 & 57.761 & 29.000 & 38.628 & 35.833 & 26.881 \\
\hline 15.500 & 88.546 & 22.333 & 57.170 & 29.167 & 38.268 & 36.000 & 26.650 \\
\hline 15.667 & 87.565 & 22.500 & 56.593 & 29.333 & 37.936 & 36.167 & 26.434 \\
\hline 15.833 & 86.613 & 22.667 & 56.017 & 29.500 & 37.576 & 36.333 & 26.203 \\
\hline 16.000 & 85.617 & 22.833 & 55.454 & 29.667 & 37.230 & 36.500 & 26.002 \\
\hline 16.167 & 84.564 & 23.000 & 54.863 & 29.833 & 36.884 & 36.667 & 25.786 \\
\hline 16.333 & 83.712 & 23.167 & 54.300 & 30.000 & 36.552 & 36.833 & 25.569 \\
\hline 16.500 & 82.803 & 23.333 & 53.738 & 30.167 & 36.206 & 37.000 & 25.353 \\
\hline 16.667 & 81.909 & 23.500 & 53.205 & 30.333 & 35.889 & 37.167 & 25.137 \\
\hline 16.833 & 81.029 & 23.667 & 52.685 & 30.500 & 35.558 & 37.333 & 24.921 \\
\hline 17.000 & 80.134 & 23.833 & 52.152 & 30.667 & 35.241 & 37.500 & 24.705 \\
\hline 17.167 & 79.268 & 24.000 & 51.633 & 30.833 & 34.909 & 37.667 & 24.503 \\
\hline 17.333 & 78.417 & 24.167 & 51.128 & 31.000 & 34.578 & 37.833 & 24.287 \\
\hline 17.500 & 77.580 & 24.333 & 50.609 & 31.167 & 34.246 & 38.000 & 24.085 \\
\hline 17.667 & 76.744 & 24.500 & 50.119 & 31.333 & 33.929 & 38.167 & 23.869 \\
\hline 17.833 & 75.907 & 24.667 & 49.643 & 31.500 & 33.626 & 38.333 & 23.681 \\
\hline 18.000 & 75.084 & 24.833 & 49.138 & 31.667 & 33.338 & 38.500 & 23.480 \\
\hline 38.667 & 23.278 & 45.500 & 16.692 & 52.333 & 12.312 & 59.167 & 9.143 \\
\hline 38.833 & 23.076 & 45.667 & 16.563 & 52.500 & 12.226 & 59.333 & 9.085 \\
\hline
\end{tabular}




\begin{tabular}{|c|c|c|c|c|c|c|c|}
\hline$t(\min )$ & $s(f t)$ & $t(\min )$ & $s$ (ft) & $t(\min )$ & $s(f t)$ & $t(\min )$ & $s(f t)$ \\
\hline 39.000 & 22.889 & 45.833 & 16.447 & 52.667 & 12.125 & 59.500 & 9.013 \\
\hline 39.167 & 22.687 & 46.000 & 16.303 & 52.833 & 12.038 & 59.667 & 8.955 \\
\hline 39.333 & 22.514 & 46.167 & 16.188 & 53.000 & 11.952 & 59.833 & 8.898 \\
\hline 39.500 & 22.327 & 46.333 & 16.058 & 53.167 & 11.880 & 60.000 & 8.840 \\
\hline 39.667 & 22.139 & 46.500 & 15.929 & 53.333 & 11.779 & 60.167 & 8.754 \\
\hline 39.833 & 21.952 & 46.667 & 15.813 & 53.500 & 11.693 & 60.333 & 8.696 \\
\hline 40.000 & 21.779 & 46.833 & 15.698 & 53.667 & 11.606 & 60.500 & 8.624 \\
\hline 40.167 & 21.592 & 47.000 & 15.569 & 53.833 & 11.534 & 60.667 & 8.581 \\
\hline 40.333 & 21.419 & 47.167 & 15.453 & 54.000 & 11.462 & 60.833 & 8.523 \\
\hline 40.500 & 21.246 & 47.333 & 15.338 & 54.167 & 11.361 & 61.000 & 8.451 \\
\hline 40.667 & 21.073 & 47.500 & 15.223 & 54.333 & 11.289 & 61.167 & 8.379 \\
\hline 40.833 & 20.900 & 47.667 & 15.093 & 54.500 & 11.217 & 61.333 & 8.321 \\
\hline 41.000 & 20.742 & 47.833 & 14.992 & 54.667 & 11.131 & 61.500 & 8.264 \\
\hline 41.167 & 20.583 & 48.000 & 14.877 & 54.833 & 11.059 & 61.667 & 8.206 \\
\hline 41.333 & 20.396 & 48.167 & 14.762 & 55.000 & 10.958 & 61.833 & 8.149 \\
\hline 41.500 & 20.237 & 48.333 & 14.646 & 55.167 & 10.871 & 62.000 & 8.091 \\
\hline 41.667 & 20.064 & 48.500 & 14.546 & 55.333 & 10.814 & 62.167 & 8.019 \\
\hline 41.833 & 19.906 & 48.667 & 14.430 & 55.500 & 10.742 & 62.333 & 7.961 \\
\hline 42.000 & 19.733 & 48.833 & 14.315 & 55.667 & 10.641 & 62.500 & 7.918 \\
\hline 42.167 & 19.574 & 49.000 & 14.229 & 55.833 & 10.569 & 62.667 & 7.846 \\
\hline 42.333 & 19.401 & 49.167 & 14.113 & 56.000 & 10.497 & 62.833 & 7.803 \\
\hline 42.500 & 19.257 & 49.333 & 14.012 & 56.167 & 10.425 & 63.000 & 7.745 \\
\hline 42.667 & 19.113 & 49.500 & 13.912 & 56.333 & 10.353 & 63.167 & 7.688 \\
\hline 42.833 & 18.955 & 49.667 & 13.811 & 56.500 & 10.266 & 63.333 & 7.630 \\
\hline 43.000 & 18.811 & 49.833 & 13.724 & 56.667 & 10.194 & 63.500 & 7.572 \\
\hline 43.167 & 18.667 & 50.000 & 13.609 & 56.833 & 10.122 & 63.667 & 7.529 \\
\hline 43.333 & 18.508 & 50.167 & 13.523 & 57.000 & 10.065 & 63.833 & 7.471 \\
\hline 43.500 & 18.364 & 50.333 & 13.422 & 57.167 & 9.964 & 64.000 & 7.428 \\
\hline 43.667 & 18.205 & 50.500 & 13.321 & 57.333 & 9.921 & 64.167 & 7.371 \\
\hline 43.833 & 18.061 & 50.667 & 13.220 & 57.500 & 9.849 & 64.333 & 7.327 \\
\hline 44.000 & 17.932 & 50.833 & 13.119 & 57.667 & 9.762 & 64.500 & 7.255 \\
\hline 44.167 & 17.773 & 51.000 & 13.033 & 57.833 & 9.704 & 64.667 & 7.198 \\
\hline 44.333 & 17.643 & 51.167 & 12.946 & 58.000 & 9.632 & 64.833 & 7.140 \\
\hline 44.500 & 17.514 & 51.333 & 12.845 & 58.167 & 9.560 & 65.000 & 7.082 \\
\hline 44.667 & 17.370 & 51.500 & 12.744 & 58.333 & 9.488 & 65.167 & 7.025 \\
\hline 44.833 & 17.226 & 51.667 & 12.672 & 58.500 & 9.416 & 65.333 & 6.967 \\
\hline 45.000 & 17.081 & 51.833 & 12.572 & 58.667 & 9.359 & 65.500 & 6.895 \\
\hline 45.167 & 16.952 & 52.000 & 12.471 & 58.833 & 9.287 & 65.667 & 6.838 \\
\hline 45.333 & 16.822 & 52.167 & 12.399 & 59.000 & 9.229 & 65.833 & 6.780 \\
\hline 66.000 & 6.737 & 72.833 & 4.662 & 79.667 & 3.092 & 86.500 & 1.896 \\
\hline 66.167 & 6.679 & 73.000 & 4.619 & 79.833 & 3.049 & 86.667 & 1.868 \\
\hline
\end{tabular}




\begin{tabular}{|c|c|c|c|c|c|c|c|}
\hline $\mathrm{t}$ (min) & $s(\mathrm{ft})$ & $t(\min )$ & $s(\mathrm{ft})$ & $\mathrm{t}(\min )$ & $s(\mathrm{ft})$ & $t(\min )$ & $s(\mathrm{ft})$ \\
\hline 66.333 & 6.621 & 73.167 & 4.590 & 80.000 & 3.020 & 86.833 & 1.839 \\
\hline 66.500 & 6.564 & 73.333 & 4.533 & 80.167 & 2.991 & 87.000 & 1.810 \\
\hline 66.667 & 6.506 & 73.500 & 4.504 & 80.333 & 2.962 & 87.167 & 1.796 \\
\hline 66.833 & 6.449 & 73.667 & 4.446 & 80.500 & 2.934 & 87.333 & 1.752 \\
\hline 67.000 & 6.405 & 73.833 & 4.403 & 80.667 & 2.905 & 87.500 & 1.724 \\
\hline 67.167 & 6.348 & 74.000 & 4.374 & 80.833 & 2.847 & 87.667 & 1.709 \\
\hline 67.333 & 6.290 & 74.167 & 4.316 & 81.000 & 2.818 & 87.833 & 1.695 \\
\hline 67.500 & 6.247 & 74.333 & 4.273 & 81.167 & 2.804 & 88.000 & 1.652 \\
\hline 67.667 & 6.175 & 74.500 & 4.244 & 81.333 & 2.761 & 88.167 & 1.652 \\
\hline 67.833 & 6.132 & 74.667 & 4.201 & 81.500 & 2.732 & 88.333 & 1.623 \\
\hline 68.000 & 6.074 & 74.833 & 4.158 & 81.667 & 2.703 & 88.500 & 1.608 \\
\hline 68.167 & 6.031 & 75.000 & 4.129 & 81.833 & 2.660 & 88.667 & 1.580 \\
\hline 68.333 & 5.973 & 75.167 & 4.086 & 82.000 & 2.631 & 88.833 & 1.565 \\
\hline 68.500 & 5.930 & 75.333 & 4.043 & 82.167 & 2.602 & 89.000 & 1.536 \\
\hline 68.667 & 5.887 & 75.500 & 4.000 & 82.333 & 2.573 & 89.167 & 1.522 \\
\hline 68.833 & 5.800 & 75.667 & 3.971 & 82.500 & 2.559 & 89.333 & 1.493 \\
\hline 69.000 & 5.757 & 75.833 & 3.913 & 82.667 & 2.530 & 89.500 & 1.479 \\
\hline 69.167 & 5.714 & 76.000 & 3.884 & 82.833 & 2.473 & 89.667 & 1.450 \\
\hline 69.333 & 5.671 & 76.167 & 3.827 & 83.000 & 2.444 & 89.833 & 1.435 \\
\hline 69.500 & 5.613 & 76.333 & 3.798 & 83.167 & 2.415 & 90.000 & 1.421 \\
\hline 69.667 & 5.570 & 76.500 & 3.769 & 83.333 & 2.386 & 90.167 & 1.392 \\
\hline 69.833 & 5.512 & 76.667 & 3.726 & 83.500 & 2.372 & 90.333 & 1.363 \\
\hline 70.000 & 5.483 & 76.833 & 3.683 & 83.667 & 2.329 & 90.500 & 1.349 \\
\hline 70.167 & 5.411 & 77.000 & 3.654 & 83.833 & 2.314 & 90.667 & 1.320 \\
\hline 70.333 & 5.368 & 77.167 & 3.611 & 84.000 & 2.285 & 90.833 & 1.306 \\
\hline 70.500 & 5.310 & 77.333 & 3.567 & 84.167 & 2.257 & 91.000 & 1.291 \\
\hline 70.667 & 5.267 & 77.500 & 3.539 & 84.333 & 2.228 & 91.167 & 1.263 \\
\hline 70.833 & 5.224 & 77.667 & 3.495 & 84.500 & 2.213 & 91.333 & 1.234 \\
\hline 71.000 & 5.181 & 77.833 & 3.467 & 84.667 & 2.170 & 91.500 & 1.219 \\
\hline 71.167 & 5.123 & 78.000 & 3.438 & 84.833 & 2.156 & 91.667 & 1.205 \\
\hline 71.333 & 5.080 & 78.167 & 3.395 & 85.000 & 2.112 & 91.833 & 1.191 \\
\hline 71.500 & 5.022 & 78.333 & 3.366 & 85.167 & 2.084 & 92.000 & 1.176 \\
\hline 71.667 & 4.979 & 78.500 & 3.337 & 85.333 & 2.055 & 92.167 & 1.147 \\
\hline 71.833 & 4.936 & 78.667 & 3.279 & 85.500 & 2.040 & 92.333 & 1.133 \\
\hline 72.000 & 4.893 & 78.833 & 3.250 & 85.667 & 2.012 & 92.500 & 1.119 \\
\hline 72.167 & 4.849 & 79.000 & 3.207 & 85.833 & 1.983 & 92.667 & 1.090 \\
\hline 72.333 & 4.806 & 79.167 & 3.178 & 86.000 & 1.954 & 92.833 & 1.075 \\
\hline 72.500 & 4.763 & 79.333 & 3.150 & 86.167 & 1.940 & 93.000 & 1.061 \\
\hline 72.667 & 4.720 & 79.500 & 3.121 & 86.333 & 1.911 & 93.167 & 1.032 \\
\hline 93.333 & 1.003 & 94.500 & 0.874 & 95.667 & 0.773 & 96.833 & 0.629 \\
\hline 93.500 & 1.003 & 94.667 & 0.859 & 95.833 & 0.758 & 97.000 & 0.643 \\
\hline
\end{tabular}




\begin{tabular}{|c|c|}
\hline $\mathbf{t}(\mathbf{m i n})$ & $\mathbf{s}(\mathbf{f t})$ \\
\hline 93.667 & 0.975 \\
\hline 93.833 & 0.960 \\
\hline 94.000 & 0.946 \\
\hline 94.167 & 0.917 \\
\hline 94.333 & 0.902 \\
\hline
\end{tabular}

\begin{tabular}{|c|c|}
\hline $\mathbf{t}$ (min) & $\mathbf{s}$ (ft) \\
\hline 94.833 & 0.845 \\
\hline 95.000 & 0.830 \\
\hline 95.167 & 0.830 \\
\hline 95.333 & 0.816 \\
\hline 95.500 & 0.802 \\
\hline
\end{tabular}

\begin{tabular}{|l|l|}
\hline $\mathbf{t}(\mathbf{m i n})$ & $\mathbf{s}$ (ft) \\
\hline 96.000 & 0.744 \\
\hline 96.167 & 0.730 \\
\hline 96.333 & 0.715 \\
\hline 96.500 & 0.701 \\
\hline 96.667 & 0.686 \\
\hline
\end{tabular}

\begin{tabular}{|c|c|}
\hline $\mathbf{t}$ (min) & $\mathbf{s}$ (ft) \\
\hline 97.167 & 0.629 \\
\hline 97.333 & 0.614 \\
\hline 97.500 & 0.600 \\
\hline 97.667 & 0.600 \\
\hline
\end{tabular}

\section{D-3. Analysis of Injection Test, R-22, Screen 2}

Test Date: 15 Nov 00

\section{Aquifer Data}

Saturated thickness: $\quad 69.5 \mathrm{ft}$

Anisotropy ratio $(\mathrm{Kz} / \mathrm{Kr})$ : $\quad 1$

\section{Well Data}

Initial displacement: $\quad 276.9 \mathrm{ft}$

Depth of penetration: $\quad 51.4 \mathrm{ft}$

Casing radius: $\quad 0.0990 \mathrm{ft}$

Borehole radius: $\quad 0.5104 \mathrm{ft}$

Screen length: $\quad 41.9 \mathrm{ft}$

Filter pack porosity: $\quad 0.25$

\section{Solution}

Analytical method: Bouwer-Rice

Conceptual model: $\quad$ confined

$\mathrm{K}=$

$0.036 \mathrm{ft} / \mathrm{d}$

$\mathrm{y}_{0}=$

$266.8 \mathrm{ft}$ 


\section{D-4. Plot for Injection Test, R-22, Screen 3}

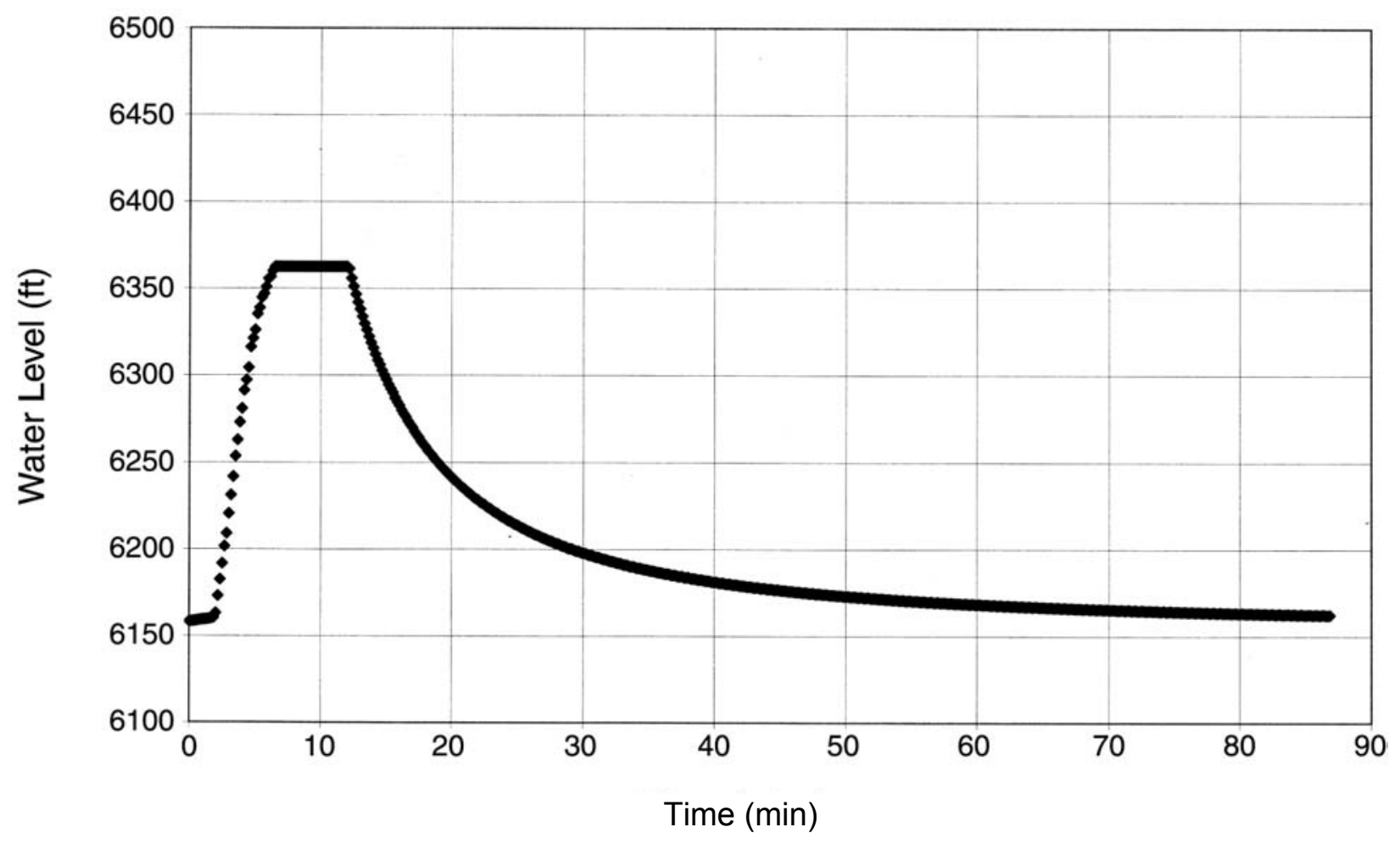

D-5. Recovery Data for Injection Test, R-22, Screen 3

\begin{tabular}{|c|c|}
\hline $\mathbf{t}(\mathbf{m i n})$ & $\mathbf{s}(\mathbf{f t})$ \\
\hline 0.000 & 313.571 \\
\hline 0.167 & 306.154 \\
\hline 0.333 & 298.874 \\
\hline 0.500 & 291.737 \\
\hline 0.667 & 284.746 \\
\hline 0.833 & 277.892 \\
\hline 1.000 & 271.181 \\
\hline 1.167 & 264.615 \\
\hline 1.333 & 258.188 \\
\hline 1.500 & 251.903 \\
\hline 1.667 & 245.763 \\
\hline 1.833 & 239.762 \\
\hline 2.000 & 233.902 \\
\hline 2.167 & 228.188 \\
\hline 2.333 & 222.613 \\
\hline 2.500 & 217.180 \\
\hline 2.667 & 211.892 \\
\hline 2.833 & 206.742 \\
\hline
\end{tabular}

\begin{tabular}{|c|c|}
\hline $\mathbf{t}(\mathbf{m i n})$ & $\mathbf{s}(\mathbf{f t})$ \\
\hline 3.000 & 202.215 \\
\hline 3.167 & 196.704 \\
\hline 3.333 & 192.047 \\
\hline 3.500 & 187.405 \\
\hline 3.667 & 182.850 \\
\hline 3.833 & 178.816 \\
\hline 4.000 & 174.595 \\
\hline 4.167 & 170.562 \\
\hline 4.333 & 166.962 \\
\hline 4.500 & 163.060 \\
\hline 4.667 & 159.548 \\
\hline 4.833 & 156.426 \\
\hline 5.000 & 152.828 \\
\hline 5.167 & 149.447 \\
\hline 5.333 & 146.774 \\
\hline 5.500 & 143.508 \\
\hline 5.667 & 140.778 \\
\hline 5.833 & 138.351 \\
\hline
\end{tabular}

\begin{tabular}{|c|c|}
\hline $\mathbf{t}(\mathbf{m i n})$ & $\mathbf{s}(\mathbf{f t})$ \\
\hline 6.000 & 135.375 \\
\hline 6.167 & 132.905 \\
\hline 6.333 & 130.666 \\
\hline 6.500 & 127.864 \\
\hline 6.667 & 125.626 \\
\hline 6.833 & 123.589 \\
\hline 7.000 & 120.961 \\
\hline 7.167 & 118.881 \\
\hline 7.333 & 117.062 \\
\hline 7.500 & 114.622 \\
\hline 7.667 & 112.745 \\
\hline 7.833 & 110.969 \\
\hline 8.000 & 108.601 \\
\hline 8.167 & 106.768 \\
\hline 8.333 & 105.136 \\
\hline 8.500 & 102.942 \\
\hline 8.667 & 101.267 \\
\hline 8.833 & 99.853 \\
\hline
\end{tabular}

\begin{tabular}{|c|c|}
\hline $\mathbf{t}(\mathbf{m i n})$ & $\mathbf{s}(\mathbf{f t})$ \\
\hline 9.000 & 97.861 \\
\hline 9.167 & 96.374 \\
\hline 9.333 & 95.061 \\
\hline 9.500 & 93.199 \\
\hline 9.667 & 91.770 \\
\hline 9.833 & 90.514 \\
\hline 10.000 & 88.811 \\
\hline 10.167 & 87.498 \\
\hline 10.333 & 86.430 \\
\hline 10.500 & 84.756 \\
\hline 10.667 & 83.573 \\
\hline 10.833 & 82.505 \\
\hline 11.000 & 80.961 \\
\hline 11.167 & 79.937 \\
\hline 11.333 & 78.783 \\
\hline 11.500 & 77.441 \\
\hline 11.667 & 76.489 \\
\hline 11.833 & 75.464 \\
\hline
\end{tabular}




\begin{tabular}{|c|c|c|c|c|c|c|c|}
\hline $\mathrm{t}$ (min) & $s(\mathrm{ft})$ & $t(\min )$ & $s(\mathrm{ft})$ & $\mathrm{t}(\min )$ & $s(\mathrm{ft})$ & $t(\min )$ & $s(\mathrm{ft})$ \\
\hline 12.000 & 74.137 & 18.833 & 44.008 & 25.667 & 29.029 & 32.500 & 20.353 \\
\hline 12.167 & 73.228 & 19.000 & 43.719 & 25.833 & 28.582 & 32.667 & 20.079 \\
\hline 12.333 & 72.305 & 19.167 & 42.912 & 26.000 & 28.237 & 32.833 & 19.762 \\
\hline 12.500 & 70.977 & 19.333 & 42.551 & 26.167 & 28.237 & 33.000 & 19.805 \\
\hline 12.667 & 69.982 & 19.500 & 42.278 & 26.333 & 27.819 & 33.167 & 19.647 \\
\hline 12.833 & 69.362 & 19.667 & 41.456 & 26.500 & 27.444 & 33.333 & 19.272 \\
\hline 13.000 & 68.063 & 19.833 & 41.110 & 26.667 & 27.372 & 33.500 & 19.258 \\
\hline 13.167 & 67.212 & 20.000 & 40.937 & 26.833 & 27.156 & 33.667 & 19.258 \\
\hline 13.333 & 66.563 & 20.167 & 40.115 & 27.000 & 26.694 & 33.833 & 18.796 \\
\hline 13.500 & 65.323 & 20.333 & 39.769 & 27.167 & 26.579 & 34.000 & 18.768 \\
\hline 13.667 & 64.515 & 20.500 & 39.639 & 27.333 & 26.550 & 34.167 & 18.869 \\
\hline 13.833 & 63.938 & 20.667 & 38.846 & 27.500 & 25.959 & 34.333 & 18.364 \\
\hline 14.000 & 62.784 & 20.833 & 38.515 & 27.667 & 25.844 & 34.500 & 18.307 \\
\hline 14.167 & 61.919 & 21.000 & 38.385 & 27.833 & 25.887 & 34.667 & 18.451 \\
\hline 14.333 & 61.370 & 21.167 & 37.678 & 28.000 & 25.282 & 34.833 & 17.961 \\
\hline 14.500 & 60.289 & 21.333 & 37.289 & 28.167 & 25.152 & 35.000 & 17.874 \\
\hline 14.667 & 59.524 & 21.500 & 37.188 & 28.333 & 25.239 & 35.167 & 18.033 \\
\hline 14.833 & 59.048 & 21.667 & 36.568 & 28.500 & 24.633 & 35.333 & 17.572 \\
\hline 15.000 & 57.981 & 21.833 & 36.150 & 28.667 & 24.504 & 35.500 & 17.442 \\
\hline 15.167 & 57.274 & 22.000 & 36.035 & 28.833 & 24.590 & 35.667 & 17.572 \\
\hline 15.333 & 56.798 & 22.167 & 35.502 & 29.000 & 23.999 & 35.833 & 17.226 \\
\hline 15.500 & 55.875 & 22.333 & 35.040 & 29.167 & 23.869 & 36.000 & 17.024 \\
\hline 15.667 & 55.125 & 22.500 & 34.882 & 29.333 & 23.941 & 36.167 & 17.125 \\
\hline 15.833 & 54.693 & 22.667 & 34.507 & 29.500 & 23.437 & 36.333 & 16.909 \\
\hline 16.000 & 53.871 & 22.833 & 33.959 & 29.667 & 23.235 & 36.500 & 16.635 \\
\hline 16.167 & 53.092 & 23.000 & 33.757 & 29.833 & 23.307 & 36.667 & 16.721 \\
\hline 16.333 & 52.659 & 23.167 & 33.555 & 30.000 & 22.947 & 36.833 & 16.563 \\
\hline 16.500 & 51.866 & 23.333 & 32.936 & 30.167 & 22.630 & 37.000 & 16.231 \\
\hline 16.667 & 51.131 & 23.500 & 32.734 & 30.333 & 22.616 & 37.167 & 16.303 \\
\hline 16.833 & 50.727 & 23.667 & 32.604 & 30.500 & 22.443 & 37.333 & 16.260 \\
\hline 17.000 & 50.064 & 23.833 & 31.941 & 30.667 & 22.010 & 37.500 & 15.871 \\
\hline 17.167 & 49.314 & 24.000 & 31.710 & 30.833 & 21.938 & 37.667 & 15.871 \\
\hline 17.333 & 48.896 & 24.167 & 31.682 & 31.000 & 21.953 & 37.833 & 15.958 \\
\hline 17.500 & 48.377 & 24.333 & 31.004 & 31.167 & 21.434 & 38.000 & 15.496 \\
\hline 17.667 & 47.584 & 24.500 & 30.773 & 31.333 & 21.362 & 38.167 & 15.482 \\
\hline 17.833 & 47.165 & 24.667 & 30.788 & 31.500 & 21.463 & 38.333 & 15.655 \\
\hline 18.000 & 46.762 & 24.833 & 30.139 & 31.667 & 20.915 & 38.500 & 15.165 \\
\hline 18.167 & 45.954 & 25.000 & 29.909 & 31.833 & 20.800 & 38.667 & 15.136 \\
\hline 18.333 & 45.565 & 25.167 & 29.909 & 32.000 & 20.901 & 38.833 & 15.309 \\
\hline 18.500 & 45.204 & 25.333 & 29.332 & 32.167 & 20.483 & 39.000 & 14.891 \\
\hline 18.667 & 44.383 & 25.500 & 29.044 & 32.333 & 20.281 & 39.167 & 14.776 \\
\hline
\end{tabular}




\begin{tabular}{|c|c|c|c|c|c|c|c|}
\hline $\mathrm{t}$ (min) & $s(\mathrm{ft})$ & $t(\min )$ & $s(\mathrm{ft})$ & $\mathrm{t}(\min )$ & $s(\mathrm{ft})$ & $\mathrm{t}(\min )$ & $s(\mathrm{ft})$ \\
\hline 39.333 & 14.935 & 46.167 & 11.130 & 53.000 & 8.306 & 59.833 & 6.275 \\
\hline 39.500 & 14.603 & 46.333 & 10.972 & 53.167 & 8.508 & 60.000 & 6.304 \\
\hline 39.667 & 14.445 & 46.500 & 10.741 & 53.333 & 8.263 & 60.167 & 6.534 \\
\hline 39.833 & 14.560 & 46.667 & 10.799 & 53.500 & 8.119 & 60.333 & 6.203 \\
\hline 40.000 & 14.373 & 46.833 & 10.871 & 53.667 & 8.263 & 60.500 & 6.160 \\
\hline 40.167 & 14.113 & 47.000 & 10.482 & 53.833 & 8.206 & 60.667 & 6.361 \\
\hline 40.333 & 14.171 & 47.167 & 10.540 & 54.000 & 7.932 & 60.833 & 6.145 \\
\hline 40.500 & 14.128 & 47.333 & 10.713 & 54.167 & 8.004 & 61.000 & 6.030 \\
\hline 40.667 & 13.782 & 47.500 & 10.280 & 54.333 & 8.119 & 61.167 & 6.174 \\
\hline 40.833 & 13.811 & 47.667 & 10.280 & 54.500 & 7.759 & 61.333 & 6.073 \\
\hline 41.000 & 13.883 & 47.833 & 10.525 & 54.667 & 7.831 & 61.500 & 5.872 \\
\hline 41.167 & 13.465 & 48.000 & 10.093 & 54.833 & 8.018 & 61.667 & 6.001 \\
\hline 41.333 & 13.494 & 48.167 & 10.064 & 55.000 & 7.615 & 61.833 & 6.073 \\
\hline 41.500 & 13.652 & 48.333 & 10.280 & 55.167 & 7.644 & 62.000 & 5.742 \\
\hline 41.667 & 13.177 & 48.500 & 9.992 & 55.333 & 7.860 & 62.167 & 5.800 \\
\hline 41.833 & 13.177 & 48.667 & 9.848 & 55.500 & 7.543 & 62.333 & 6.016 \\
\hline 42.000 & 13.378 & 48.833 & 9.978 & 55.667 & 7.471 & 62.500 & 5.627 \\
\hline 42.167 & 12.903 & 49.000 & 9.863 & 55.833 & 7.629 & 62.667 & 5.670 \\
\hline 42.333 & 12.903 & 49.167 & 9.646 & 56.000 & 7.500 & 62.833 & 5.900 \\
\hline 42.500 & 13.090 & 49.333 & 9.747 & 56.167 & 7.283 & 63.000 & 5.526 \\
\hline 42.667 & 12.672 & 49.500 & 9.704 & 56.333 & 7.356 & 63.167 & 5.526 \\
\hline 42.833 & 12.600 & 49.667 & 9.430 & 56.500 & 7.485 & 63.333 & 5.742 \\
\hline 43.000 & 12.787 & 49.833 & 9.473 & 56.667 & 7.125 & 63.500 & 5.483 \\
\hline 43.167 & 12.470 & 50.000 & 9.618 & 56.833 & 7.168 & 63.667 & 5.396 \\
\hline 43.333 & 12.312 & 50.167 & 9.229 & 57.000 & 7.384 & 63.833 & 5.511 \\
\hline 43.500 & 12.456 & 50.333 & 9.257 & 57.167 & 6.981 & 64.000 & 5.497 \\
\hline 43.667 & 12.283 & 50.500 & 9.473 & 57.333 & 6.995 & 64.167 & 5.266 \\
\hline 43.833 & 12.024 & 50.667 & 9.084 & 57.500 & 7.240 & 64.333 & 5.353 \\
\hline 44.000 & 12.110 & 50.833 & 9.056 & 57.667 & 6.866 & 64.500 & 5.483 \\
\hline 44.167 & 12.081 & 51.000 & 9.257 & 57.833 & 6.851 & 64.667 & 5.122 \\
\hline 44.333 & 11.736 & 51.167 & 8.984 & 58.000 & 7.082 & 64.833 & 5.194 \\
\hline 44.500 & 11.779 & 51.333 & 8.854 & 58.167 & 6.822 & 65.000 & 5.425 \\
\hline 44.667 & 11.909 & 51.500 & 8.984 & 58.333 & 6.707 & 65.167 & 5.050 \\
\hline 44.833 & 11.476 & 51.667 & 8.926 & 58.500 & 6.808 & 65.333 & 5.050 \\
\hline 45.000 & 11.491 & 51.833 & 8.652 & 58.667 & 6.822 & 65.500 & 5.295 \\
\hline 45.167 & 11.707 & 52.000 & 8.710 & 58.833 & 6.534 & 65.667 & 5.036 \\
\hline 45.333 & 11.246 & 52.167 & 8.840 & 59.000 & 6.606 & 65.833 & 4.950 \\
\hline 45.500 & 11.231 & 52.333 & 8.451 & 59.167 & 6.779 & 66.000 & 5.094 \\
\hline 45.667 & 11.447 & 52.500 & 8.494 & 59.333 & 6.390 & 66.167 & 5.007 \\
\hline 45.833 & 11.087 & 52.667 & 8.724 & 59.500 & 6.448 & 66.333 & 4.820 \\
\hline 46.000 & 10.986 & 52.833 & 8.321 & 59.667 & 6.664 & 66.500 & 4.906 \\
\hline
\end{tabular}




\begin{tabular}{|l|l|}
\hline $\mathbf{t}(\mathbf{m i n})$ & $\mathbf{s}(\mathbf{f t})$ \\
\hline 66.667 & 5.036 \\
\hline 66.833 & 4.690 \\
\hline 67.000 & 4.748 \\
\hline 67.167 & 4.993 \\
\hline 67.333 & 4.633 \\
\hline 67.500 & 4.618 \\
\hline 67.667 & 4.834 \\
\hline 67.833 & 4.647 \\
\hline 68.000 & 4.474 \\
\hline 68.167 & 4.532 \\
\hline 68.333 & 4.690 \\
\hline 68.500 & 4.359 \\
\hline 68.667 & 4.431 \\
\hline 68.833 & 4.661 \\
\hline 69.000 & 4.301 \\
\hline 69.167 & 4.301 \\
\hline 69.333 & 4.546 \\
\hline
\end{tabular}

\begin{tabular}{|l|l|}
\hline $\mathbf{t}(\mathbf{m i n})$ & $\mathbf{s}(\mathbf{f t})$ \\
\hline 69.500 & 4.287 \\
\hline 69.667 & 4.186 \\
\hline 69.833 & 4.316 \\
\hline 70.000 & 4.359 \\
\hline 70.167 & 4.071 \\
\hline 70.333 & 4.143 \\
\hline 70.500 & 4.359 \\
\hline 70.667 & 3.999 \\
\hline 70.833 & 4.013 \\
\hline 71.000 & 4.258 \\
\hline 71.167 & 4.056 \\
\hline 71.333 & 3.898 \\
\hline 71.500 & 4.028 \\
\hline 71.667 & 4.143 \\
\hline 71.833 & 3.783 \\
\hline 72.000 & 3.840 \\
\hline 72.167 & 4.100 \\
\hline
\end{tabular}

\begin{tabular}{|l|l|}
\hline $\mathbf{t}(\mathbf{m i n})$ & $\mathbf{s}$ (ft) \\
\hline 72.333 & 3.768 \\
\hline 72.500 & 3.739 \\
\hline 72.667 & 3.898 \\
\hline 72.833 & 3.855 \\
\hline 73.000 & 3.610 \\
\hline 73.167 & 3.711 \\
\hline 73.333 & 3.898 \\
\hline 73.500 & 3.523 \\
\hline 73.667 & 3.566 \\
\hline 73.833 & 3.826 \\
\hline 74.000 & 3.566 \\
\hline 74.167 & 3.466 \\
\hline 74.333 & 3.595 \\
\hline 74.500 & 3.639 \\
\hline 74.667 & 3.365 \\
\hline 74.833 & 3.437 \\
\hline 75.000 & 3.667 \\
\hline
\end{tabular}

\begin{tabular}{|l|l|}
\hline $\mathbf{t}(\mathbf{m i n})$ & $\mathbf{s}(\mathbf{f t})$ \\
\hline 75.167 & 3.293 \\
\hline 75.333 & 3.336 \\
\hline 75.500 & 3.581 \\
\hline 75.667 & 3.307 \\
\hline 75.833 & 3.221 \\
\hline 76.000 & 3.394 \\
\hline 76.167 & 3.394 \\
\hline 76.333 & 3.134 \\
\hline 76.500 & 3.221 \\
\hline 76.667 & 3.408 \\
\hline 76.833 & 3.048 \\
\hline 77.000 & 3.105 \\
\hline 77.167 & 3.365 \\
\hline 77.333 & 3.048 \\
\hline 77.500 & 3.019 \\
\hline 77.667 & 3.192 \\
\hline 77.833 & 3.134 \\
\hline
\end{tabular}

\section{D-6. Analysis of Injection Test, R-22, Screen 3}

Test Date: 16 Nov 00

Aquifer Data

Saturated thickness: $\quad 49.4 \mathrm{ft}$

Anisotropy ratio $(\mathrm{Kz} / \mathrm{Kr})$ : $\quad 1$

\section{Well Data}

Initial displacement:

$313.6 \mathrm{ft}$

Depth of penetration:

$44.3 \mathrm{ft}$

Casing radius:

$0.0990 \mathrm{ft}$

Borehole radius:

$0.5104 \mathrm{ft}$

Screen length: $\quad 6.7 \mathrm{ft}$

Filter pack porosity: $\quad 0.25$

\section{Solution}

Analytical method: Bouwer-Rice

Conceptual model: $\quad$ confined

$\mathrm{K}=$

$0.21 \mathrm{ft} / \mathrm{d}$

$\mathrm{y}_{0}=$

$240.5 \mathrm{ft}$ 


\section{D-7. Plot for Injection Test, R-22, Screen 4a}

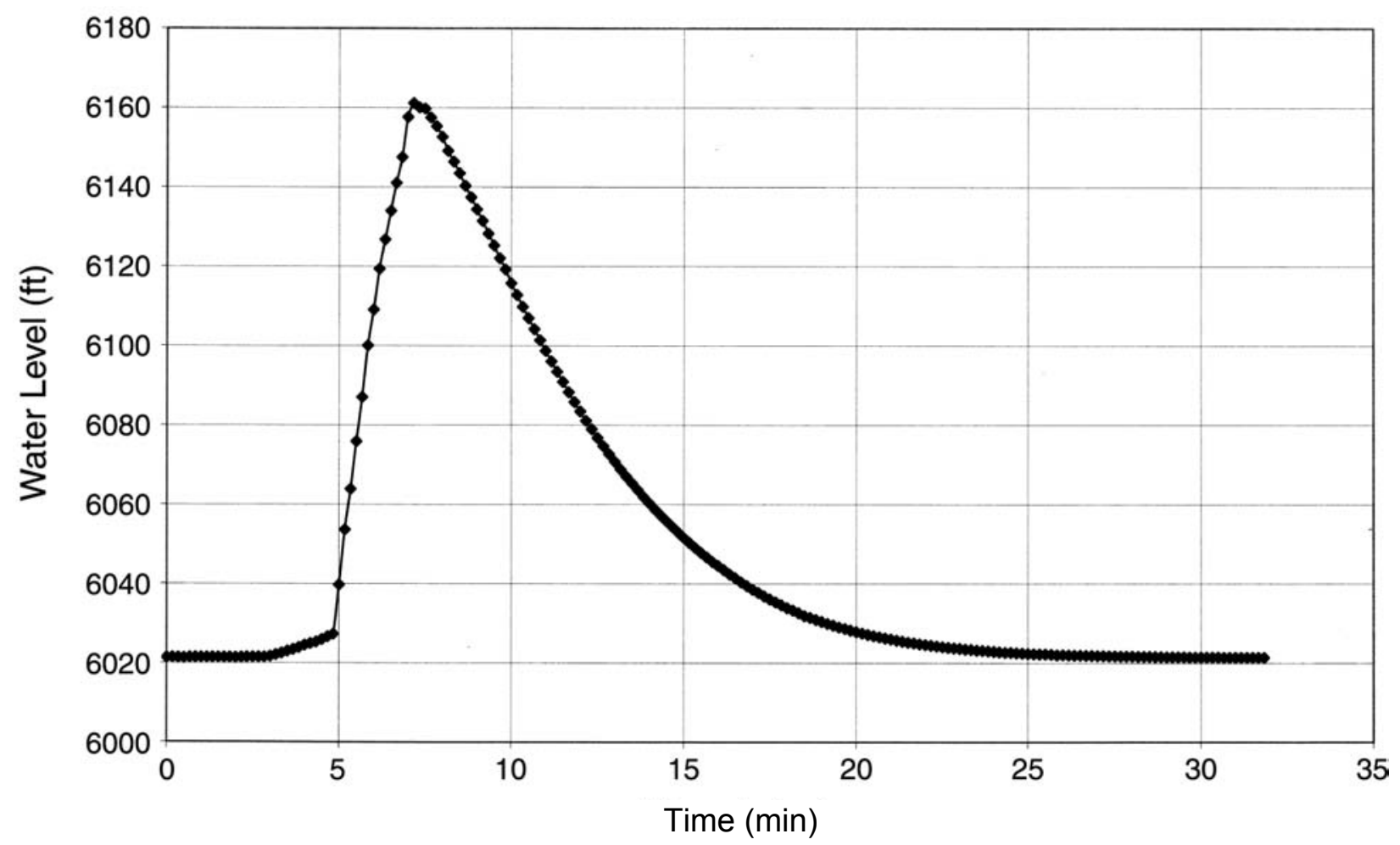

D-8. Recovery Data for Injection Test, R-22, Screen 4a

\begin{tabular}{|c|c|}
\hline $\mathbf{t}(\mathbf{m i n})$ & $\mathbf{s}(\mathbf{f t})$ \\
\hline 0.000 & 139.655 \\
\hline 0.167 & 138.585 \\
\hline 0.333 & 138.296 \\
\hline 0.500 & 136.057 \\
\hline 0.667 & 133.861 \\
\hline 0.833 & 131.189 \\
\hline 1.000 & 127.650 \\
\hline 1.167 & 124.948 \\
\hline 1.333 & 122.016 \\
\hline 1.500 & 118.882 \\
\hline 1.667 & 115.936 \\
\hline 1.833 & 112.918 \\
\hline 2.000 & 110.016 \\
\hline 2.167 & 106.796 \\
\hline 2.333 & 103.850 \\
\hline 2.500 & 100.588 \\
\hline 2.667 & 97.758 \\
\hline 2.833 & 94.279 \\
\hline
\end{tabular}

\begin{tabular}{|c|c|}
\hline $\mathbf{t}(\mathbf{m i n})$ & $\mathbf{s}(\mathbf{f t})$ \\
\hline 3.000 & 91.320 \\
\hline 3.167 & 88.376 \\
\hline 3.333 & 85.518 \\
\hline 3.500 & 82.747 \\
\hline 3.667 & 79.947 \\
\hline 3.833 & 77.234 \\
\hline 4.000 & 74.594 \\
\hline 4.167 & 71.997 \\
\hline 4.333 & 69.429 \\
\hline 4.500 & 66.846 \\
\hline 4.667 & 64.365 \\
\hline 4.833 & 61.956 \\
\hline 5.000 & 59.619 \\
\hline 5.167 & 57.498 \\
\hline 5.333 & 55.335 \\
\hline 5.500 & 53.272 \\
\hline 5.667 & 51.253 \\
\hline 5.833 & 49.277 \\
\hline
\end{tabular}

\begin{tabular}{|c|c|}
\hline $\mathbf{t}(\mathbf{m i n})$ & $\mathbf{s}$ (ft) \\
\hline 6.000 & 47.388 \\
\hline 6.167 & 45.571 \\
\hline 6.333 & 43.826 \\
\hline 6.500 & 42.125 \\
\hline 6.667 & 40.409 \\
\hline 6.833 & 38.794 \\
\hline 7.000 & 37.222 \\
\hline 7.167 & 35.708 \\
\hline 7.333 & 34.252 \\
\hline 7.500 & 32.839 \\
\hline 7.667 & 31.470 \\
\hline 7.833 & 30.086 \\
\hline 8.000 & 28.788 \\
\hline 8.167 & 27.563 \\
\hline 8.333 & 26.367 \\
\hline 8.500 & 25.199 \\
\hline 8.667 & 24.089 \\
\hline 8.833 & 23.022 \\
\hline
\end{tabular}

\begin{tabular}{|c|c|}
\hline $\mathbf{t}(\mathbf{m i n})$ & $\mathbf{s}$ (ft) \\
\hline 9.000 & 21.985 \\
\hline 9.167 & 20.932 \\
\hline 9.333 & 19.938 \\
\hline 9.500 & 18.943 \\
\hline 9.667 & 18.021 \\
\hline 9.833 & 17.099 \\
\hline 10.000 & 16.248 \\
\hline 10.167 & 15.427 \\
\hline 10.333 & 14.634 \\
\hline 10.500 & 13.870 \\
\hline 10.667 & 13.150 \\
\hline 10.833 & 12.458 \\
\hline 11.000 & 11.795 \\
\hline 11.167 & 11.147 \\
\hline 11.333 & 10.455 \\
\hline 11.500 & 9.994 \\
\hline 11.667 & 9.475 \\
\hline 11.833 & 8.985 \\
\hline
\end{tabular}




\begin{tabular}{|l|l|}
\hline $\mathbf{t}(\mathbf{m i n})$ & $\mathbf{s}(\mathbf{f t})$ \\
\hline 12.000 & 8.481 \\
\hline 12.167 & 8.034 \\
\hline 12.333 & 7.587 \\
\hline 12.500 & 7.184 \\
\hline 12.667 & 6.795 \\
\hline 12.833 & 6.420 \\
\hline 13.000 & 6.060 \\
\hline 13.167 & 5.714 \\
\hline 13.333 & 5.397 \\
\hline 13.500 & 5.095 \\
\hline 13.667 & 4.806 \\
\hline 13.833 & 4.518 \\
\hline 14.000 & 4.259 \\
\hline 14.167 & 4.014 \\
\hline 14.333 & 3.769 \\
\hline 14.500 & 3.553 \\
\hline 14.667 & 3.337 \\
\hline
\end{tabular}

\begin{tabular}{|c|c|}
\hline $\mathbf{t}$ (min) & $\mathbf{s}$ (ft) \\
\hline 14.833 & 3.150 \\
\hline 15.000 & 2.948 \\
\hline 15.167 & 2.775 \\
\hline 15.333 & 2.602 \\
\hline 15.500 & 2.444 \\
\hline 15.667 & 2.299 \\
\hline 15.833 & 2.155 \\
\hline 16.000 & 2.026 \\
\hline 16.167 & 1.910 \\
\hline 16.333 & 1.766 \\
\hline 16.500 & 1.665 \\
\hline 16.667 & 1.550 \\
\hline 16.833 & 1.464 \\
\hline 17.000 & 1.349 \\
\hline 17.167 & 1.190 \\
\hline 17.333 & 1.190 \\
\hline
\end{tabular}

\begin{tabular}{|l|l|}
\hline $\mathbf{t}(\mathbf{m i n})$ & $\mathbf{s}(\mathbf{f t})$ \\
\hline 17.500 & 1.104 \\
\hline 17.667 & 1.003 \\
\hline 17.833 & 0.931 \\
\hline 18.000 & 0.873 \\
\hline 18.167 & 0.815 \\
\hline 18.333 & 0.758 \\
\hline 18.500 & 0.700 \\
\hline 18.667 & 0.571 \\
\hline 18.833 & 0.614 \\
\hline 19.000 & 0.556 \\
\hline 19.167 & 0.498 \\
\hline 19.333 & 0.470 \\
\hline 19.500 & 0.441 \\
\hline 19.667 & 0.398 \\
\hline 19.833 & 0.369 \\
\hline 20.000 & 0.340 \\
\hline
\end{tabular}

\begin{tabular}{|c|c|}
\hline$t$ (min) & $\mathbf{s}$ (ft) \\
\hline 20.167 & 0.311 \\
\hline 20.333 & 0.282 \\
\hline 20.500 & 0.254 \\
\hline 20.667 & 0.225 \\
\hline 20.833 & 0.210 \\
\hline 21.000 & 0.196 \\
\hline 21.167 & 0.167 \\
\hline 21.333 & 0.153 \\
\hline 21.500 & 0.124 \\
\hline 21.667 & 0.095 \\
\hline 21.833 & 0.081 \\
\hline 22.000 & 0.066 \\
\hline 22.167 & 0.052 \\
\hline 22.333 & 0.037 \\
\hline 22.500 & 0.023 \\
\hline 22.667 & 0.009 \\
\hline
\end{tabular}

\section{D-9. Analysis of Injection Test, R-22, Screen 4a}

Test Date: 17 Nov 00

Aquifer Data

Saturated thickness: $\quad 49.0 \mathrm{ft}$

Anisotropy ratio $(\mathrm{Kz} / \mathrm{Kr})$ : $\quad 1$

\section{Well Data}

Initial displacement:

Depth of penetration:

$139.7 \mathrm{ft}$

Casing radius:

$44.9 \mathrm{ft}$

Borehole radius:

$0.0990 \mathrm{ft}$

Screen length:

$0.4375 \mathrm{ft}$

Filter pack porosity:

$6.7 \mathrm{ft}$

0.25

\section{Solution}

Analytical method: Bouwer-Rice

Conceptual model: $\quad$ confined

$\mathrm{K}=$

$0.54 \mathrm{ft} / \mathrm{d}$

$\mathrm{y}_{0}=$

$160.9 \mathrm{ft}$ 


\section{D-10. Plot for Injection Test, R-22, Screen 5}

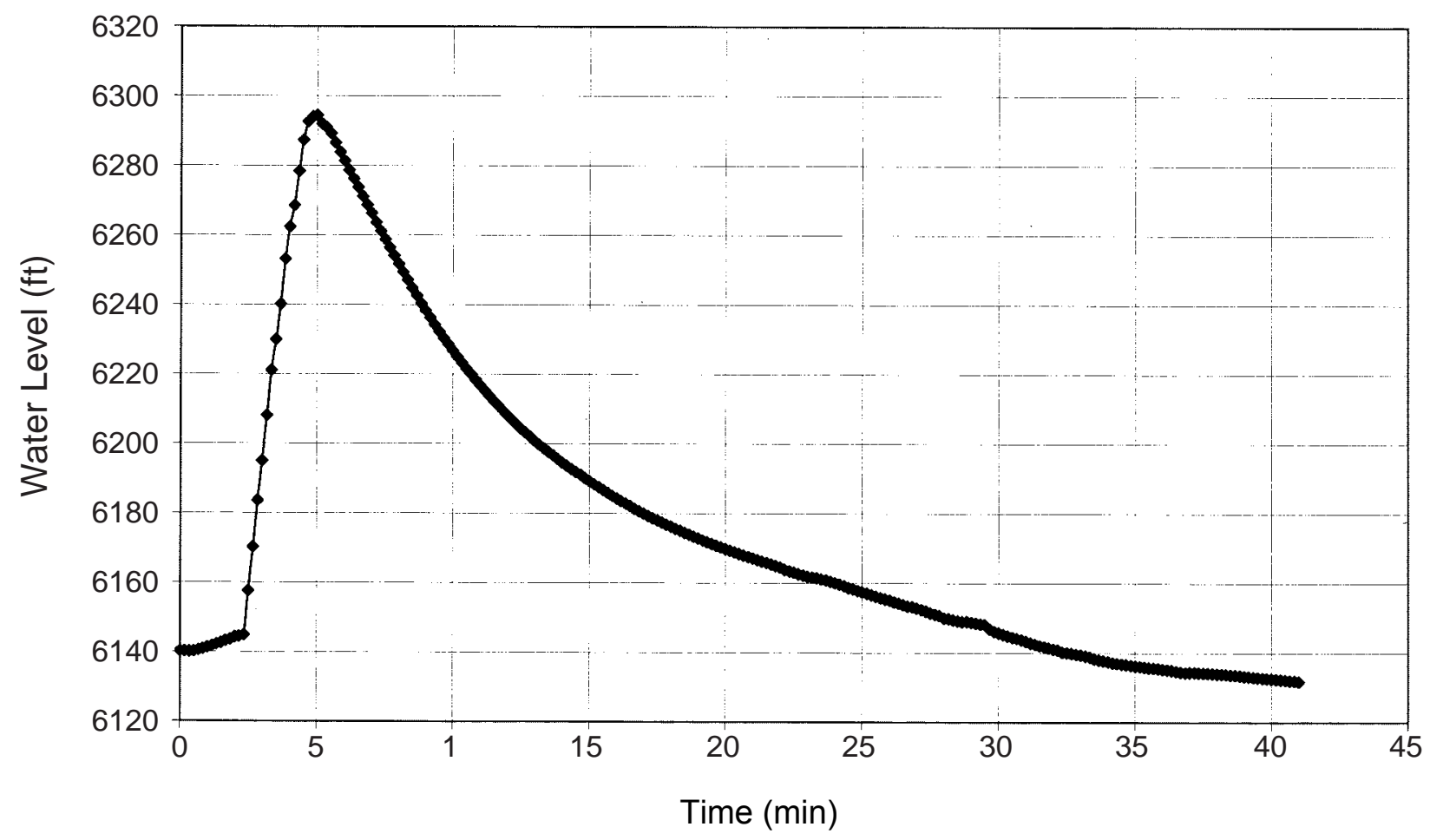

D-11. Recovery Data for Injection Test, R-22, Screen 5

\begin{tabular}{|c|c|}
\hline $\mathbf{t}(\mathbf{m i n})$ & $\mathbf{s}(\mathbf{f t})$ \\
\hline 0.000 & 154.101 \\
\hline 0.167 & 151.573 \\
\hline 0.333 & 150.648 \\
\hline 0.500 & 148.900 \\
\hline 0.667 & 146.227 \\
\hline 0.833 & 143.540 \\
\hline 1.000 & 140.954 \\
\hline 1.167 & 138.354 \\
\hline 1.333 & 135.841 \\
\hline 1.500 & 133.357 \\
\hline 1.667 & 130.743 \\
\hline 1.833 & 128.331 \\
\hline 2.000 & 125.963 \\
\hline 2.167 & 123.349 \\
\hline 2.333 & 120.880 \\
\hline 2.500 & 118.469 \\
\hline 2.667 & 116.101 \\
\hline 2.833 & 113.748 \\
\hline
\end{tabular}

\begin{tabular}{|c|c|}
\hline $\mathbf{t}(\mathbf{m i n})$ & $\mathbf{s}(\mathbf{f t})$ \\
\hline 3.000 & 111.380 \\
\hline 3.167 & 109.027 \\
\hline 3.333 & 106.746 \\
\hline 3.500 & 104.422 \\
\hline 3.667 & 102.199 \\
\hline 3.833 & 100.063 \\
\hline 4.000 & 97.970 \\
\hline 4.167 & 95.950 \\
\hline 4.333 & 93.915 \\
\hline 4.500 & 91.953 \\
\hline 4.667 & 90.077 \\
\hline 4.833 & 88.244 \\
\hline 5.000 & 86.440 \\
\hline 5.167 & 84.695 \\
\hline 5.333 & 82.905 \\
\hline 5.500 & 81.217 \\
\hline 5.667 & 79.587 \\
\hline 5.833 & 77.986 \\
\hline
\end{tabular}

\begin{tabular}{|c|c|}
\hline $\mathbf{t}(\mathbf{m i n})$ & $\mathbf{s}(\mathbf{f t})$ \\
\hline 6.000 & 76.399 \\
\hline 6.167 & 74.855 \\
\hline 6.333 & 73.326 \\
\hline 6.500 & 71.927 \\
\hline 6.667 & 70.528 \\
\hline 6.833 & 69.143 \\
\hline 7.000 & 67.816 \\
\hline 7.167 & 66.489 \\
\hline 7.333 & 65.162 \\
\hline 7.500 & 63.936 \\
\hline 7.667 & 62.768 \\
\hline 7.833 & 61.571 \\
\hline 8.000 & 60.446 \\
\hline 8.167 & 59.336 \\
\hline 8.333 & 58.269 \\
\hline 8.500 & 57.274 \\
\hline 8.667 & 56.235 \\
\hline 8.833 & 55.212 \\
\hline
\end{tabular}

\begin{tabular}{|c|c|}
\hline $\mathbf{t}(\mathbf{m i n})$ & $\mathbf{s}(\mathbf{f t})$ \\
\hline 9.000 & 54.202 \\
\hline 9.167 & 53.279 \\
\hline 9.333 & 52.371 \\
\hline 9.500 & 51.463 \\
\hline 9.667 & 50.655 \\
\hline 9.833 & 49.761 \\
\hline 10.000 & 48.867 \\
\hline 10.167 & 47.973 \\
\hline 10.333 & 47.166 \\
\hline 10.500 & 46.359 \\
\hline 10.667 & 45.551 \\
\hline 10.833 & 44.715 \\
\hline 11.000 & 43.951 \\
\hline 11.167 & 43.187 \\
\hline 11.333 & 42.466 \\
\hline 11.500 & 41.717 \\
\hline 11.667 & 40.996 \\
\hline 11.833 & 40.261 \\
\hline
\end{tabular}




\begin{tabular}{|c|c|}
\hline $\mathbf{t}(\mathbf{m i n})$ & $\mathbf{s}$ (ft) \\
\hline 12.000 & 39.597 \\
\hline 12.167 & 38.920 \\
\hline 12.333 & 38.228 \\
\hline 12.500 & 37.637 \\
\hline 12.667 & 37.017 \\
\hline 12.833 & 36.455 \\
\hline 13.000 & 35.850 \\
\hline 13.167 & 35.244 \\
\hline 13.333 & 34.639 \\
\hline 13.500 & 34.034 \\
\hline 13.667 & 33.500 \\
\hline 13.833 & 32.953 \\
\hline 14.000 & 32.434 \\
\hline 14.167 & 31.929 \\
\hline 14.333 & 31.396 \\
\hline 14.500 & 30.877 \\
\hline 14.667 & 30.387 \\
\hline 14.833 & 29.883 \\
\hline 15.000 & 29.436 \\
\hline 15.167 & 28.946 \\
\hline 15.333 & 28.485 \\
\hline 15.500 & 28.023 \\
\hline 15.667 & 27.591 \\
\hline
\end{tabular}

\begin{tabular}{|c|c|}
\hline $\mathbf{t}(\mathbf{m i n})$ & $\mathbf{s}(\mathbf{f t})$ \\
\hline 15.833 & 27.144 \\
\hline 16.000 & 26.698 \\
\hline 16.167 & 26.251 \\
\hline 16.333 & 25.833 \\
\hline 16.500 & 25.429 \\
\hline 16.667 & 24.997 \\
\hline 16.833 & 24.565 \\
\hline 17.000 & 24.147 \\
\hline 17.167 & 23.470 \\
\hline 17.333 & 23.049 \\
\hline 17.500 & 22.660 \\
\hline 17.667 & 22.242 \\
\hline 17.833 & 21.852 \\
\hline 18.000 & 21.506 \\
\hline 18.167 & 21.261 \\
\hline 18.333 & 21.031 \\
\hline 18.500 & 20.786 \\
\hline 18.667 & 20.469 \\
\hline 18.833 & 20.108 \\
\hline 19.000 & 19.705 \\
\hline 19.167 & 19.315 \\
\hline 19.333 & 18.883 \\
\hline 19.500 & 18.335 \\
\hline & \\
\hline
\end{tabular}

\begin{tabular}{|c|c|}
\hline $\mathbf{t}(\mathbf{m i n})$ & $\mathbf{s}(\mathbf{f t})$ \\
\hline 19.667 & 17.932 \\
\hline 19.833 & 17.485 \\
\hline 20.000 & 17.125 \\
\hline 20.167 & 16.692 \\
\hline 20.333 & 16.274 \\
\hline 20.500 & 15.856 \\
\hline 20.667 & 15.424 \\
\hline 20.833 & 15.020 \\
\hline 21.000 & 14.660 \\
\hline 21.167 & 14.199 \\
\hline 21.333 & 13.810 \\
\hline 21.500 & 13.449 \\
\hline 21.667 & 13.017 \\
\hline 21.833 & 12.859 \\
\hline 22.000 & 12.441 \\
\hline 22.167 & 11.994 \\
\hline 22.333 & 11.561 \\
\hline 22.500 & 11.057 \\
\hline 22.667 & 10.668 \\
\hline 22.833 & 10.308 \\
\hline 23.000 & 9.515 \\
\hline 23.167 & 9.472 \\
\hline 23.333 & 9.097 \\
\hline & \\
\hline
\end{tabular}

\begin{tabular}{|l|l|}
\hline $\mathbf{t}(\mathbf{m i n})$ & $\mathbf{s}$ (ft) \\
\hline 23.500 & 8.838 \\
\hline 23.667 & 8.578 \\
\hline 23.833 & 8.622 \\
\hline 24.000 & 8.377 \\
\hline 24.167 & 8.117 \\
\hline 24.333 & 7.887 \\
\hline 24.500 & 7.728 \\
\hline 24.667 & 6.489 \\
\hline 24.833 & 5.797 \\
\hline 25.000 & 5.350 \\
\hline 25.167 & 4.904 \\
\hline 25.333 & 4.500 \\
\hline 25.500 & 4.097 \\
\hline 25.667 & 3.751 \\
\hline 25.833 & 3.333 \\
\hline 26.000 & 2.915 \\
\hline 26.167 & 2.469 \\
\hline 26.333 & 2.094 \\
\hline 26.500 & 1.691 \\
\hline 26.667 & 1.359 \\
\hline 26.833 & 0.999 \\
\hline 27.000 & 0.696 \\
\hline 27.167 & 0.480 \\
\hline & \\
\hline
\end{tabular}

D-12. Analysis of Injection Test, R-22, Screen 5

Test Date: 17 Aug 00

Aquifer Data

Saturated thickness: $\quad 43.0 \mathrm{ft}$

Anisotropy ratio $(\mathrm{Kz} / \mathrm{Kr})$ : $\quad 1$

Well Data

Initial displacement:

$154.1 \mathrm{ft}$

Depth of penetration: $\quad 17.3 \mathrm{ft}$

Casing radius: $\quad 0.0990 \mathrm{ft}$

Borehole radius: $\quad 0.4375 \mathrm{ft}$

Screen length: $\quad 5 \mathrm{ft}$

Filter pack porosity: $\quad 0.25$

\section{Solution}

Analytical method: Bouwer-Rice

Conceptual model: $\quad$ confined

$\mathrm{K}=$

$0.27 \mathrm{ft} / \mathrm{d}$

$\mathrm{y}_{0}=$

$153.6 \mathrm{ft}$ 



\section{Appendix E}

\section{Well R-31 Test Data}

Contents

E-1 Plot for Injection Tests, Screen 3

E-2 Recovery Data for Injection Test, Screen 3a

E-3 Analysis of Injection Test, Screen 3a

E-4 Plot for Injection Test, Screen 4

E-5 Recovery Data for Injection Test, Screen 4

E-6 Analysis of Injection Test, Screen 4

E-7 Plot for Injection Test, Screen 5

E-8 Recovery Data for Injection Test, Screen 5

E-9 Analysis of Injection Test, Screen 5 



\section{E-1. Plot for Injection Tests, R-31, Screen 3}

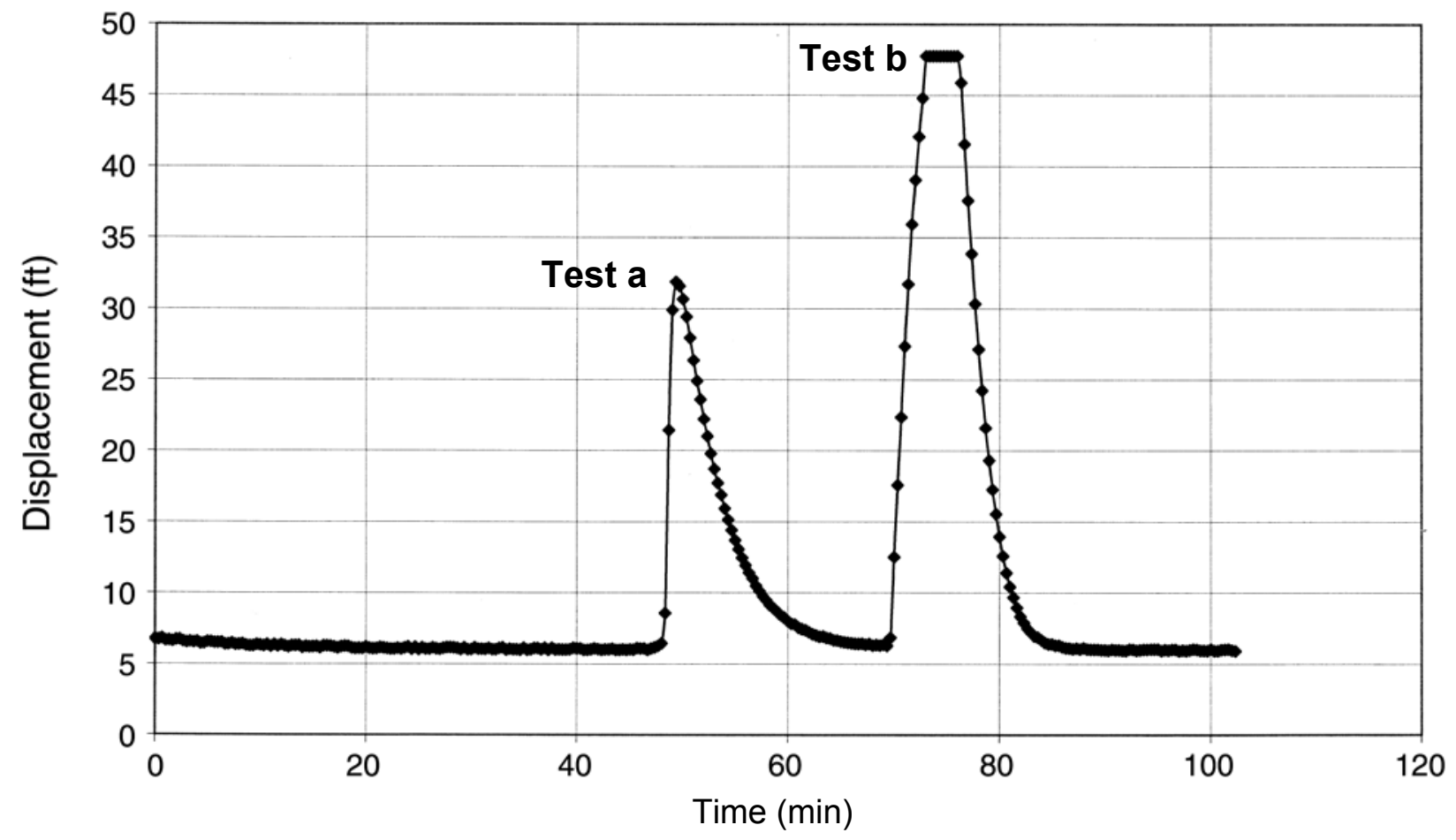

\section{E-2. Recovery Data for Injection Test, R-31, Screen 3a}

\begin{tabular}{|c|c|}
\hline $\mathbf{t}(\mathbf{m i n})$ & $\mathbf{s}(\mathbf{f t})$ \\
\hline 0.000 & 25.825 \\
\hline 0.333 & 25.517 \\
\hline 0.667 & 24.606 \\
\hline 1.000 & 23.369 \\
\hline 1.333 & 21.869 \\
\hline 1.667 & 20.303 \\
\hline 2.000 & 18.847 \\
\hline 2.333 & 17.529 \\
\hline 2.667 & 16.150 \\
\hline 3.000 & 14.954 \\
\hline 3.333 & 13.724 \\
\hline 3.667 & 12.653 \\
\hline 4.000 & 11.661 \\
\hline 4.333 & 10.825 \\
\hline 4.667 & 9.874 \\
\hline 5.000 & 9.070 \\
\hline
\end{tabular}

\begin{tabular}{|c|c|}
\hline $\mathbf{t}$ (min) & $\mathbf{s}$ (ft) \\
\hline 5.333 & 8.348 \\
\hline 5.667 & 7.631 \\
\hline 6.000 & 7.007 \\
\hline 6.333 & 6.392 \\
\hline 6.667 & 5.864 \\
\hline 7.000 & 5.359 \\
\hline 7.333 & 4.940 \\
\hline 7.667 & 4.429 \\
\hline 8.000 & 4.060 \\
\hline 8.333 & 3.685 \\
\hline 8.667 & 3.402 \\
\hline 9.000 & 3.062 \\
\hline 9.333 & 2.863 \\
\hline 9.667 & 2.623 \\
\hline 10.000 & 2.372 \\
\hline 10.333 & 2.196 \\
\hline
\end{tabular}

\begin{tabular}{|l|l|}
\hline $\mathbf{t}(\mathbf{m i n})$ & $\mathbf{s}(\mathbf{f t})$ \\
\hline 10.667 & 1.963 \\
\hline 11.000 & 1.764 \\
\hline 11.333 & 1.709 \\
\hline 11.667 & 1.501 \\
\hline 12.000 & 1.383 \\
\hline 12.333 & 1.317 \\
\hline 12.667 & 1.173 \\
\hline 13.000 & 1.026 \\
\hline 13.333 & 0.948 \\
\hline 13.667 & 0.858 \\
\hline 14.000 & 0.881 \\
\hline 14.333 & 0.763 \\
\hline 14.667 & 0.734 \\
\hline 15.000 & 0.605 \\
\hline 15.333 & 0.584 \\
\hline
\end{tabular}

\begin{tabular}{|c|c|}
\hline $\mathbf{t}(\mathbf{m i n})$ & $\mathbf{s}(\mathbf{f t})$ \\
\hline 15.667 & 0.512 \\
\hline 16.000 & 0.472 \\
\hline 16.333 & 0.435 \\
\hline 16.667 & 0.394 \\
\hline 17.000 & 0.363 \\
\hline 17.333 & 0.342 \\
\hline 17.667 & 0.357 \\
\hline 18.000 & 0.299 \\
\hline 18.333 & 0.345 \\
\hline 18.667 & 0.233 \\
\hline 19.000 & 0.279 \\
\hline 19.333 & 0.239 \\
\hline 19.667 & 0.285 \\
\hline 20.000 & 0.227 \\
\hline 20.333 & 0.780 \\
\hline
\end{tabular}


E-3. Analysis of Injection Test, R-31, Screen 3a

Test Date: 18 Mar 00

Aquifer Data

Saturated thickness: $\quad 18.0 \mathrm{ft}$

Anisotropy ratio $(\mathrm{Kz} / \mathrm{Kr})$ : $\quad 1$

\section{Well Data}

Initial displacement: $\quad 25.8 \mathrm{ft}$

Depth of penetration: $\quad 17.3 \mathrm{ft}$

Casing radius: $\quad 0.0990 \mathrm{ft}$

Borehole radius: $\quad 0.5469 \mathrm{ft}$

Screen length: $\quad 10 \mathrm{ft}$

Filter pack porosity: $\quad 0.25$

\section{Solution}

Analytical method: Bouwer-Rice

Conceptual model: $\quad$ confined

$\mathrm{K}=\quad 0.41 \mathrm{ft} / \mathrm{d}$

$\mathrm{y}_{0}=\quad 29.57 \mathrm{ft}$ 


\section{E-4. Plot for Injection Test, R-31, Screen 4}

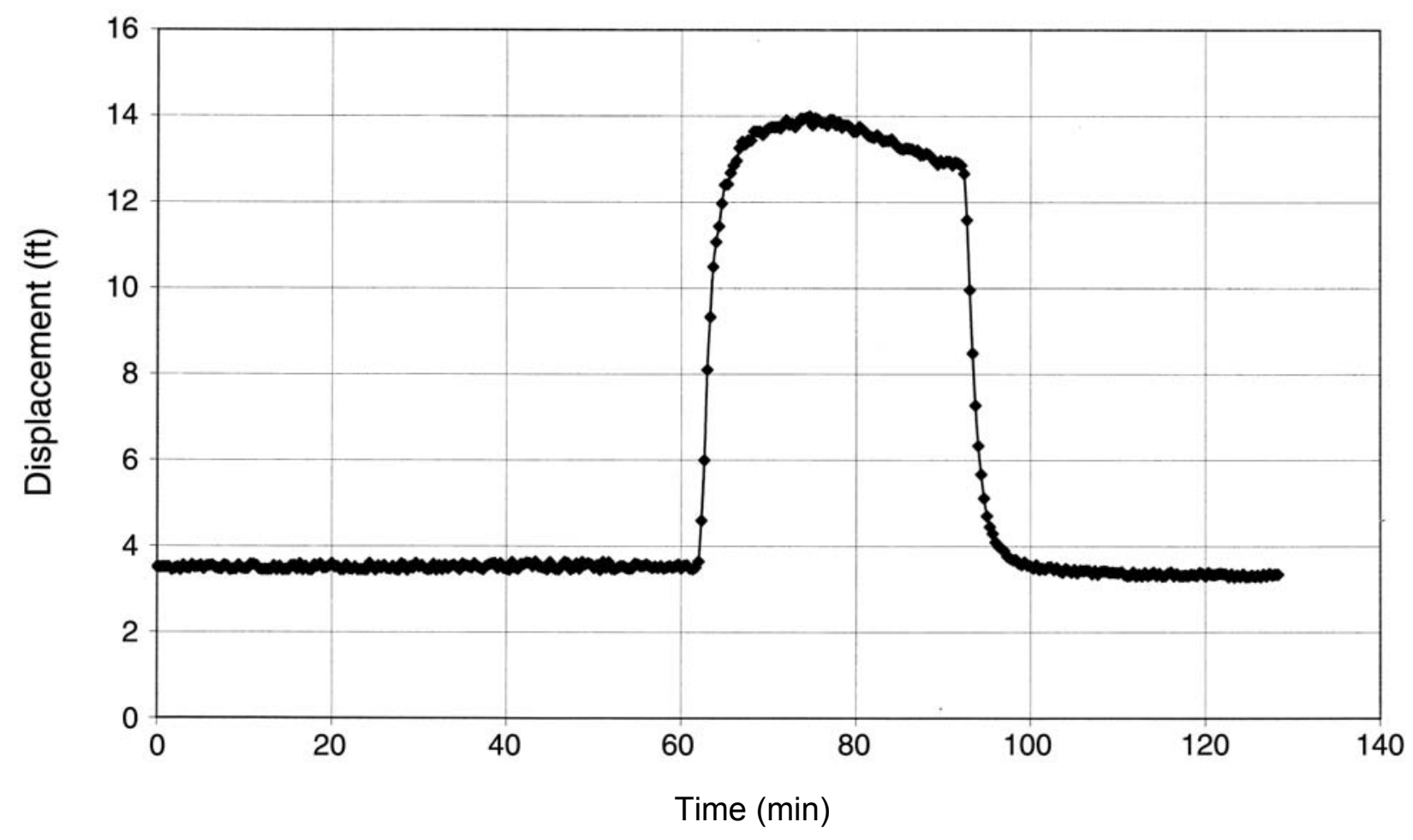

E-5. Recovery Data for Injection Test, R-31, Screen 4

\begin{tabular}{|c|c|}
\hline $\mathbf{t}(\mathbf{m i n})$ & $\mathbf{s}(\mathbf{f t})$ \\
\hline 0.000 & 9.603 \\
\hline 0.333 & 9.333 \\
\hline 0.667 & 8.256 \\
\hline 1.000 & 6.631 \\
\hline 1.333 & 5.157 \\
\hline 1.667 & 3.946 \\
\hline 2.000 & 3.003 \\
\hline 2.333 & 2.341 \\
\hline 2.667 & 1.784 \\
\hline 3.000 & 1.372 \\
\hline 3.333 & 1.125 \\
\hline 3.667 & 0.966 \\
\hline 4.000 & 0.767 \\
\hline 4.333 & 0.672 \\
\hline 4.667 & 0.618 \\
\hline
\end{tabular}

\begin{tabular}{|c|c|}
\hline $\mathbf{t}(\mathbf{m i n})$ & $\mathbf{s}(\mathbf{f t})$ \\
\hline 5.000 & 0.566 \\
\hline 5.333 & 0.436 \\
\hline 5.667 & 0.393 \\
\hline 6.000 & 0.353 \\
\hline 6.333 & 0.356 \\
\hline 6.667 & 0.272 \\
\hline 7.000 & 0.240 \\
\hline 7.333 & 0.301 \\
\hline 7.667 & 0.226 \\
\hline 8.000 & 0.209 \\
\hline 8.333 & 0.160 \\
\hline 8.667 & 0.235 \\
\hline 9.000 & 0.131 \\
\hline 9.333 & 0.160 \\
\hline
\end{tabular}

\begin{tabular}{|c|c|}
\hline $\mathbf{t}(\mathbf{m i n})$ & $\mathbf{s}$ (ft) \\
\hline 9.667 & 0.140 \\
\hline 10.000 & 0.183 \\
\hline 10.333 & 0.191 \\
\hline 10.667 & 0.125 \\
\hline 11.000 & 0.171 \\
\hline 11.333 & 0.099 \\
\hline 11.667 & 0.062 \\
\hline 12.000 & 0.148 \\
\hline 12.333 & 0.108 \\
\hline 12.667 & 0.065 \\
\hline 13.000 & 0.125 \\
\hline 13.333 & 0.047 \\
\hline 13.667 & 0.111 \\
\hline 14.000 & 0.099 \\
\hline
\end{tabular}

\begin{tabular}{|c|c|}
\hline $\mathbf{t}(\mathbf{m i n})$ & $\mathbf{s}(\mathbf{f t})$ \\
\hline 14.333 & 0.111 \\
\hline 14.667 & 0.102 \\
\hline 15.000 & 0.027 \\
\hline 15.333 & 0.099 \\
\hline 15.667 & 0.021 \\
\hline 16.000 & 0.082 \\
\hline 16.333 & 0.093 \\
\hline 16.667 & 0.085 \\
\hline 17.000 & 0.059 \\
\hline 17.333 & 0.062 \\
\hline 17.667 & 0.059 \\
\hline 18.000 & 0.050 \\
\hline 18.333 & 0.073 \\
\hline 18.667 & 0.013 \\
\hline
\end{tabular}


E-6. Analysis of Injection Test, R-31, Screen 4

Test Date: 28 Mar 00

Aquifer Data

Saturated thickness: $\quad \quad 77.2 \mathrm{ft}$

Anisotropy ratio $(\mathrm{Kz} / \mathrm{Kr})$ : $\quad 1$

\section{Well Data}

Initial displacement: $\quad 9.6 \mathrm{ft}$

Depth of penetration: $\quad 56.6 \mathrm{ft}$

Casing radius: $\quad 0.0990 \mathrm{ft}$

Borehole radius: $\quad 0.4479 \mathrm{ft}$

Screen length: $\quad 10 \mathrm{ft}$

Filter pack porosity: $\quad 0.25$

\section{Solution}

Analytical method: Bouwer-Rice

Conceptual model: $\quad$ confined

$\mathrm{K}=\quad 1.23 \mathrm{ft} / \mathrm{d}$

$\mathrm{y}_{0}=\quad 12.25 \mathrm{ft}$ 


\section{E-7. Plot for Injection Test, R-31, Screen 5}

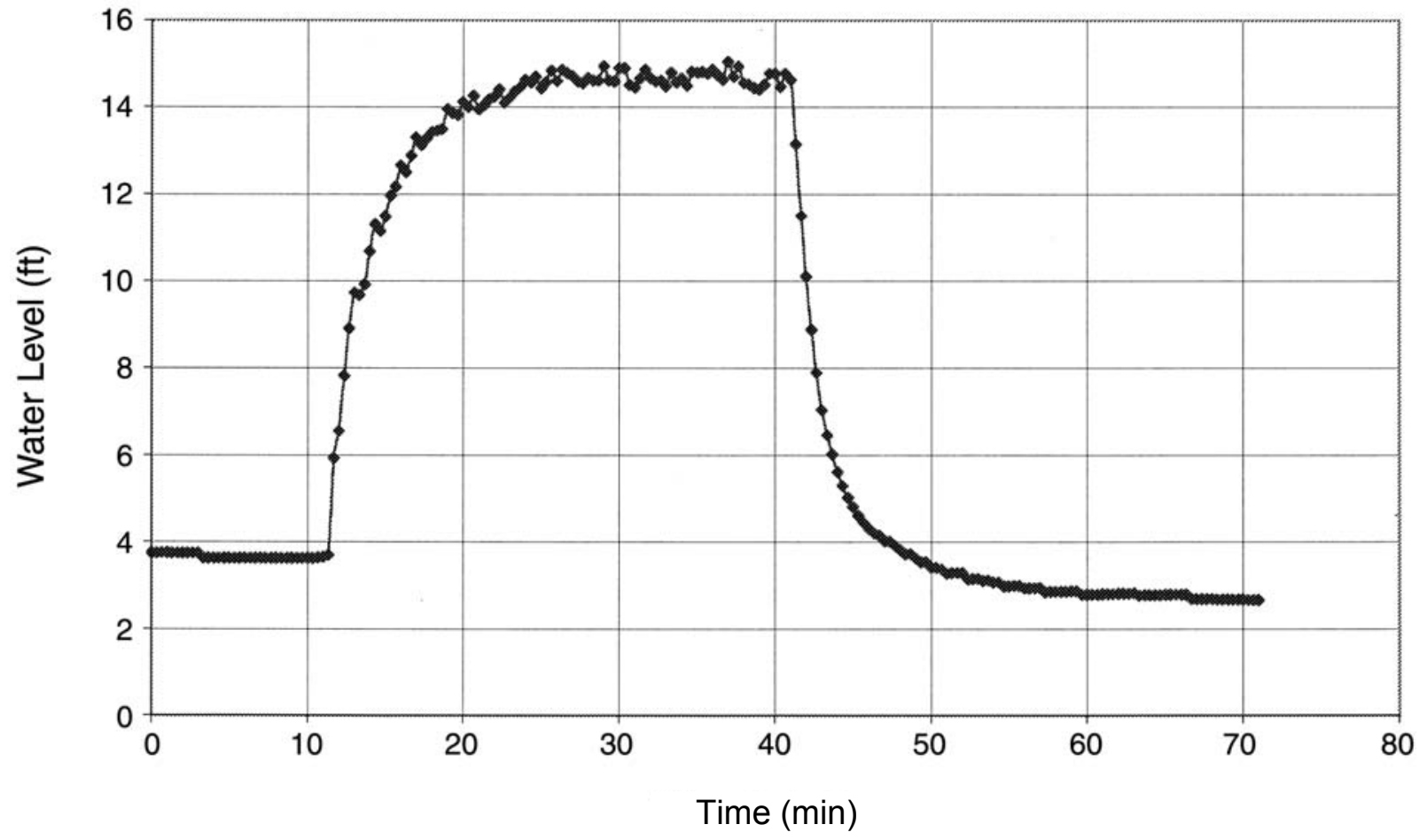

E-8. Recovery Data for Injection Test, R-31, Screen 5

\begin{tabular}{|c|c|}
\hline $\mathbf{t}(\mathbf{m i n})$ & $\mathbf{s}(\mathbf{f t})$ \\
\hline 0.333 & 10.481 \\
\hline 0.667 & 8.822 \\
\hline 1.000 & 7.428 \\
\hline 1.333 & 6.204 \\
\hline 1.667 & 5.201 \\
\hline 2.000 & 4.367 \\
\hline 2.333 & 3.791 \\
\hline 2.667 & 3.343 \\
\hline 3.000 & 2.942 \\
\hline 3.333 & 2.617 \\
\hline 3.667 & 2.349 \\
\hline 4.000 & 2.131 \\
\hline 4.333 & 1.933 \\
\hline 4.667 & 1.773 \\
\hline 5.000 & 1.633 \\
\hline 5.333 & 1.514 \\
\hline 5.667 & 1.478 \\
\hline 6.000 & 1.348 \\
\hline 6.333 & 1.339 \\
\hline 6.667 & 1.233 \\
\hline
\end{tabular}

\begin{tabular}{|c|c|}
\hline $\mathbf{t}$ (min) & $\mathbf{S}$ (ft) \\
\hline 7.000 & 1.142 \\
\hline 7.333 & 1.042 \\
\hline 7.667 & 1.046 \\
\hline 8.000 & 0.956 \\
\hline 8.333 & 0.858 \\
\hline 8.667 & 0.862 \\
\hline 9.000 & 0.738 \\
\hline 9.333 & 0.742 \\
\hline 9.667 & 0.697 \\
\hline 10.000 & 0.604 \\
\hline 10.333 & 0.610 \\
\hline 10.667 & 0.617 \\
\hline 11.000 & 0.607 \\
\hline 11.333 & 0.465 \\
\hline 11.667 & 0.474 \\
\hline 12.000 & 0.481 \\
\hline 12.333 & 0.432 \\
\hline 12.667 & 0.438 \\
\hline 13.000 & 0.393 \\
\hline 13.333 & 0.399 \\
\hline & \\
\hline
\end{tabular}

\begin{tabular}{|l|l|}
\hline $\mathbf{t}(\mathbf{m i n})$ & $\mathbf{s}(\mathbf{f t})$ \\
\hline 13.667 & 0.304 \\
\hline 14.000 & 0.308 \\
\hline 14.333 & 0.312 \\
\hline 14.667 & 0.317 \\
\hline 15.000 & 0.256 \\
\hline 15.333 & 0.261 \\
\hline 15.667 & 0.263 \\
\hline 16.000 & 0.269 \\
\hline 16.333 & 0.173 \\
\hline 16.667 & 0.178 \\
\hline 17.000 & 0.180 \\
\hline 17.333 & 0.184 \\
\hline 17.667 & 0.187 \\
\hline 18.000 & 0.190 \\
\hline 18.333 & 0.193 \\
\hline 18.667 & 0.109 \\
\hline 19.000 & 0.113 \\
\hline 19.333 & 0.116 \\
\hline 19.667 & 0.119 \\
\hline
\end{tabular}

\begin{tabular}{|l|l|}
\hline $\mathbf{t}(\mathbf{m i n})$ & $\mathbf{s}(\mathbf{f t})$ \\
\hline 20.000 & 0.124 \\
\hline 20.333 & 0.126 \\
\hline 20.667 & 0.129 \\
\hline 21.000 & 0.132 \\
\hline 21.333 & 0.135 \\
\hline 21.667 & 0.138 \\
\hline 22.000 & 0.142 \\
\hline 22.333 & 0.093 \\
\hline 22.667 & 0.098 \\
\hline 23.000 & 0.099 \\
\hline 23.333 & 0.102 \\
\hline 23.667 & 0.105 \\
\hline 24.000 & 0.108 \\
\hline 24.333 & 0.109 \\
\hline 24.667 & 0.111 \\
\hline 25.000 & 0.112 \\
\hline 25.333 & 0.115 \\
\hline 25.667 & 0.014 \\
\hline 26.000 & 0.013 \\
\hline
\end{tabular}


E-9. Analysis of Injection Test, R-31, Screen 5

Test Date: 10 Mar 00

Aquifer Data

Saturated thickness: $\quad 198.9 \mathrm{ft}$

Anisotropy ratio $(\mathrm{Kz} / \mathrm{Kr})$ : $\quad 1$

\section{Well Data}

Initial displacement: $\quad 12.0 \mathrm{ft}$

Depth of penetration: $\quad 143.4 \mathrm{ft}$

Casing radius: $\quad 0.0990 \mathrm{ft}$

Borehole radius: $\quad 0.4479 \mathrm{ft}$

Screen length: $\quad 10 \mathrm{ft}$

Filter pack porosity: $\quad 0.25$

\section{Solution}

Analytical method: Bouwer-Rice

Conceptual model: $\quad$ confined

$\mathrm{K}=$

$0.75 \mathrm{ft} / \mathrm{d}$

$\mathrm{y}_{0}=$

$10.94 \mathrm{ft}$

Note: During the course of testing at R-31, it was learned that the well had not been properly developed. Thus, a second round of testing followed further development. However, in the interest of time, screen 5 was not retested.

Thus, the results presented are probably less than would have been obtained had the screen been retested. 
This report has been repodued directly fom the best wailable copy It is wailable electronicolly on the Mb (htp:Wwswdos govbridge).

Copies are available for sale to US. Department of Energy employes and contractors from -

Office of Scientifie and Technical Information PO. Box 62

Oak Ridge, TN 37831

(85) $576-8401$

Copies are avilable for rale to the publi from-

Mational Technical Information Service

US Department of Commeme

5285 Port Royal Roud

Spingfid, VA22616

(00) 553.6847 
- Los Alamos

Los Alamón NM 87545 